EISSN: $2706-7947$ ISSN: 2077- 4613

DOI: 10.36632/mejas/2021.11.1.8

Journal homepage: www.curresweb.com

Pages: 76-125

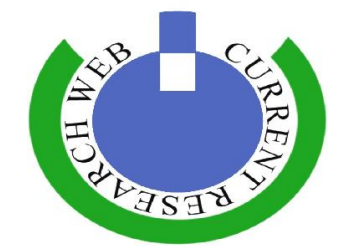

\title{
Chloride Ions as a Beneficial and Essential Micronutrient Multifunctional, Role and Regulation in Plant Physiology: A Review
}

\author{
${ }^{1}$ Abou Seeda M.A., ${ }^{2}$ Abou El-Nour E.A.A, ${ }^{3}$ Hammad S.A. and ${ }^{1}$ Yassen A.A. \\ ${ }^{I}$ Plant Nutrition Dept., National Research Centre, 33 El Buhouth St., 12622 Dokki, Giza, Egypt. \\ ${ }^{2}$ Fertilization Tech. Dept., National Research Centre, 33 El Buhouth St., 12622 Dokki, Giza, Egypt. \\ ${ }^{3}$ Soil and Water Dept. Fac.Agric. Mansoura University
}

Received: 20 November 2020 Accepted: 10 January $2021 \quad$ Published: 05 February 2021

\begin{abstract}
Chloride occurs predominantly as $\mathrm{Cl}^{-}$in soil, plant, and considering as a micronutrient largely excluded by plants due to its ubiquity and abundance in nature. It is an essential micronutrient of higher plants and participates in several physiological metabolism processes. Including osmotic and stomatal regulation, evolution of oxygen in photosynthesis, disease resistance and tolerance. Chloride $\left(\mathrm{Cl}^{-}\right)$has traditionally been considered harmful to agriculture because of its toxic effects in saline soils and its antagonistic interaction with nitrate $\left(\mathrm{NO}_{3}{ }^{-}\right)$, which impairs $\mathrm{NO}_{3}{ }^{-}$nutrition. It has been largely believed that $\mathrm{Cl}^{-}$antagonizes $\mathrm{NO}_{3}{ }^{-}$uptake and accumulation in higher plants, reducing crop yield. However, we have recently uncovered that $\mathrm{Cl}^{-}$has new beneficial macronutrient functions that improve plant growth, tissue water balance, plant water relations, photosynthetic performance, and water-use efficiency (WUE). Increasing plant biomass indicates in turn that $\mathrm{Cl}^{-}$may also improve nitrogen use efficiency (NUE). Structure of water around the sodium and potassium ions is a key test of the quality of interaction potentials, and are not completely aligned toward their electric fields, but rather tilted. This tilt is more defined for potassium than it is for sodium. The hydration number of sodium is restricted to either five or sex molecules, however for potassium has ranging from five to ten molecules. Most striking energetic difference between $\mathrm{Na}$ and $\mathrm{K}$ resides in the first shell. Water molecules have a very strong interact under such condition $\mathrm{Na}^{+}$is more effect on the soil salinity than $\mathrm{K}^{+}$. However, an increase in $\mathrm{Na}^{+}$content is always accompanied by $\mathrm{Cl}^{-}$accumulation and $\mathrm{K}^{+}$loss in plants exposed to salt $(\mathrm{NaCl})$ stress.Considering that $\mathrm{N}$ availability is a bottleneck for the growth of land plants excessive $\mathrm{NO}_{3}{ }^{-}$ fertilization frequently used in agriculture becomes a major environmental concern worldwide, causing excessive accumulation leaf $\mathrm{NO}_{3}{ }^{-}$in crops particularly in vegetables, that poses a potential risk to human health. New farming practices aimed to enhance plant nitrogen use efficiency (NUE), by reducing $\mathrm{NO}_{3}{ }^{-}$fertilization should promote a healthier and more sustainable agriculture. Given the strong interaction between $\mathrm{Cl}^{-}$and $\mathrm{NO}_{3}{ }^{-}$homeostasis in plants, we have verified if indeed $\mathrm{Cl}^{-}$affects $\mathrm{NO}_{3}^{-}$accumulation and NUE in plants. For the first time to our knowledge, we provide a direct demonstration, which shows that $\mathrm{Cl}^{-}$, contrary to impairing $\mathrm{NO}_{3}{ }^{-}$nutrition, facilitates $\mathrm{NO}_{3}{ }^{-}$utilization and improves NUE in plants. This is largely due to $\mathrm{Cl}-$ improvement of the $\mathrm{N}^{-} \mathrm{NO}_{3}{ }^{-}$utilization efficiency (NUTE), having little or moderate effect on $\mathrm{N}-\mathrm{NO}{ }^{-}$uptake efficiency (NUPE) when $\mathrm{NO}_{3}{ }^{-}$ is used as the sole $\mathrm{N}$ source. Clear positive correlations between leaf $\mathrm{Cl}^{-}$content vs. NUE / NUTE or plant growth have been established at both intra- and interspecies levels. Optimal $\mathrm{NO}_{3}{ }^{-}$versus $\mathrm{Cl}^{-}$ratios become a useful tool for increasing crop yield and quality, sustainability of agricultural land and reducing negative ecological impact of $\mathrm{NO}_{3}{ }^{-}$on the environment and human health as well .
\end{abstract}

Keywords: Chloride, crop production, plant nutrition, chloride /nitrate interaction, physiological functions

Corresponding Author: Abou Seeda M.A., Plant Nutrition Dept., National Research Centre, 33 El Buhouth St., 12622 Dokki, Giza, Egypt. E-mail:mabouseeda@gmail.com 


\section{Introduction}

Chloride $(\mathrm{Cl})$ in natural soils mainly come from either rainwater, sea spray, dust, or air pollution. However, Irrigation systems and fertilization may contribute significantly to deposition of chloride in soil. The rates of deposition ranged from 1 to $>1000 \mathrm{~kg} \mathrm{ha}^{-1}$, depending on location and cultural practices (White and Broadley, 2001). It is an essential micronutrient for higher plants and participates in several physiological processes, ascribing as a main resource of salinity stress. This review provides brief information on the major progresses of $\mathrm{Cl}$ nutrition of higher plants. The chloride $\left(\mathrm{Cl}^{-}\right)$anion is the dominant form of the halogen element chlorine in soils. Especially in the agronomic context, $\mathrm{Cl}^{-}$ has traditionally been considered a toxic anion rather than a plant nutrient Fig. (1).

A)

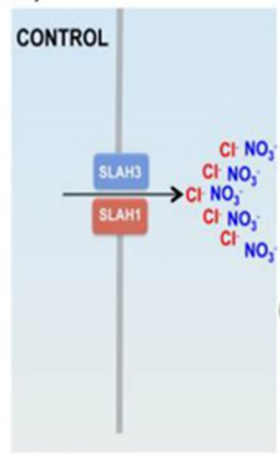

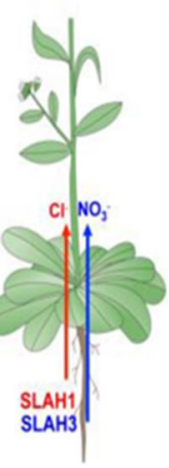

B)

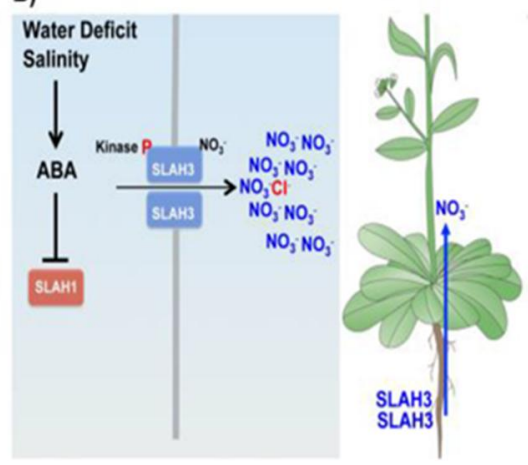

Fig. 1: Regulation of root xylem chloride ( $\mathrm{Cl}-$ ) translocation by the anion channels SLAH1 and SLAH3 according to environmental cues. Under favorable growing conditions (A), high Transcriptional activity of both SLAH1 and SLAH3 genes determines the formation of heteromeric SLAH1/SLAH3 complexes in the xylem-pole pericycle. The SLAH1 channel does not transport anions itself, but modifies the kinetic properties of SLAH3, which increases its $\mathrm{Cl}-$ conductance by seven times and mediates xylem translocation of both $\mathrm{Cl}-$ and nitrate (NO3-) anions. However, under abiotic stress conditions like water deficit or salinity (B), gene expression of AtSLAH1 is strongly inhibited by an abscisic acid (ABA)-dependent regulatory pathway. This favors the formation of SLAH3/SLAH3 homomers, which significantly reduces the $\mathrm{Cl}-$ conductance of SLAH3, decreasing xylem $\mathrm{Cl}$-translocation but maintaining xylem NO3-translocation. The schematic representation describes the regulatory mechanism (Cubero-Font et al., 2016).

This is a consequence of two main reasons: Toxicity resulting from excessive $\mathrm{Cl}^{-}$accumulation in sensitive organs under salt stress conditions, and the widespread belief that $\mathrm{Cl}^{-}$and nitrate $\left(\mathrm{NO}_{3}^{-}\right)$are antagonistic molecules. As a result, root $\mathrm{Cl}^{-}$uptake and accumulation occurs to the detriment of nitrate $\left(\mathrm{NO}_{3}^{-}\right)$nutrition, an important source of nitrogen (N) for plants Fig. (2).

Both Nitrate and Chloride are belonged to essential nutrients element for plant growth. However, plants need chloride in small concentration for healthy growth of plants ranged between about 50 to 100 mol. in the nutrient solution and can be classified as a micronutrient (Broyer et al., 1954). Therefore, the role of effectiveness of chloride on plants, dealing with two extreme situations, either its function in plant physiology (as an essential micronutrient) or its toxicity particularly under salt stress circumstances. Recently, $\mathrm{Cl}^{-}$has been described as a beneficial element for the adequate development of plants when it is accumulated to macronutrient levels (Franco-Navarro et al., 2016; Wege et al., 2017). Many researches have reported that fertilization practices including chloride may increase yield crops production $\mathrm{Xu}$, et al., (2000), until now the physiological processes affected, or to what extent the beneficial effects are $\mathrm{Cl}^{-}$, specific or even associated with the accompanying cations was unclear. Therefore, it is necessary to expand our knowledge on: (A) The identification of the biological functions requiring macronutrient $\mathrm{Cl}^{-}$levels; (B) Degree of $\mathrm{Cl}^{-}$specificity in these processes; (C) Identification of genes encoding $\mathrm{Cl}^{-}$membrane transporters relevant for plant nutrition; (D) the signal-transduction pathways regulating $\mathrm{Cl}^{-}$nutrition processes and (E) Interaction between $\mathrm{Cl}$ - and $\mathrm{NO}^{-}$in vivo. Excellent reviews have been published regarding the origin and abundance of chlorine in the environment, its function as a mineral micronutrient for plants, the occurrence and effects of $\mathrm{Cl}^{-}$deficiency, its distribution in the plant, its toxicity under saline stress conditions, and the identification of genes involved in $\mathrm{Cl}^{-}$exclusion mechanisms (Raven, 2017; Marschner 2012). The review cover, new vision 
the role of chloride as a beneficial macronutrient, for agriculture, besides the biological functions in which $\mathrm{Cl}^{-}$is involved as a beneficial macronutrient and finally gene families incriminated in regulation of $\mathrm{Cl}^{-}$transport, mainly in light of the recently identified genes, and their role in nutritional, biochemical, and stress-acclimatization functions.
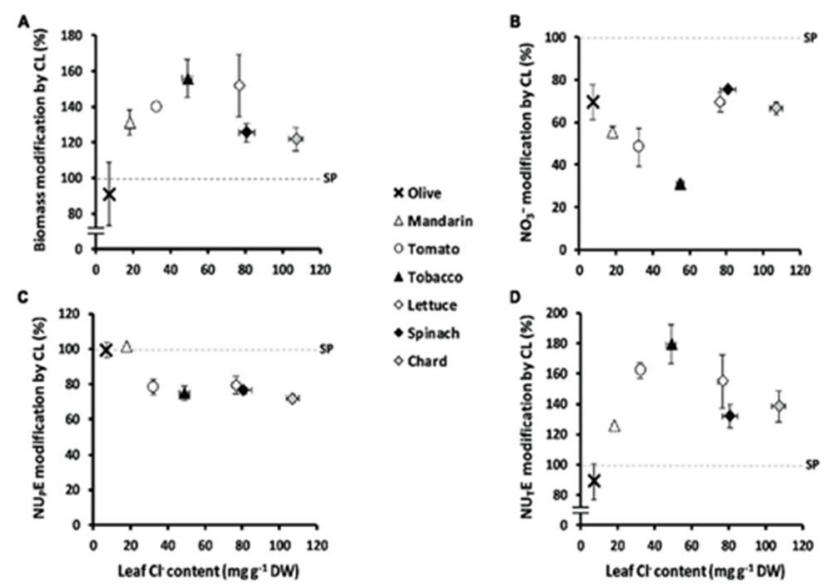

Fig.2: Illustrates effectiveness of $\mathrm{Cl}$ - nutrition on plant growth, $\mathrm{NO} 3$ - content, $\mathrm{N}$ uptake efficiency (NUPE), and $\mathrm{N}$ utilization efficiency (NUTE) in several species of agronomic interest. Plants were treated with two nutritional treatments: $5 \mathrm{mM} \mathrm{Cl}$ - salts (CL) and a mixture of SO $42-+\mathrm{PO} 43-$ salts (SP) containing the same cationic balance as in the CL treatment. Ratios of total biomass (A), NO 3 - content expressed as $\mathrm{mg} \mathrm{kg}-1$ of fresh weight (B), NUPE (C), and NUTE (D) are presented considering the \% of CL in relation to SP treatment and in contrast to leaf anion content in several species. Olive (Olea europaea L. ssp. europaea; bold cross), mandarin (Citrus reshni Hort. ex Tan; open triangles), tomato (Solanum lycopersicum L.; open circles), tobacco (Nicotiana tabacum L.; filled triangles), lettuce (Lactuca sativa L.; open diamonds); spinach (Spinacia oleracea L.; filled diamonds), and chard (Beta vulgaris L. ssp. vulgaris; gray-colored diamonds) After José et al., (2019)

\subsection{Essentiality of chloride as micronutrient}

Chloride is an essential cofactor for oxygen evolution of photosystem II (PSII) in the chloroplast, stabilizing the water splitting system at the oxidizing site of PSII. Two Cl- molecules are required to maintain the coordination structure of the Mn Ca cluster (Raven, 2017). Kawakami, et al., (2009), Fig. (3).
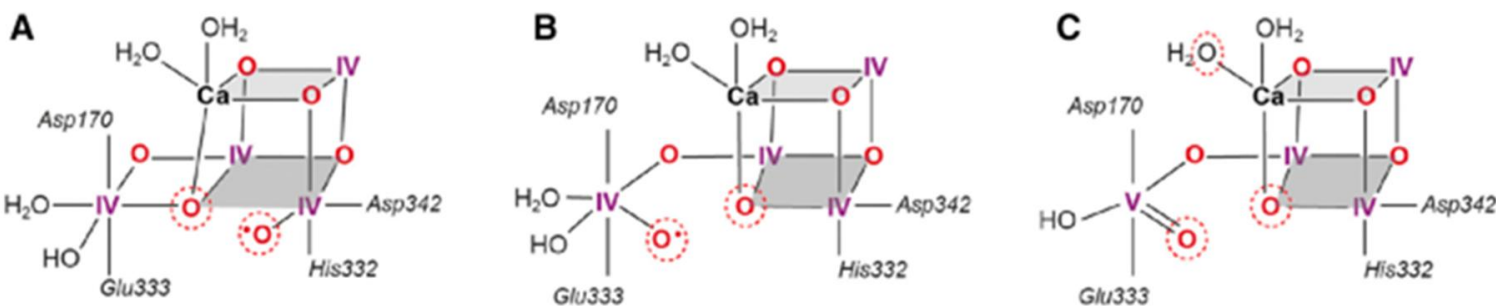

Fig. 3: Three representative model structures for the final step in the Kok cycle with O5 and O6 bound A Mn(IV)oxyl formation at Mn1, octahedral coordination, all Mn(IV), open cubane structure; B Mn(IV)-oxyl formation at $\mathrm{Mn} 4$, octahedral, closed cubane structure; $\mathrm{C} \mathrm{Mn}(\mathrm{V})=\mathrm{O}$ formation at $\mathrm{Mn} 4$, trigonal bipyramidal, closed cubane. The putative reacting oxygens presented by dotted red circles. After Pantazis (2018).

Photosynthesis has a great potential in the field of Bioenergy (Conlan et al., 2007; Govindjee, et al., 2010). Hydrogen production from water splitting has been considered as an ideal fuel for the future (Pace 2005; Lewis, 2007). Water is the source of both oxygen and hydrogen, but energy is needed for hydrogen production by water splitting. Using sunlight, splitting of water into hydrogen and oxygen is one of the most important goals of some of the research on 'artificial photosynthesis' and this could be one of the solutions for future energy needs (Pace 2005; Daniel and Alessandro 2008). The development of a catalyst for water oxidation to evolve oxygen is an important key goal for a technology-based water splitting since the reaction involves a multi-electron transfer and is much more difficult due to thermodynamic and kinetic limitations (Bockris, 1977). Other strategies involve 
attempts to employ not only energy obtained directly from the Sun, but also from the wind, ocean currents, tides or waves for water splitting, some of which may turn out to be impractical or uneconomical (Conlan et al., 2007). An efficient system for water oxidation has already evolved in cyanobacteria, algae and plants (Allakhverdiev, 2011; Fromme and Grotjohann, 2011). The biological water oxidation in the natural system is catalyzed by a $\mathrm{CaMn}_{4} \mathrm{O}_{5}\left(\mathrm{H}_{2} \mathrm{O}\right)_{4}$ cluster housed in a protein environment in Photosystem II (PSII) that controls reaction coordinates, proton movement and water access. The cluster is the only biological catalyst that could oxidize water to molecular oxygen, and it appears that it has remained unchanged during 2 billion years of evolution (Allakhverdiev, 2011; Renger 2007). In this review, we focus on the art of Nature to oxidize water for the production of hydrogen. To evolve hydrogen in a sustainable manner, it is necessary to first synthesize a stable, low cost, and efficient, environmentally friendly and easy to use catalyst for water oxidation (Bockris, 1977). The water oxidation half reaction in water splitting is both overwhelmingly rate limiting and environmentally unacceptable for large-scale $\mathrm{H} 2$ production as at this high voltage, other chemicals will be oxidized (Pace 2005; Bockris 1977).

Thus, a significant challenge in the sustainable hydrogen economy is to design a 'super anode' for water oxidation (Bockris, 1977). The role of such a super anode is not only for sustainable hydrogen economy, but also for providing electrons for other reduction-reactions that are equally important in artificial photosynthesis Pace (2005) Photosynthesis has a long history (Hill 2012; Rabinowitch 1945). Joseph Priestley (1733-1804) described the ability of plants to generate power to restore the air that had been injured by the burning of candles. Carle Wilhelm Scheele (1742-1786) and Antoine Laurent Lavoisier (1743-1794) identified this gas as oxygen. Chloride also regulates the activity of some enzymes such as the asparagine synthetase Rognes (1980), and the vacuolar proton-pumping ATPase (Churchill, and Sze, 1984).

Ge-Hong Sun-Wada et al., (2004), they reported that V-ATPase is structurally and evolutionarily related to FATPase (ATP synthase), which is responsible for ATP synthesis in mitochondria, chloroplast and bacteria, although the physiological roles of these two enzymes are completely different (Futai et al., 1989). The V-ATPase consists of two major functional sectors known as V1 and Vo Fig. (4).
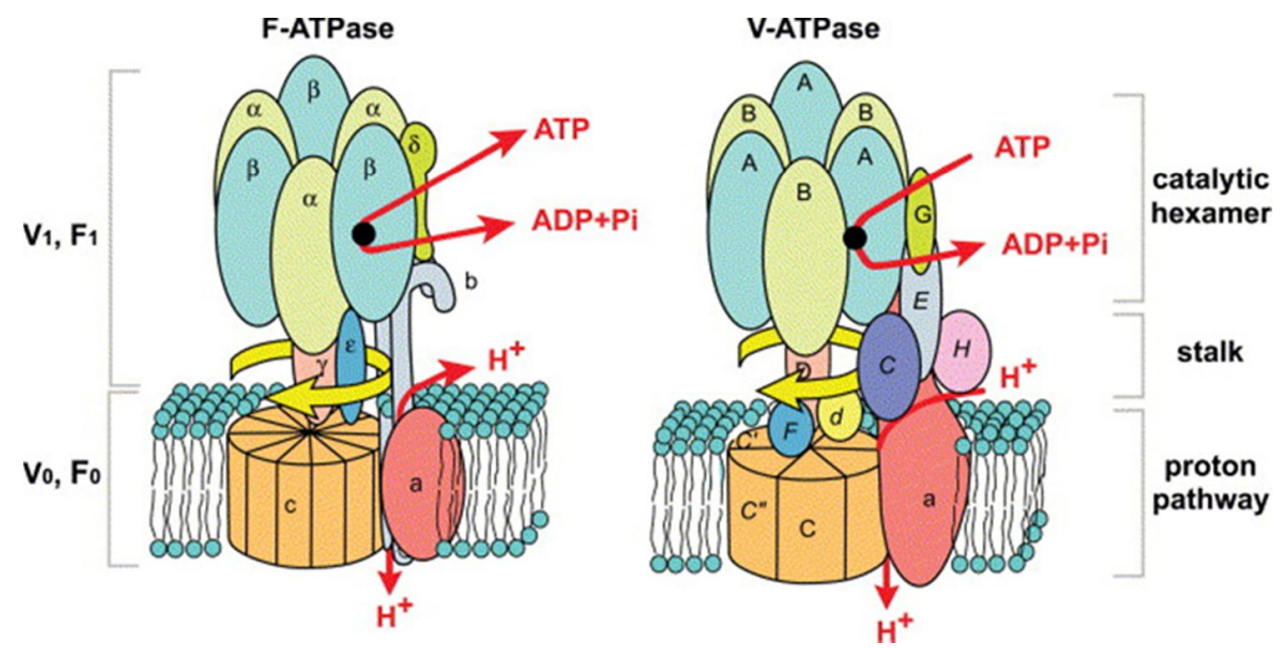

Fig. 4: Subunit organization of V-ATPase and F-ATPase. The structures of V-ATPase and F-ATPase are schematically shown together with catalysis and proton transport. Membrane intrinsic (VO, FO), and peripheral $(\mathrm{V} 1, \mathrm{~F} 1)$ sectors, the catalytic hexamer, stalk regions and proton pathway are indicated.

The V1 sector comprises at least eight different subunits (A-H). This sector contains three catalytic sites for ATP hydrolysis formed from the A and B subunits. The VO sector containing up to five subunits $(a, c, c V, c U$ and $d$ ) is responsible for proton translocation across the membranes (Anraku, 1996). A role of $\mathrm{Cl}^{-}$in regulating amylase activity has also been proposed (Metzler, 1979).To ensure these cellular functions, only micromolar amounts of $\mathrm{Cl}^{-}$are required in glycophytic plants Fig. (5). 


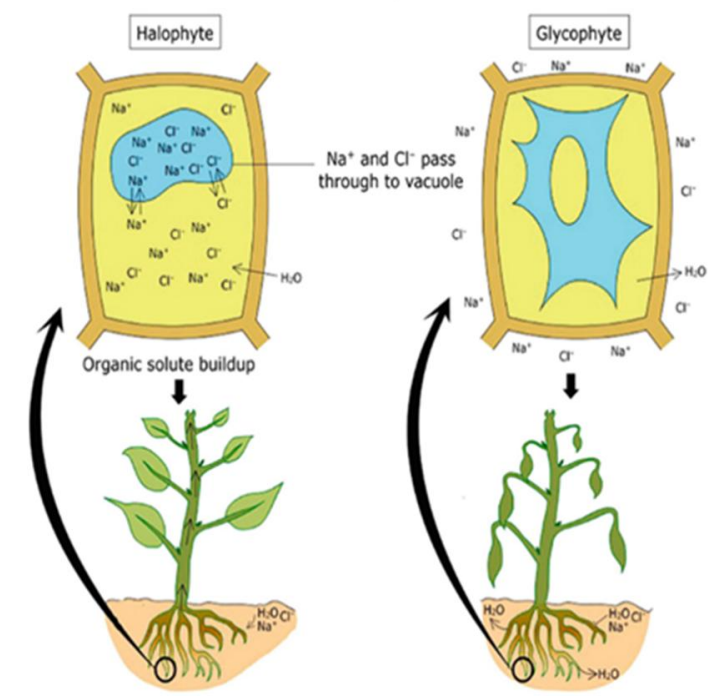

Fig. 5: Represents chloride nutrition regulates water balance in plants.

Franco-Navarro et al., (2016), reported that $\mathrm{Cl}^{-}$is a strange micronutrient since actual $\mathrm{Cl}^{-}$ concentration in plants is about two orders of magnitude higher than the content required as essential micronutrient. This accumulation requires a high cost of energy, and since $\mathrm{Cl}^{-}$is a major osmotically active solute in the vacuole, we propose that $\mathrm{Cl}^{-}$plays a role in the regulation of water balance in plants. We show here that, when accumulated to macronutrient levels, $\mathrm{Cl}^{-}$specifically regulates leaf cell elongation and water balance parameters, improving water relations at both the leaf tissue and the whole plant levels, increasing drought resistance in higher plants.

Accordingly, it has been generally accepted that the minimum $\mathrm{Cl}^{-}$requirement for adequate plant growth in most plant species is in the range of $0.2-0.4 \mathrm{mg} \cdot \mathrm{g}^{-1}$ dry weight $\left(\mathrm{mg} . \mathrm{g}^{-1} \mathrm{DW}\right.$ ) (Broyer et al., 1954; Marschner 2012). Johnson et al., (1957), Chloride is sufficiently abundant in nature to fulfil these requirements (White and Broadley, 2001).

\subsection{Chloride as a salutary nutrient to plants}

Spite the putative low requirements; the average of chloride is higher than the requirements of micronutrient concentration in plants (Xu et al., 2000). It is actually the most abundant inorganic anion in plant cells when this nutrient is available at concentrations present in most environments (Marschner, 2012). Unexpectedly chlorides content coincide with those reported as toxic elements for frequent plant species (Xu et al., 2000; White, and Broadley 2001; Marschner, 2012). Although average of chloride concentration in plants varied between 2.0 to $20.0 \mathrm{ppm}$, the critical level concentration of chloride in tissue particularly as toxicity level is about $4-7$ and $15-35 \mathrm{ppm}$ for sensitive and tolerant of glycophytes species, respectively .Thus, according to this traditional vision of plant $\mathrm{Cl}$ - homeostasis, adequate plant development requires micronutrient $\mathrm{Cl}$ - contents. However, plants accumulate about 10 to 100 times higher concentrations despite being toxic to many species. This vision implies that plants are unable to adequately regulate optimal levels of Cl- and, therefore, the dominant homeostatic strategy should be the exclusion of this element Fig. (6).

Munns, et al., (2020) stated that high-energy phosphate containing molecules other than ATP could be used for energizing processes. Vacuolar pyro phosphatases (Vacuolar H+-PPase, EC.3.6.1.1) pump protons across the tonoplast into vacuoles Gaxiola et al., (2016); Schilling et al., (2017), using pyrophosphate (PPi) as an energy source (Fig. 3). They work together with vacuolar H+-ATPases to acidify the vacuole (Kriegel et al., 2015; Schilling et al., 2017). Plants with high expression of vacuolar $\mathrm{H}+-\mathrm{PPases}$ have significant abiotic stress tolerance, including salinity tolerance (Gaxiola et al., 2016; Schilling et al., 2017. Vacuolar H+-PPases may be particularly important when ATP supply is limited during abiotic stress. A significant portion of vacuolar acidification may be generated by non-ATPase pathways and used by $\mathrm{Na}^{+} / \mathrm{H}^{+}$and $\mathrm{Cl}^{-} / \mathrm{H}^{+}$antiporters to sequester $\mathrm{Na}^{+}$and $\mathrm{Cl}^{-}$in the vacuole as part of a tissue tolerance mechanism (Li et al., 2006; Kriegel et al., 2015; Nguyen et al., 2016). H+-PPases are dependent on potassium ions $\left(\mathrm{K}^{+}\right)$, thus $\mathrm{K}$ retention in the cytoplasm under salinity may be critical for their function (Shabala et al., 2014). $\mathrm{H}^{+}$-PPases have been shown more recently to be involved with 
rapid mobilization of sugars and carbohydrates from source to sink tissue Pizzio et al., (2015) Gaxiola et al., (2016), and in faster metabolism of sugars in cells (Ferjani et al., 2012. Both processes will contribute to enhancing a cell's energy budget.

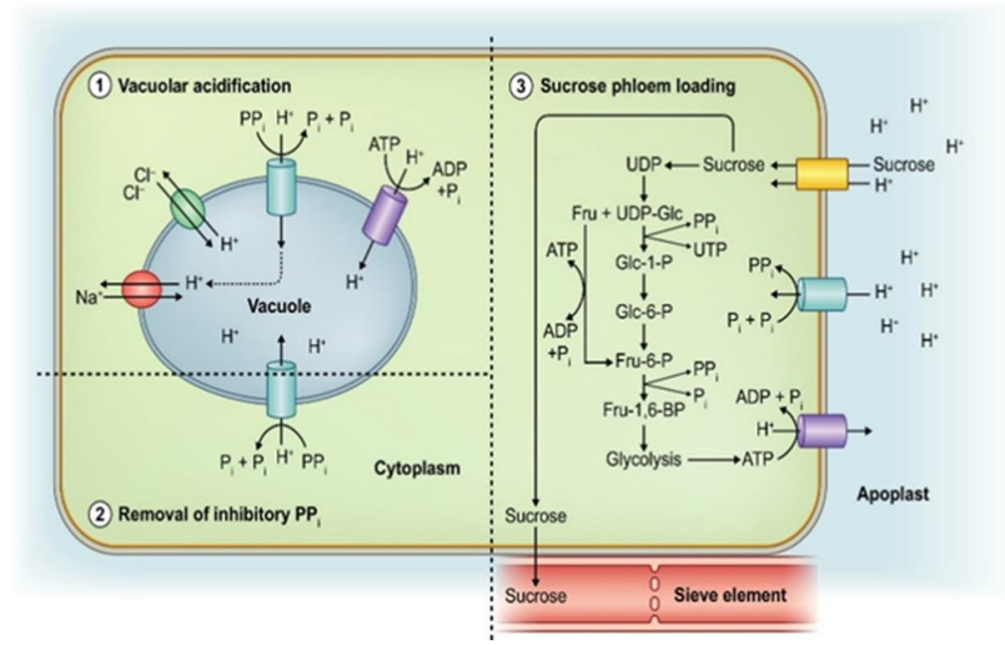

Fig. 6: A variety of roles for the vacuolar proton-pumping pyro phosphatase. A generic plant cell showing the variety of ways the vacuolar proton pumping pyro phosphatase $(\mathrm{H}+-\mathrm{PPase})$ can provide an alternative source of energy during salinity stress. (1) Vacuolar acidification. Localized to the tonoplast, the vacuolar H+-PPase (blue) will use energy released from the hydrolysis of PPi to orthophosphate (Pi) to pump protons $(\mathrm{H}+)$ into the vacuole. Along with vacuolar ATPases (purple), vacuolar $\mathrm{H}+$-PPases establish an electrochemical potential for $\mathrm{H}+$ across the tonoplast, which is used by other vacuolar transporters (red and brown) to sequester $\mathrm{Na}+$ and $\mathrm{Cl}$ into the vacuole. (2) Removal of inhibitory pyrophosphate (PPi). Vacuolar H+-PPases regulate PPi concentrations in the cytosol. Accumulation of PPi in the cytosol, particularly in younger tissues, can inhibit PPi-dependent metabolic pathways, such as gluconeogenesis and the Smirnoff-Wheeler pathway. (3) Enhancing sucrose transport from source to sink tissues. In phloem companion cells, H+-PPases are shown to be localize to the plasma membrane, where it is hypothesized they synthesize PPi from orthophosphate. This additional PPi is used to enhance sucrose metabolism in these cells, thereby generating more ATP to pump protons into the apoplast that can be used by sucrose transporters, ultimately enhancing sucrose transport into sieve elements. Not all of these processes will be occurring in all cells at all times, and some may be cell-type specific. After Khadilkar et al., (2016) and Schilling et al., (2017).

The common view that currently exists about management of chloride in agriculture. Recent researches reported that prolonged application of fertilizers containing chlorides as impurities as low as (4-5 $\mathrm{mM} \mathrm{Cl}^{-}$) resulted an accumulation of chloride in leaf tissues by about 25 and $50 \mathrm{mg} \cdot \mathrm{g}^{-1} \mathrm{DW}$ in different plant species. Although these chlorides content sometimes exceed the critical toxicity values mentioned above, these plants develop normally and grow without apparent symptoms of stress (Franco-Navarro et al., 2016; Brumós et al., 2010; Cubero-Font 2016). Root $\mathrm{Cl}^{-}$uptake and longdistance transport require a considerable use of metabolic energy Brumós et al., (2010), Felle (1994), Britto, et al., (2006), clearly indicating that shoot $\mathrm{Cl}^{-}$accumulation to macronutrient levels responds to specific biological adaptations From the chemical and physical characteristic of both sodium and potassium, Timothy et al., (2020) reported that, water molecules in the first hydration shell were found to have the same intramolecular geometries and dipole moments as those of the bulk. Furthermore, their dipoles were not aligned to the electric field produced by the ion, but quite tilted. The hydration number for the sodium was found to be five or six water molecules, whereas the potassium's hydration number had a probability distribution ranging from five to ten. From an analysis of the energetic contributions of each hydration shell to the total enthalpy of hydration, we propose that the hydrated ions have a distinct behavior. Sodium has a stronger interaction with its first hydration shell than potassium, giving the latter a more flexible structure. From the above results, we can see that there are differences between the hydration of sodium and potassium. First, losing the second hydration shell is more costly for the former. Also the fact that for the latter the average interaction energy of first shell waters with the ion is very similar to that with the solvent leads to an orientational freedom and explains why the hydration number has a distribution so close to a Gaussian one Fig (7). 


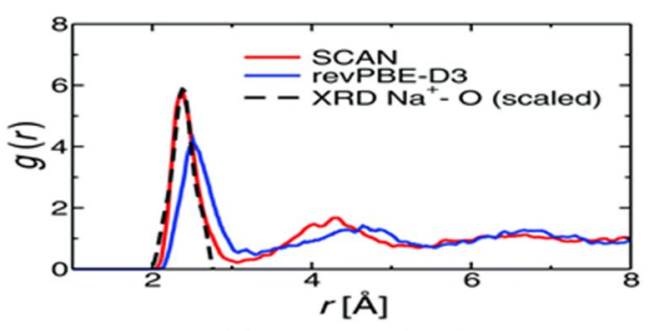

(a) Sodium $\left(\mathrm{Na}^{+}\right)$

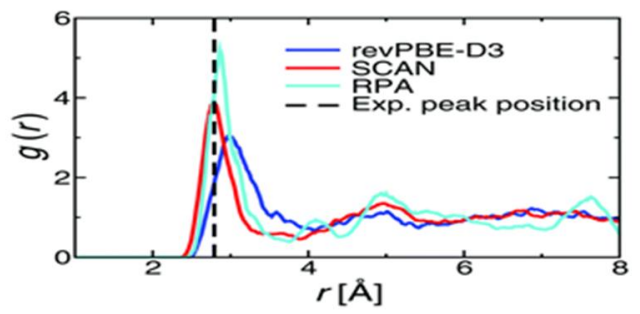

(b) Potassium $\left(\mathrm{K}^{+}\right)$

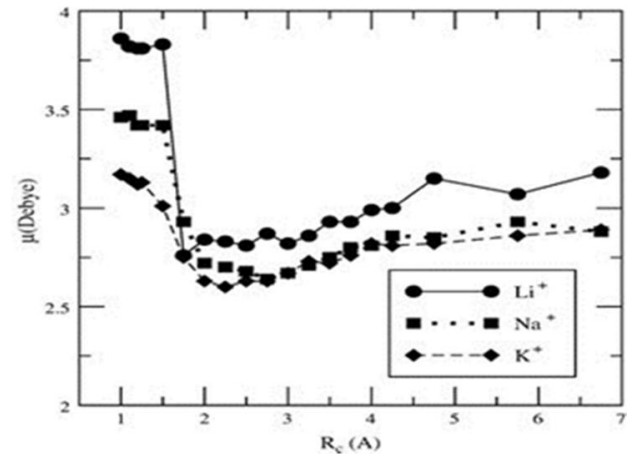

Fig. 7: Represents RDFs of solvated sodium and potassium ions in water with the revPBE-D3 and SCAN functionals demonstrating that the SCAN functional reproduces the experimentally observed peak position $\left(\mathrm{Na}^{+}\right.$, $\left.\mathrm{K}^{+}\right)$and peak shape $\left(\mathrm{Na}^{+}\right)$much more accurately and number of water molecules in the first hydration shell of the ion ( $\mathrm{n}\left(\mathrm{H}_{2} \mathrm{O}\right)$ After Timothy et al., (2020).

Cation hydration structure depicts the radial distribution function (RDF) for the sodium and potassium ions utilizing both revPBE-D3 and SCAN functionals. Significant differences are apparent. For $\mathrm{Na}^{+}$we compared with the rescaled $\mathrm{Na}^{+}-\mathrm{O}$ peak extracted from XRD of $\mathrm{NaCl}$ at $6 \mathrm{M} 20$ and for $\mathrm{K}^{+}$ we compare with the experimentally determined peak position. As described by Kim, et al., (1995), Metroplis et al., (1953).

Timothy et al., (2020) stated that the ability to reproduce the experimental structure of water around the sodium and potassium ions is a key test of the quality of interaction potentials due to the central importance of these ions in a wide range of important phenomena. Here, we simulate the $\mathrm{Na}^{+}$and $\mathrm{K}^{+}$ ions in bulk water using three density functional theory functionals: (a) the generalized gradient approximation (GGA) based dispersion corrected revised Perdew, Burke, and Ernzerhof functional (revPBE-D3) (b) the recently developed strongly constrained and appropriately normed (SCAN) functional (c) the random phase approximation (RPA) functional for potassium. We compare with experimental X-ray diffraction (XRD) and X-ray absorption fine structure (EXAFS) measurements to demonstrate that SCAN accurately reproduces key structural details of the hydration structure around the sodium and potassium cations, whereas revPBE-D3 fails to do so. However, we show that SCAN provides a worse description of pure water in comparison with revPBE-D3. RPA also shows an improvement for $\mathrm{K}^{+}$, but slow convergence prevents rigorous comparison. Finally, we analyse cluster energetics to show SCAN and RPA have smaller fluctuations of the mean error of ion-water cluster binding energies compared with rev PBE-D3.

Such an agreement supports the reliability with which our model can be used to understand the molecular processes involved in the hydration, specifically the differences between the two ions. The hydration numbers for both ions are concentration dependent. Therefore, it is very important to know this value at infinite dilution. Bernal-Uruchurtu, and Ortega-Blake (1995), they found that waters around monovalent cations are not completely aligned toward their electric fields, but rather tilted. This tilt is more defined for potassium than it is for sodium. We also see that none of the ions induces a further modification of the water geometry or dipole moment relative to the bulk. The hydration number of sodium is restricted to either five or sex molecules, whereas that of potassium has a broader probability distribution ranging from five to ten molecules. The energetic analysis shows that the repulsion between the water molecules in the first shell is counteracted by their interaction with the ion. The reference value of the energy of a water molecule in bulk is recovered only after $10 \AA$ away from the cations. The most striking energetic difference between Na1 and K1 resides in the first shell; where the water molecules have a very strong interact under such condition $\mathrm{Na}^{+}$is more effect on the soil salinity than $\mathrm{K}^{+}$ 
Several researchers (Munns and Tester, 2008; Horie et al., 2012; Deinlein et al., 2014; Maathuis, 2014; Wu et al., 2015; Hanin et al., 2016; Wu et al., 2018a). Reported that traditionally, adverse effects of soil salinity have been attributed to with $\mathrm{Na}+$ toxicity, prompting the majority of studies on this topic However, an increase in $\mathrm{Na}^{+}$content (Munns and Tester, 2008; $\mathrm{Wu}, 2018$ ) is always accompanied by $\mathrm{Cl}^{-}$accumulation (Tavakkoli et al., 2010) and $\mathrm{K}^{+}$loss (Wu et al., 2018b) in plants exposed to salt ( $\mathrm{NaCl}$ ) stress. $\mathrm{K}^{+}$is the major inorganic nutrient cation in non-halophytes (Dreyer and Uozumi, 2011), and plays important roles in plant cell activities (Anschütz et al., 2014; Shabala and Pottosin, 2014; Wu et al., 2018c) and stress responses (Wang et al., 2013). $\mathrm{Cl}^{-}$is a plant micronutrient and regulates leaf osmotic potential, and turgor, and stimulates growth in plants (Franco-Navarro et al., 2016). However high $\mathrm{Cl}^{-}$solutions are toxic, and impair photosynthesis and growth (Tavakkoli et al., 2010; Tavakkoli et al., 2011). Specific reasons for these detrimental effects are much less understood than those of $\mathrm{Na}^{+}$, but the excessive accumulation of $\mathrm{Cl}^{-}$in chloroplasts is one effect (Seemann and Critchley, 1985; Geilfus, 2018b). In recent years, the role of $\mathrm{Cl}^{-}$in plant salinity stress tolerance has attracted more attention. (Bazihizina et al., 2019) reviewed the role of $\mathrm{Cl}^{-}$in halophytes. They suggest that rather than targeting $\mathrm{Cl}-$ exclusion, a better way to breed salt tolerant crops would be to improve the selectivity of the broadly selective anion-transporting proteins. $\mathrm{Cl}-$ as an essential micronutrient and its beneficial role in plants (Raven, 2017; Wege et al., 2017), the role of $\mathrm{Cl}^{-}$in organelle development (Geilfus, 2018a; Geilfus, 2018b), and control of $\mathrm{Cl}^{-}$transport in plants (Li et al., 2017b) have been recently reviewed. Moreover, it is suggested nowadays that $\mathrm{Cl}^{-}$is a beneficial macronutrient for plants (Franco-Navarro et al., 2016; Franco-Navarro et al., 2019). Unlike the abovementioned recent reviews, the present mini review is focused on the main traits related to controlling $\mathrm{Cl}^{-}$transport, and its role in plant salt tolerance.

Effectiveness of salinity on root dissection and its impact on the energy needed for plant salt tolerance, since plants must exclude nearly all the salt in the soil solution while taking up water with at least uptake of $\mathrm{Na}^{+}$and $\mathrm{Cl}^{-}$in low amounts (Munns et al., 2020). Three aspects that affect the ability of roots to exclude salt while taking up water, without exhausting the energy budget of the plant. Root type systems and their postmortem was affected by salinity stress, most important aspect of roots compared to shoots is that the stele tissues (xylem, phloem, pericycle and parenchyma cells) are internal, surrounded by a cortex and an epidermis (Fig. 6a-d). Epidermal cells may differentiate into root hairs Fig. ( ).Shoots has stele tissues distributed throughout parenchyma cells. Evidence has emerged that the root cortex must do the heavy lifting of excluding $\mathrm{Na}^{+}$from shoots (Munns et al., 2020). Within this context, the large differences between cortex and stele anatomies are intriguing (Varney et al., 1991; Watt et al., (2008, 2009). Large variation depends on root type (axile versus branch types), age and soil (Fig. 6a-d). The single root model underlies our current framework for salinity tolerance mechanisms (e.g. Fig. 5). This is generally an axile root from the embryo (seminal; Fig. 6a) or stem (nodal; Fig. 6d); branch roots are rarely considered (Faiyue et al., 2012). The single root model greatly underestimates pathways for salts and water from soil to shoot, based on distances and cell sizes. In wheat, within $10 \mathrm{~d}$ of germination, the plant develops a system of different root types with branch roots (termed lateral or fine roots) that have emerged from an axile root (Fig. 8a or d). The complexity of the system increases with time: by the time of flowering, wheat roots below the topsoil can be $90 \%$ branch roots with the fine structure and anatomy shown in Fig. 8(c) (Watt et al., 2008). Soil conditions, including high salinity, strongly influence allocation between axile and branch roots (Rich and Watt, 2013).

Roots of wheat plant (durum) system were studied in a gradient of under salinity stress in order to imitator distribution under natural soil conditions (Rahnama et al., 2011). Seminal axile root lengths in saline gradients were $25 \%$ less than those of the control, whereas branch length was $500 \%$ greater. The consequences of shifts to different root types could be large in terms of anatomy: in the saline gradient, $26 \%$ of total root length shifted to finer branch roots Fig. $(6 \mathrm{~b}, \mathbf{c})$, in addition, the branch roots emerged much closer to the axile tip ( $3 \mathrm{~cm}$ in saline conditions Compared with $20 \mathrm{~cm}$ in nonsaline). Salinity inhibits cell division in the primary roots of species including wheat and barley (Rahnama et al., 2011; Shelden et al., 2013). Branch root initiation and extension was uninhibited by external salt (Rahnama et al., 2011). Decreasing primary root length and allocating energy to the initiation of lateral roots may be linked to adaptation to salinity, a mechanism that also was seen by Zolla et al., (2010) in Arabidopsis. Branch roots arise from pericycle cells and water for elongation may come from the phloem (Boyer $e t$ al., 2010). Salinity can promote differentiation of underlying xylem tissues in cotton (Reinhardt and Rost, 1995). 

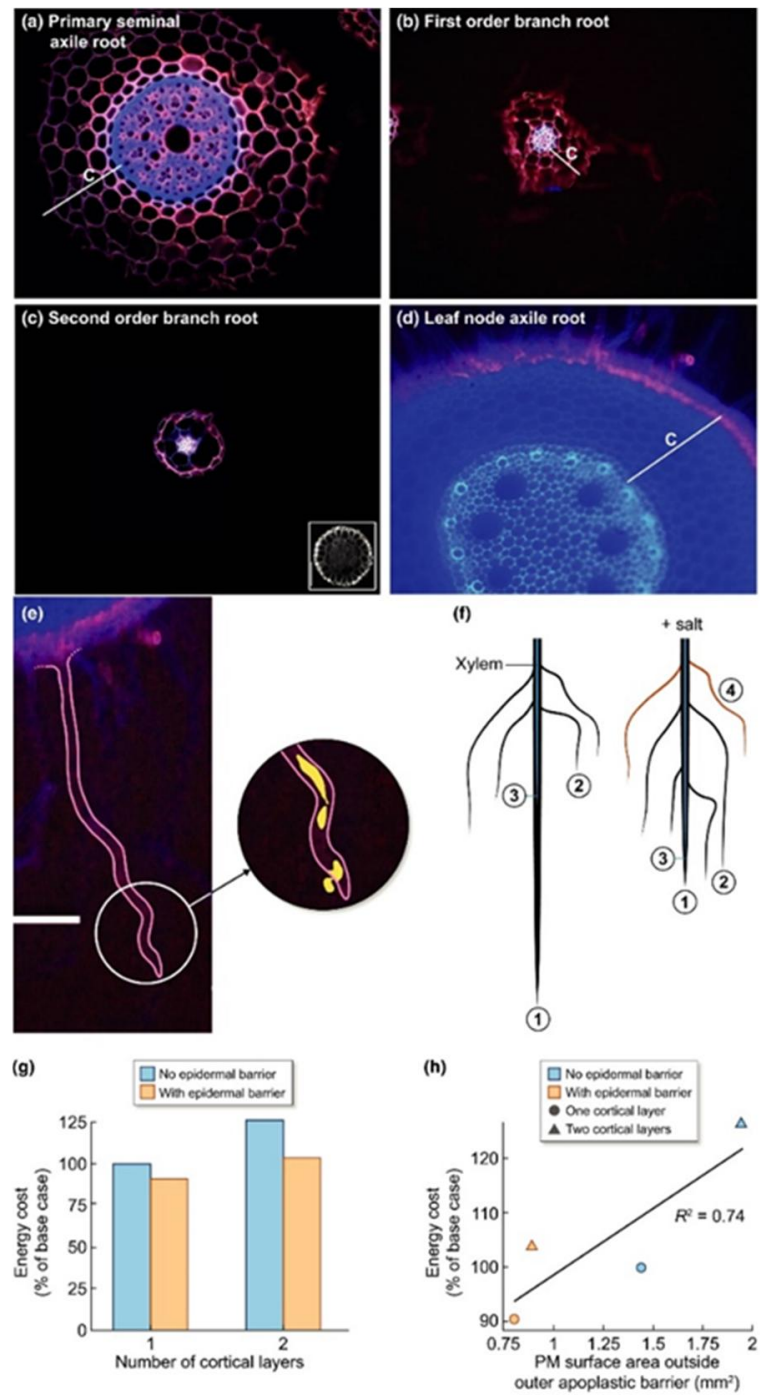

Fig. 8: Changes in anatomy, root system and root cells that may be important in the energetics of salinity tolerance. $(a-d)$ Cross-sections of wheat roots, all at the same magnification. Inset of (c), Arabidopsis primary root crosssection, shown at same signification as wheat second-order branch root (bar, $50 \mathrm{~lm}$; from Sotta and Fujiwara, 2017). (e) Speculation about importance of root hairs as a pidermal barrier to $\mathrm{Na}+$ movement into the root. Left. Root hair of nodal root in (d) outlined to indicate surface area with soil. Right, enlargement of hair tip with hypothesized, drawn transport of vesicles (yellow) delivering $\mathrm{Na}+$ to the outside of the cells (bar, $25 \mathrm{~lm}$ ). Speculation and drawing based on the root hairs of sorghum, which can transport sorgoleone to the surface and to the soil in vesicles (see the subsection 'Cell specializations at the epidermis including hair growth and functions'). (f) Schematic view of influence of salinity on a root system. Events: (1) shortening of primary root; (2) increased first-order branch root length; (3) branch root and xylem maturity closer to the tip; (4) increased rate of root aging. See text for references to original research for these events. (g) Modelled effects of either one or two cortical cell layers, and presence of an epidermal barrier, on energy costs of transmembrane transport. (h) Positive relationship between plasma membrane surface area outside an apoplastic barrier and energy cost. The Foster and Miklavcic (2017) model root geometry was adapted to simulate wheat roots with one or two cortical layers. For all simulations, the external medium contained $100 \mathrm{mM} \mathrm{NaCl}$, and a hydraulic pressure of $0.3 \mathrm{MPa}$ was assumed at the top boundary of the root. The remaining simulation conditions were as described in Foster and Miklavcic (2017) for the nonuniformtransport scenario. C, cortex; PM, plasma membrane. After Munns et al., (2020).

Shabir et al., (2020) reported that both two ions $\mathrm{Na}^{+}$and $\mathrm{Cl}^{-}$are taken up by the outer root cells. At that time transported to the root xylem and finally from the root to the shoot, where they may be stored in vacuoles or in the apoplastic space, or possibly recirculated back to the root system or to older leaves that are less active Fig. (9). 


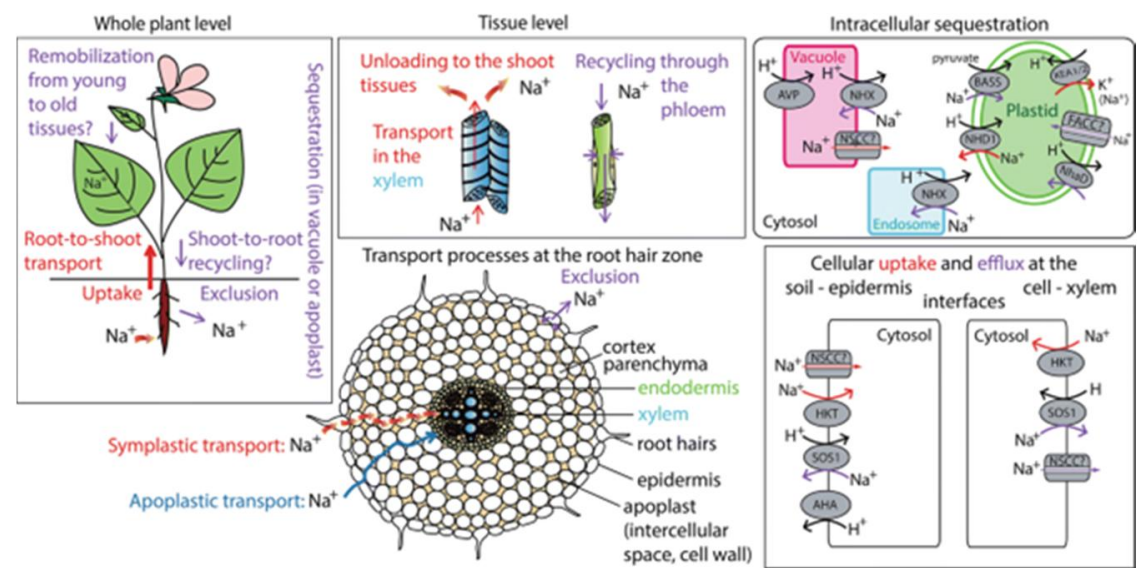

Fig. 9: Summary of $\mathrm{Na}+$ fuxes and transport in plants. Represented processes include those at the whole-plant level, in various tissues and tissues interfaces, as well as within cells. Ions, e.g. $\mathrm{Na}^{+}$, from the soil can enter the root cortex via apoplastic transport through cell wall spaces and intercellular cavities. Except for the branching zone (sites of lateral root formation) and the meristematic and elongation zones, the endodermis forms a barrier that stops the apoplastic flow of $\mathrm{Na}^{+}$and forces all ions to move through the symplast into the xylem. With respect to root hairs, ions can enter the cytoplasm through specifc channels and transporters, and are then transported via the symplast to the central vascular cylinder. Once loaded into the xylem, $\mathrm{Na}^{+}$is transported to the shoot, where it is unloaded from the xylem into the shoot tissues and apoplast. It is still a matter of debated whether $\mathrm{Na}^{+}$ recycling can occur through the phloem back down to the root. Specifc transport mechanisms are probably involved in excluding $\mathrm{Na}^{+}$flow from the xylem towards back into cortex and from epidermis cells back into the soil. Redistribution of $\mathrm{Na}^{+}$from young tissues and organs towards older 'sinks', organs that may be sacrificed, is another possibility that has been suggested as a salt tolerance mechanism. Processes or components are unproven at present are indicated by question marks.

Several researchers reported that, $\mathrm{Cl}^{-}$may play definitive physiological appearance that increasing the dry matter and furthermore improving plant performance Franco-Navarro et al., (2016), FrancoNavarro et al., (2016). Broadley et al., (2012) stated that those elements that stimulate growth are defined as advantageous elements, but are not important in certain plant species, particularly under specific conditions. Where Chloride is not an important macronutrient, however it stimulates growth when accumulated to macronutrient levels. In addition, chloride has been defined as a beneficial macronutrient Franco-Navarro et al., (2016) Fig. (10).

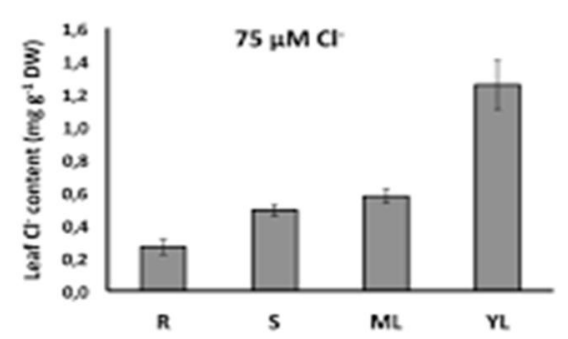

A

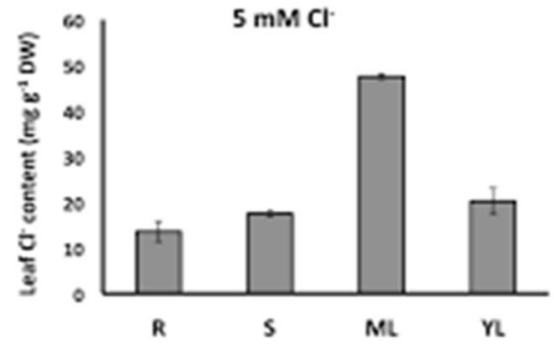

B

Fig. 10: Represents chloride accumulated in tissues of tobacco plants subjected to level of chloride concentration, (A), distribution of chloride throughout the plant, reaching its maximum concentration in adult leaves, where it is stored in their large vacuoles. When subjected at lower concentrations, sufficient to meet micronutrient requirements but insufficient as a macronutrient $(\mathbf{B})$, tobacco plants prioritize preferential the accumulation of chloride particularly in actively growing young leaves, indicating chloride has a biological role in plant cell growth. After José et al., (2019)

José et al., (2019) reported that, tobacco plants is gradually increased by application of chloride at a concentration of $50 \mathrm{mg} \cdot \mathrm{g}^{-1} \mathrm{DW}$ which is represented a 5 -fold of the critical toxicity threshold previously reported for this species (Xu et al., 2000). Therefore prolonged treatments below 5-10 mM $\mathrm{Cl}$ - can determine high leaf accumulations with no stress symptoms and/or growth responses, shorter 
salt stress treatments above $10-15 \mathrm{mM} \mathrm{Cl}$ - can produce symptoms of toxicity with relatively low leaf Cl- contents (Xu et al., 2000; Downton, 1985, Bar et al., (1997). This is indicative that moderate Clapplications enable adequate transport and distribution of $\mathrm{Cl}$ - at the subcellular, organ, and whole-plant levels. Brumós et al., (2010), stated that different varieties of citrus treated with $4.5 \mathrm{mM}$ chlorides particularly after 30 weeks were accumulated chloride between 150 and $425 \mathrm{mM}$ in their leaf tissues with no symptoms of salt stress.

\section{Movement of chloride in in relation to soil- water- root system}

$\mathrm{Cl}$ moves through the soil system to root network systems up to xylem, symplastic transport is the key pathway for chlorides uptake, in a study involving the use of ${ }^{36} \mathrm{Cl}$ as a tracer in the grapevine (Vitis vinifera) (Gong et al., 2011). The symplastic pathway has also been shown to dominate $\mathrm{Cl}$ transport in (CitrusBrumo's et al., 2009). Once taken up into the cytosol, $\mathrm{Cl}$ follows its chemical gradient through the plasmodesmata from cell to cell towards the plasma membrane (PM) of the root xylem pole pericycle cells, which contribute to the xylem loading of Cl Cubero-Font et al., (2016) Fig. (11).
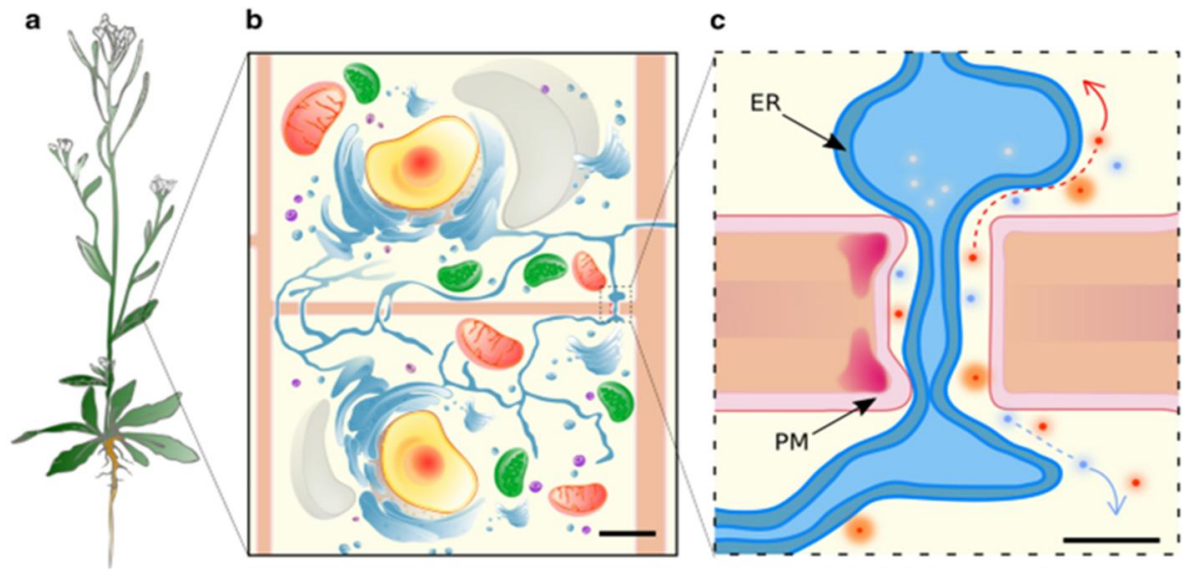

Fig. 11: Whole organism to single-cell multiscale view, emphasizing cell-cell connectivity via plasmodesmata (PD). a Schematic representation of Arabidopsis thaliana at flowering stage. b Two plant cells showing their cytoplasmic contents (nucleus in yellow, mitochondria in red, vacuole in grey, cell wall in coral, endoplasmic reticulum (ER) in blue, peroxisome in violet and ribosomes in purple, cytoplasm in light yellow, chloroplast in green) and displaying PD at their cell-cell interfaces. c PD are plasma membrane (PM; pink) lined, cell wall (coral) spanning pores that enable transport of molecules (red and light blue circles), mostly across the cytoplasmic sleeve (light yellow space). PD neck constriction via deposition of the wall polysaccharide callose (red) can reduce trafficking across the pores. The proposed model is through reduced ER-PM spacing (left side of panel c). Physical continuity of the endomembrane system (ER and PM) is also observable in panels' $b$ and $c$ with the ER becoming highly constricted within PD and largely preventing lumenal transport of macromolecules. The colored arrows show examples of potential directional transports. Diferences in PD densities between cellular interfaces (basal vs lateral sides in panel b) are also represented. Scale bars: $50 \mu \mathrm{m}$ in (b) and $50 \mathrm{~nm}$ in (c). Abbreviations: ER, endoplasmic reticulum. PD, plasmodesmata. PM, plasma membrane.

Li et al., (2020) stated that plasmodesmata are intercellular pores connecting together most plant cells. These structures consist of a central constricted form of the endoplasmic reticulum, encircled by some cytoplasmic space, in turn delimited by the plasma membrane, itself ultimately surrounded by the cell wall. The presence and structure of plasmodesmata create multiple routes for intercellular trafficking of a large spectrum of molecules (encompassing RNAs, proteins, hormones and metabolites) and enable local signalling events. Movement across plasmodesmata is finely controlled in order to balance processes requiring communication with that necessitating symplastic isolation Fig. (12). 


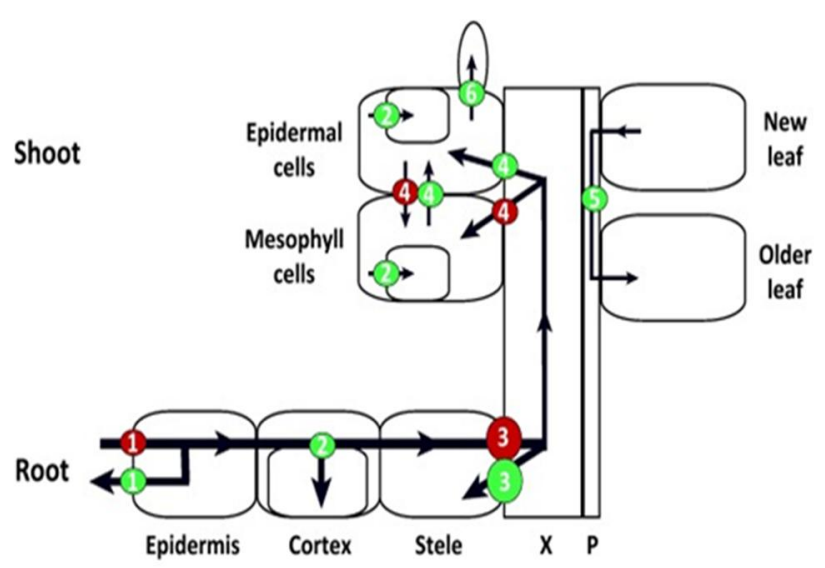

A

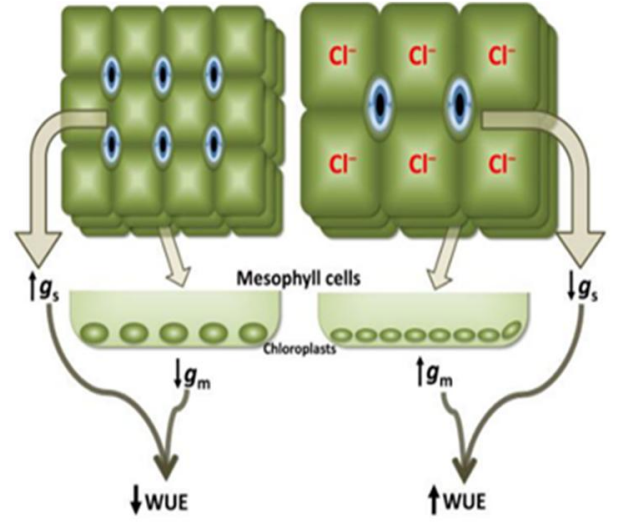

B

Fig. 12: Diagrams represent role of Chloride $\left(\mathrm{Cl}^{-}\right)(\mathrm{A})$, chloride move in root / shoot system (B) and its translocation in plant cells to a level that gradually significantly increases size of leaf cells, resulting in a reduction in stomatal density and, therefore, conductance (gs). At the same time, $\mathrm{Cl}$ improving mesophyll diffusion conductance to $\mathrm{CO}_{2}$, furthermore increasing surface area of chloroplasts exposed to the intercellular airspace. Higher mesophyll diffusion conductance compensates for the reduction in stomatal conductance, resulting in overall higher water use efficiency (WUE).After José et al., (2019).

We highlight the extensive and dynamic interactions that exist between the plasma/endoplasmic reticulum membranes, cytoplasm and cell wall domains, binding them together to effectively define plasmodesmata shapes and purposes.

After $\mathrm{Cl}$ is loaded into the xylem, it is pulled by the transpiration stream towards the aboveground organs (Ko"hler and Raschke 2000; Gilliham and Tester 2005). The protein-mediated uptake of Cl is influenced by the electrochemical gradient of $\mathrm{Cl}$, which is composed of the $\mathrm{Cl}$ concentration gradient across the PM Sanders and Hansen (1981) and the difference in membrane potentials, which is negative on the inside, reaching -120 to $-160 \mathrm{mV}$ at the cytosolic side Sze et al., (1999) Fig. (13).
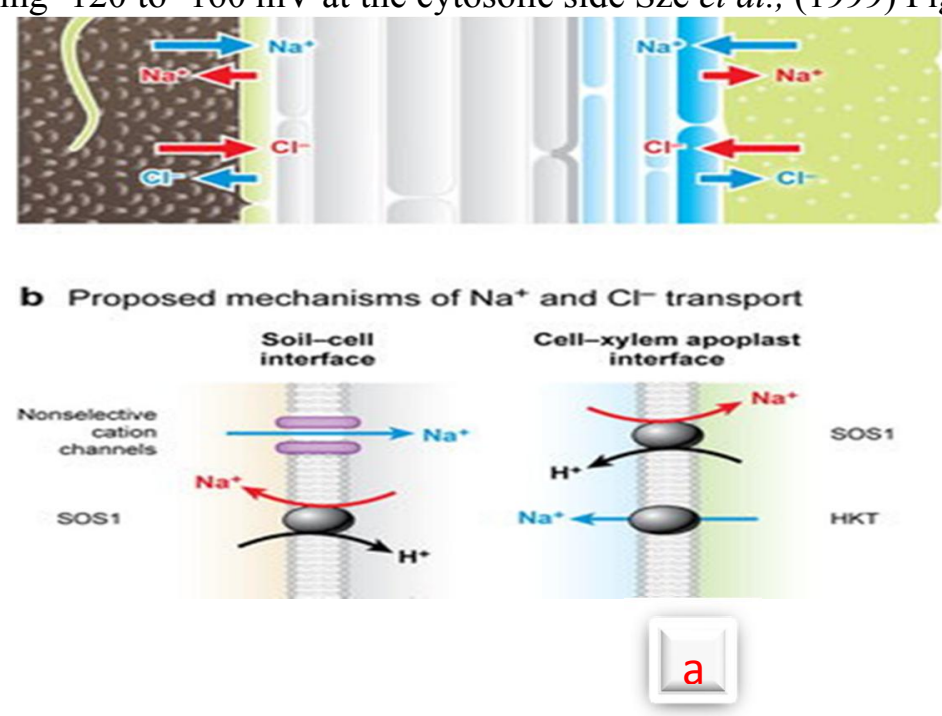

Figs. (13 a and b): Illustrate thermodynamics and mechanisms of $\mathrm{Na}^{+}$and $\mathrm{Cl}^{-}$transport at the soil-root and stellar cell-xylemvessel interfaces in roots. Indicative cytosolic $\mathrm{pH}$, ion concentrations, and voltages (Tester and Davenport, 2003; White and Broadley 2001. (a) Longitudinal sectionof wheat root provided by (Dr. Watt et al., 2008). The cells between the endodermis and the xylemvessel are not labeled, but include pericycle cellsand xylem parenchyma (darker blue) as well asphloem parenchyma. The stele of dicotyledonousplants is more complex because it includes cambialvascular elements. The thermodynamics of ionmovements are indicated by the arrow colors: Active transport is shown as a red arrow; passivetransport is shown as a blue arrow. (b) Theproposed mechanisms of passive and active $\mathrm{Na}+$ and $\mathrm{Cl}-$ transport at the two interfaces, mediatedby ion channels and carriers (uniporters andH ${ }^{+}$-coupled antiporters and symporters).Abbreviations: SOS1, salt overly sensitive mutant 1; HKT, high-affinity $K^{+}$transporter (Munns and Tester, 2008). 
Munns, and Tester, (2008), Stated that, thermodynamics of each of these processes for $\mathrm{Na}^{+}$ represented in Fig. ( a), and molecular mechanisms are shown in Fig. (b). The thermodynamic analysis assumes that cytosolic $\mathrm{Na}^{+}$concentrations of $30 \mathrm{mM}$ and an electrical potential of $120 \mathrm{mM}$, but even if values differ by a factor of two, the principles remain unchanged. The xylem parenchyma, the efflux of $\mathrm{Na}^{+}$from the cells would be active even if the xylem $\mathrm{Na}^{+}$concentrations were nearly ten times lower than cytosoliconly were necessary with cytoplasmic free $\mathrm{Na}^{+}$concentrations greater than approximately $100 \mathrm{mM}$ (which, with an activity coefficient of 0.7 , is a total concentration of around $140 \mathrm{mM}$ ). Another way to look at this is if the cytoplasmic free $\mathrm{Na}^{+}$were $30 \mathrm{mM}$ and the membrane potential difference were $-60 \mathrm{mV}$, active influx would only be necessary with xylem apoplastic concentrations below 3 $\mathrm{mM}$. Consideration of the thermodynamics of a $\mathrm{Na}^{+} / \mathrm{H}^{+}$antiporter is simpler, because the electroneutral exchange this antiporters catalyzes is unaffected by membrane potential. Thus, the direction of $\mathrm{Na}^{+}$ movement is determined simply by the differences in free concentrations of $\mathrm{Na}^{+}$and $\mathrm{H}^{+}$. $\mathrm{A} \mathrm{Na}^{+} / \mathrm{H}^{+}$ antiporters could only work in the opposite direction to that indicated (i.e., it could only pump $\mathrm{Na}^{+}$into cells) if, for a $\mathrm{pH}$ difference of one unit (xylem more acidic), the xylem concentration increased to 10 times that found in the cytoplasm (i.e., to over $300 \mathrm{mM}$ for a cytoplasmic $\mathrm{Na}^{+}$concentration of $30 \mathrm{mM}$ ). Alternatively, if the $\mathrm{pH}$ became more alkaline than $\mathrm{pH} 7.7$, then the $\mathrm{Na}^{+} / \mathrm{H}^{+}$antiporters could pump Na+ into xylem parenchyma cells from a free concentration of $10 \mathrm{mM}$. These conditions would rarely, if ever, occur, and thus, the $\mathrm{Na}^{+} / \mathrm{H}^{+}$antiporter will mostly act to pump $\mathrm{Na}^{+}$out of cells. The various processes of $\mathrm{Na}^{+}$transport are each briefly considered here, but the reader is referred to the more extensive analysis of these processes in (Tester and Davenport, 127). Fluorescence resonance energy transfer based measurements obtained by using the recombinant anion indicator CLOMELEON have revealed cytosolic $\mathrm{Cl}$ concentrations of $10-15 \mathrm{mM}$ in Arabidopsis root cells (Lorenzen et al., 2004; Saleh and Plieth 2013).

Teakle and Tyerman (2010) have reported that chloride concentrations were range from (5 to 20) $\mathrm{mM}$, seems to be valid for many glycophytic plants not stressed excessively by $\mathrm{Cl}$ salts. Thus, under non-saline conditions, the chloride concentration in the cytosol is considered to be higher than that in the soil solution (i.e. 0.06- 0.25 mM; Parker et al., (1983), Brucher (2007) or in the apoplastic fluid (Shahzad et al., 2013). This phenomenon has led to the assumption that, under non-stressed conditions, $\mathrm{Cl}$ uptake is active because it accumulates against both the electrical and the chemical component of its electrochemical gradient. According this basis, chloride influx in barley roots Hordeum vulgare; Jacoby and Rudich (1980) and the common coral weed Chara coralline, Sanders and Hansen (1981) has been predicted to be actively mediated by co-transport with $\mathrm{H}^{+}$. Finally, Felle (1994) has presented electrophysiological evidence that the influx of $\mathrm{Cl}$ into the root hair cells of white mustard (Sinapis Alba) is energetically coupled to the movement of protons down their gradient, i.e. from the acid apoplast into the neutral cytosol. . This symport functions with an estimated coupling ratio of $(1 \mathrm{Cl}: 2$ $\mathrm{H}^{+}$). The gradient of $\mathrm{pH}$ across the membrane is maintained by the extrusion of $\mathrm{H}+$ via the $\mathrm{PM} \mathrm{H+-}$ ATPase ultimately energizing the activity of this $\mathrm{Cl} / 2 \mathrm{H}^{+}$symporters (Felle, 1994). Notably, the molecular details of this symporters have not been adequately resolved and the functional annotation of the underlying genes lags behind the electrophysiological evidence. Key message: symplastic transport is a relevant pathway for the radial movement of $\mathrm{Cl}$ across the root towards the xylem. Under non-Cl salinity conditions, $\mathrm{Cl}$ uptake into root cells (i.e. the root hair or root cortical cell) is active, because $\mathrm{Cl}$ accumulates against both components of its electrochemical gradient. $\mathrm{A} \mathrm{Cl} / 2 \mathrm{H}+$ symport facilitate $\mathrm{Cl}$ influx Fig. (14). 
A
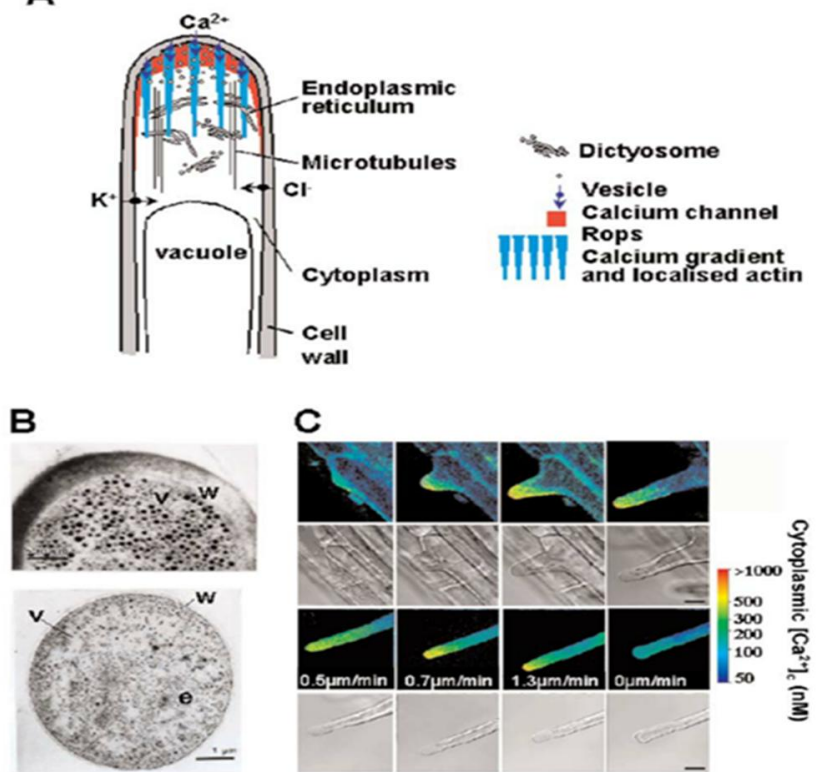

Fig. 14: Illustrates hair Tip Growth. (A) Diagram summarizing the mechanism of tip growth in Arabidopsis root hairs. The tip is packed with membrane-bound vesicles deliv- ering new cell wall material. These vesicles are made in the endoplasmic reticulum (ER) and dictyosomes that are abundant behind the tip. Rop protein is localized to the tip along with F-actin, and a tip-focused calcium gradient. This calcium gradient is thought to be generated by hyperpolarization-activated calcium channels, which are localized to the plasma membrane at the hair tip. Other channels import osmotically active $\mathrm{K}+$ and $\mathrm{Cl}$ - ions, which help to sustain turgor pressure as the hair grows. The direction of growth is controlled by microtubules, which run along the length of the hair. (B) Cytoarchitecture at the tip of an elongating root hair. Transmission electron micrographs of sections of an elongating hair showing the cell wall (w), vesicles (v), and endoplasmic reticulum (e). Top - The hair apex is packed with vesicles. Bottom - A section from just behind the apex shows dense endoplasmic reticulum surrounded by vesicles. (C) Tipgrowing root hairs have a tip-focused calcium gradient. Time course showing the establishment and maintenance of a calcium gradient in an elongating root hair, and its disappearance when growth ceases. The concentration of cytoplasmic free calcium $([\mathrm{Ca} 2+] \mathrm{c})$ was imaged using indo-1 and pseudo-color coded according to the inset scale. $[\mathrm{Ca} 2+] \mathrm{c}$ is shown in the first and third rows with corre- sponding transmitted light images of the same cell in the second and fourth rows After Wymer et al., 1997).

\subsection{Passive chloride influx under salinity conditions.}

Uptake of chloride caused a kinetics change in their entirety particularly under conditions of salinity when external $\mathrm{Cl}$ concentrations exceed the cytosolic $\mathrm{Cl}$ concentration. This occurs because an increase of the $\mathrm{Cl}$ concentration outside the PM results in a membrane potential that is less negative than the $\mathrm{Cl}$ equilibrium potential, authorizing a passive $\mathrm{Cl}$ influx Tyerman and Skerrett (1998) Fig. (15).

During this process Chloride influx into root cells is passive, being facilitated by anion channels (Hedrich 1994; Barbier-Brygoo et al., 2000. Skerrett and Tyerman (1994) have described an anion channel that mediates passive inward fluxes of $\mathrm{Cl}$ into the protoplasts of the root cells of wheat (Triticum aestivum) particularly under salinity conditions. This favors a rapid increase in cytosolic $\mathrm{Cl}$. The molecular identity of this channel remains to be elucidated.

\section{6-Control of Cl Xylem under loading and unloading process}

The loading and unloading of the xylem with $\mathrm{Cl}$ is the rate limiting process that determines the $\mathrm{Cl}$ concentration in the shoot, including under salinity ( $\mathrm{Li}$ et al., 2017). The plant endeavors to maintain the shoot $\mathrm{Cl}$ content below toxic concentrations by restricting xylem-driven root to shoot transport. This can be achieved either (i) by increasing the $\mathrm{Cl}$ efflux from the root cells back into the soil solution Sun et al., (2009), Li et al., (2016b) or (ii) by reducing the xylem loading and thus restricting acropetal transport (Teakle et al., 2007; Brumo's et al., 2010; Li et al., 2016a). Research into Cl-sensitive glycophytes showing damage associated with the accumulation of excessive $\mathrm{Cl}$, namely Lotus corniculatus Sanchez et al., (2011), Citrus rootstocks Brumo's et al., (2010) and grapevine (Vitis vinifera) Henderson et al., (2014), clearly shows that reduced net $\mathrm{Cl}$ loading into the root xylem is the critical step that allows the better performance of crops in salt-affected soils. 


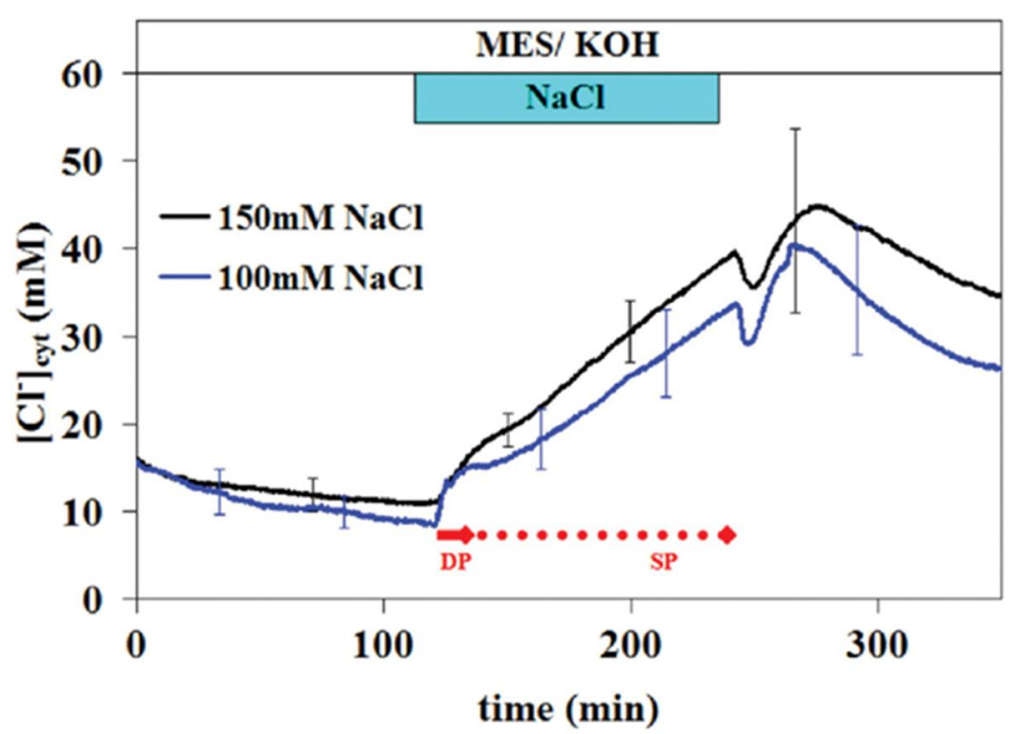

Fig. 15: Diagram of Kinetics influx of chloride at two different $\mathrm{NaCl}$ concentrations. Flow through in vivo experiments with Arabidopsis thaliana plants grown on full MS were performed in a buffer system consisting of $5 \mathrm{mM} \mathrm{MES} / \mathrm{KOH}(\mathrm{pH}=6.0) .100 \mathrm{mM}$ and $150 \mathrm{mM} \mathrm{NaCl}$ were applied after $120 \mathrm{~min}$.; Curves are averages from 4 independent experiments. The data were normalized by the mean of the time interval $5 \mathrm{~min} \leq \mathrm{t} \leq 15$ min. Error bars represent StDv. The red lines at the bottom indicate the two distinct phases: depolarization phase (DP, full line), saturation phase (SP, dotted line).

\subsection{Chloride efflux from roots}

The extrusion of $\mathrm{Cl}$ out of the root cells into the external solution, as described for the roots of the desert poplar Populus euphratica; Sun et al., (2009) and Arabidopsis Lorenzen et al., (2004), is an efficient mechanism for the avoidance of $\mathrm{Cl}$ accumulation in the plant during $\mathrm{Cl}$ salinity. $\mathrm{Cl}$ efflux is positively correlated with salt tolerance in many glycophytes, because the net uptake of $\mathrm{Cl}$ can be minimized by $\mathrm{Cl}$ efflux (Britto et al., 2004; Sun et al., 2009; Li et al., 2016b). A member of the nitrate excretion transporter (NAXT) subfamily, namely the nitrate transporter 1/peptide transporter (NRT1/PTR) family 2.5 protein (NPF2.5), has been found to be expressed in the PM of the root cortical cells, being up-regulated by $\mathrm{NaCl}$ ( $\mathrm{Li}$ et al., 2016b). Arabidopsis T-DNA knockout mutants show a reduced $\mathrm{Cl}$ efflux from the root but accumulate more $\mathrm{Cl}$ in shoots during salt stress. This strongly suggests an involvement of NPF2.5 activity in plant salinity tolerance via the excretion of $\mathrm{Cl}$ out of the root cells into the soil solution. Further indications for candidate genes that are involved in $\mathrm{Cl}$ stress responses can be derived from transcriptomic studies on Citrus (Brumo's et al., 2009) and grapevine (Vitis spp.) genotypes that contrast in their degree of $\mathrm{Cl}$ accumulation in the shoot (Henderson et al. 2014). The putative grapevine anion channels VvNRT1.5 and VvNAXT1, which are both NPF proteins, are thought to be involved in $\mathrm{Cl}$ efflux from roots, because their transcripts are more abundant in the Cl-excluding rootstocks (Henderson et al., 2014). Recent results demonstrate that the Arabidopsis NRT1.5 protein is actually a proton-coupled $\mathrm{H}+/ \mathrm{K}+$ antiporter that mediates $\mathrm{K}+$ release from root parenchyma cells into the xylem (Li et al., 2017) Fig. (16).

Tegeder and Masclaux-Daubresse (2018), reported that nitrogen is an essential nutrient for plant growth. Worldwide, large quantities of nitrogenous fertilizer are applied to ensure maximum crop productivity. However, nitrogen fertilizer application is expensive and negatively affects the environment, and subsequently human health. A strategy to address this problem is the development of crops that are efficient in acquiring and using nitrogen and that can achieve high seed yields with reduced nitrogen input. Review integrates the current knowledge regarding inorganic and organic nitrogen management at the whole-plant level, spanning from nitrogen uptake to remobilization and utilization in source and sink organs. Plant partitioning and transient storage of inorganic and organic nitrogen forms are evaluated, as is how they affect nitrogen availability, metabolism and mobilization. Essential functions of nitrogen transporters in source and sink organs and their importance in regulating nitrogen movement in support of metabolism, vegetative and reproductive growth are assessed. Finally, plant engineering, demonstrating that nitrogen transporters are effective targets to improve crop 
productivity and nitrogen use efficiency. Varieties of inorganic and organic $\mathrm{N}$ transporters with different substrate affinities and specificities have been identified in roots are presented in Fig. (16), illustrated that the presence of highly diverse of the uptake systems allows the plant root to adjust to fluctuations in soil $\mathrm{N}$ compositions and concentrations during the growing season, including under nutrient stress conditions. Different transporters as well as downstream $\mathrm{N}$ assimilatory processes are coordinated are currently unclear, but it may involve the presence of common regulatory systems.

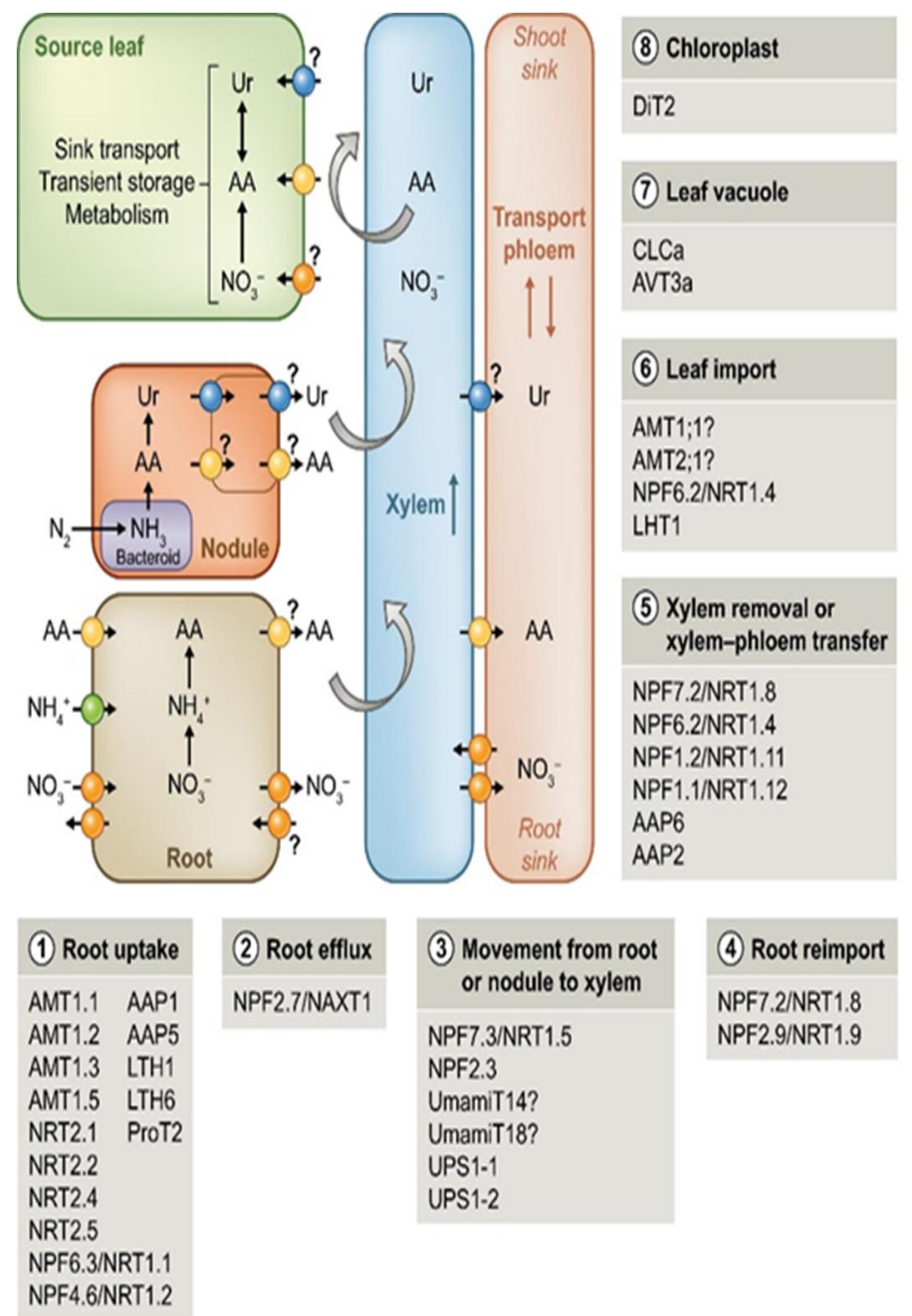

Fig. 16: Schematic representation of nitrogen Chloroplast $(\mathrm{N})$ root uptake and partitioning from root to leaves. Inorganic N transporters for nitrate (NO3_; arrow with orange circle) and ammonium (NH4 +; green circle), as well as organic $\mathrm{N}$ transporters for amino acids (AA; yellow circle) and ureides (Ur; blue circle) are shown at root, nodule, xylem, phloem and source leaf levels. Arrows for the respective transporters either refer to uptake of $\mathrm{N}$ from the apoplast and import into the cell, or indicate cellular efflux. Listed are characterized Arabidopsis nitrate, ammonium, amino acid and ureide transporters that are involved in N (1) root uptake, (2) root efflux, (3) movement from the root or nodule to the xylem and xylem loading, (4) root reimport, (5) xylem removal and xylem-phloem transfer, (6) import into leaf mesophyll cells, (7) import into leaf vacuoles or (8) exchange across the chloroplast envelope. Question marks indicate unknown transporters. For details, see Sections I, II and III in the main text. The nomenclature of the nitrate transporter genes has recently changed (Leran et al., 2014); both the terms Nitrate Transporter1/Peptide Transporter Family (NPF) and Nitrate Transporter1 (NRT1) are used in the figure. AAP, Amino Acid Permease; AMT, Ammonium Transporter; AVT, Amino Acid Vacuolar Transporter; CLC, Chloride Channel; DiT, Dicarboxylate Transporter; LHT, Lysine/ Histidine-like Transporter; NAXT, Nitrate Excretion Transporter; ProT, Proline and Glycine Betaine Transporter; UmamiT, Usually Multiple Acids Move In and Out Transporter; UPS, Ureide Permease. After Tegeder and Masclaux-Daubresse (2018) 


\subsection{Uptake of nitrate and ammonium by root}

Low- and high-affinity nitrate transporters (Fan et al., 2017) mediate nitrate uptake from the soil. Nitrate transporters of the Nitrate Transporter1 (NRT1) family, recently renamed the Nitrate Transporter1/Peptide Transporter Family (NPF) (Leran et al., 2014), are low-affinity systems, with the exception of Arabidopsis NPF6.3/NRT1.1 and rice (Oryza sativa) NRT1.1B, which have both a low and high affinity for nitrate (Wang et al., 1998; Huang et al., 1999; Liu et al., 1999). Of 53 NPF/NRT1 proteins in Arabidopsis, 16 have been characterized so far. High-affinity nitrate transporters belong to the NRT2 family, seven of which have been studied (Fan et al., 2017). Members of the NPF/NRT1 and NRT2 transporter families are proton-coupled importers, except for the bidirectional NPF7.3/NRT1.5 transporter (Lin et al., 2008), and NPF2.7/Nitrate Excretion Transporter1(NAXT1), which mediates nitrate efflux (Segonzac et al., 2007). Additional nitrate transporters are found within the Chloride Channel (CLC) family, which consists of either anion channels or anion proton exchangers (De Angeli et al., 2006) Fig. (17).

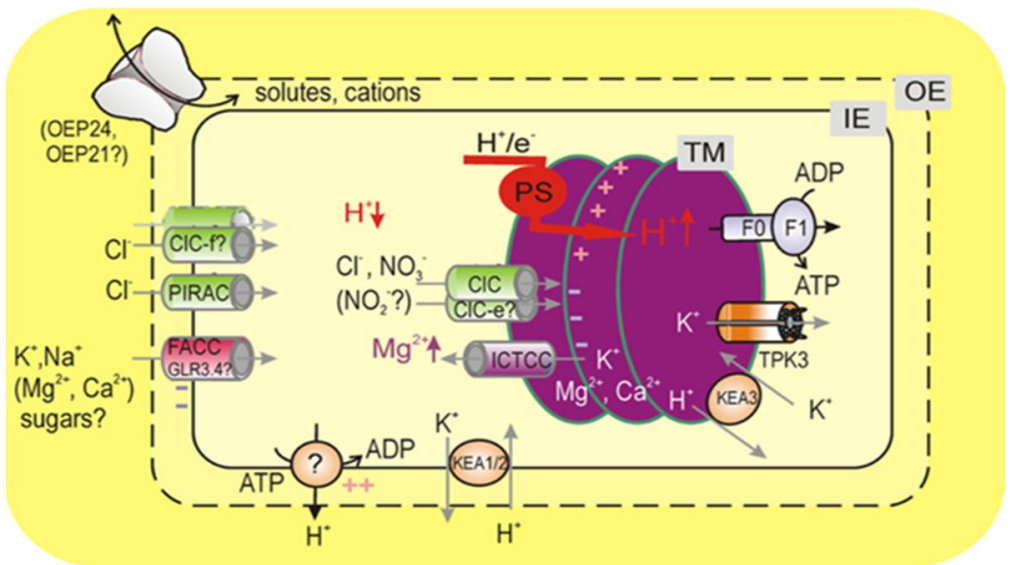

Fig. 17: Diagram illustrates a Chloroplast ion transport under the light. Light-driven export of $\mathrm{H}+$ into the thylakoid lumen by photosynthetic electron transfer chain (PS) causes a hyperpolarization of the thylakoid $\Delta \Psi$. At steady state, this voltage difference is partly dissipated by channel-mediated fluxes of anions, $\mathrm{K}^{+}$, and $\mathrm{Mg}^{2+}$. Light-driven $\mathrm{H}^{+}$and parallel $\mathrm{Cl}$ - fluxes to the thylakoid lumen cause the depletion of these ions in stroma, which is compensated by their uptake across the envelope. For maintenance of alkaline stromal $\mathrm{pH}, \mathrm{H}^{+}$could be actively extruded to cytosol by the IE $\mathrm{H}+$ pump, which requires a counter influx of monovalent cations across the envelope for electrical balance. $\mathrm{K}^{+} / \mathrm{H}^{+}$exchange across the envelope is essential for control of the chloroplast volume and stromal $\mathrm{pH}$. Abbreviations: TM, IE, and OE are thylakoid, inner envelope, and outer envelope membranes, F0F1 is thylakoid ATP-synthetase (F-type $\mathrm{H}^{+}$-ATPase), TPK3 (tandem-pore $\mathrm{K}^{+} 3$ channel, functionally characterized in recombinant system). In situ functionally (by patch-clamp) detected channels were $\mathrm{ClC}$ (anion-selective channel from a ClC family), ICTCC (intermediate-conductance thylakoid cation channel), FACC (fast activating chloroplast cation channel), PIRAC (protein import related anion channel), and outer envelope porins (most possibly, active OEP24 or OEP21). Other: GLR3.4 (glutamate receptor type 3.4 channel) and KEA1/2 (cation/proton antiporters from family 2, CPA2). Another member of the CPA2 family, the thylakoid-localized $\mathrm{KEA} 3$, accelerates dissipation of the trans thylakoid $\Delta \mathrm{pH}$ upon the light offset after De Angeli et al., (2006).

In Arabidopsis, at least six transporters are involved in root nitrate uptake Fig. (18 ). NPF6.3/NRT1.1 (also called Chlorate resistance Protein 1 (CHL1)) and NPF4.6/NRT1.2 mainly operate under high nitrate supply, while NRT2.1, NRT2.2, NRT2.4 and NRT2.5 function under nitrate starvation (Tsay et al., 1993; Huang et al., 1996, 1999; Liu et al., 1999; Cerezo et al., 2001; Filleur et al., 2001; Little et al., 2005; Orsel et al., 2006; Remans et al., 2006; Kiba et al., 2012; Lezhneva et al., 2014).

The four NRT2 transporters take up c. 95\% of the total nitrate under limited N supply, with NRT2.1 and NRT2.2 being the main contributors (Lezhneva et al., 2014). Based on expression and localization studies, NRT2.4 and NRT2.5 seem mainly to be involved in direct nitrate acquisition from the soil via the epidermis and cortex at the root hair zone, while NRT2.1 and NRT2.2 additionally import apoplastic nitrate into cortical and endodermal cells (Kiba et al., 2012; Lezhneva et al., 2014). Nitrate transporters have also been functionally characterized in tomato (Solanum lycopersicum), rice and maize (Zea mays) 
(Garnett et al., 2013; Fu et al., 2015; Xia et al., 2015; Fan et al., 2017). Because excess ammonium is toxic to plant cells, its uptake and assimilation are tightly regulated. Saturable high-affinity (i.e. Ammonium Transporters (AMTs)) and nonsaturable low-affinity uptake systems (i.e. aquaporins or cation channels) control ammonium transport and homeostasis in plants. Six AMT genes were found in Arabidopsis (Gazzarrini et al., 1999), 10 in rice (Sonoda et al., 2003), 14 in poplar (Populus trichocarpa) (Couturier et al., 2007) and 3 in pine (Pinus pinaster) (Castro- Rodriguez et al., 2016). In Arabidopsis, four AMTs function in ammonium root acquisition, with AMT1;1, AMT1;3 and AMT1;5 being involved in direct soil uptake via the epidermis (Loque et al., 2006; Yuan et al., 2007a; . AMT 1; 2 is expressed in cortical and endodermal cells and mediates apoplastic absorption of ammonium. Collectively, AMT 1;1, AMT1;2 and AMT1;3 import up to $95 \%$ of the ammonium. In rice, OsAMT 1;1, OsAMT1;2 and OsAMT1;3 play a role in root ammonium uptake (Li et al., 2016). OsAMT1;1 and OsAMT1;2 expression is up-regulated in response to high ammonium concentrations, whereas OsAMT1;3 is expressed under $\mathrm{N}$ deprivation, suggesting its function in rice adaption to low-ammonium environments (Ferreira et al., 2015).

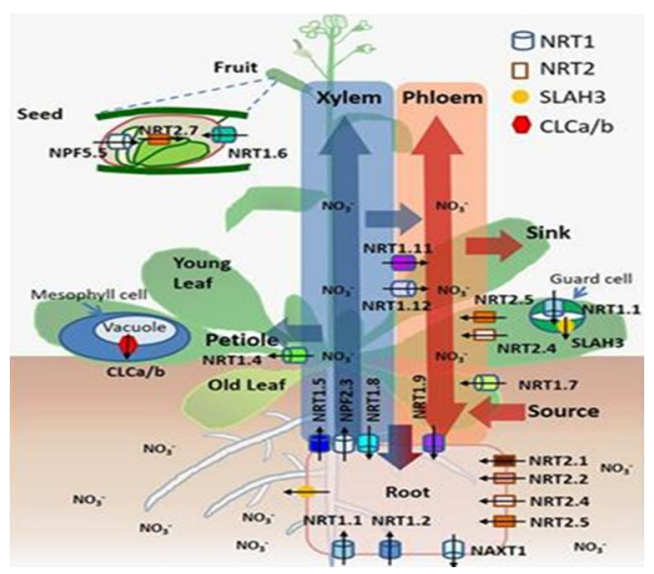

Fig. 18: Summary of spatiotemporal functionality of nitrate transporters/channels and nitrate transport routes in Arabidopsis. Nitrate is taken up by roots, loaded/unloaded by xylem and phloem, and transported to leaves, shoots and seeds. Arrows indicate the directions of nitrate movement. Transporters and channels are depicted according to their localization. After Guan (2017).

\subsection{Uptake of amino acids by plant roots}

Although peptides, proteins and other N-Compounds are also taken up, research on root uptake of organic N has focused on amino acids Rentsch et al., (2007); Komarova et al., (2008); PaungfooLonhienne et al., (2008). In Arabidopsis, over 100 putative amino acid transporters have been identified belonging to the Amino acid Polyamine Choline (APC) transporter superfamily, and the Usually Multiple Acids Move In and Out Transporters (UmamiT) family Rentsch et al., (2007); Pratelli and Pilot (2014). Most of the amino acid transporters characterized to date are localized to the plasma membrane and function in cellular import of a broad range of amino acids in co-transport with protons. Root uptake systems belong to three families within the APC group: the Amino Acid Permeases (AAPs), Lysine /Histidine-like Transporters (LHTs) and Proline and Glycine Betaine Transporters (ProTs) . Generally, substrate specificity and affinity vary between and within the different transporter families. AAPs are considered moderate-affinity systems with broad substrate specificity. Arabidopsis AAP1 is involved in root uptake of glutamate and neutral amino acids Lee et al., (2007); Perchlik et al., (2014), and AAP5 functions in acquisition of basic amino acids Svennerstam et al., (2008), (2011). LHTs are assumed high-affinity transport systems. LHT1 imports neutral and acidic amino acids into the root Chen and Bush, (1997); Hirner et al., (2006); Svennerstam et al., (2007); Ganeteg et al., (2017), but also seems to transport the ethylene precursor 1-aminocyclopropane-1-carboxylic acid (Shin et al., 2015). LHT6 acquires acidic amino acids, glutamine and alanine from the rhizosphere (Perchlik et al., 2014). Finally, Arabidopsis ProT2 functions in import of proline and glycine betaine, and root expression of ProT2 is up-regulated in salt stressed plants, suggesting increased uptake of the 
compatible solutes under water deficiency Rentsch et al., (1996); Grallath et al.,(2005); Lehmann et al., (2011) Fig. (19).

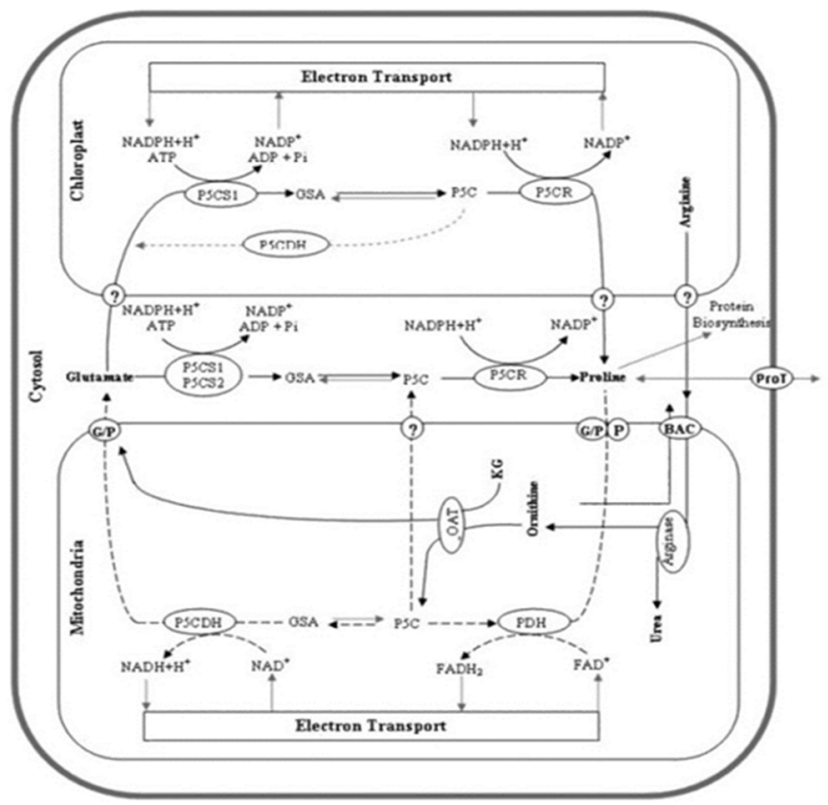

Fig. 19: Diagram illustrates proline metabolism in higher plants, which solid lines represents biosynthetic pathways while catabolic pathways are shown with dashed lines.BAC, basic amino acid transporter (for arginine and ornithine exchange); Glu, glutamate; $\mathrm{G} / \mathrm{P}$, mitochondrial glutamate/proline antiporter; KG, $\alpha$-ketoglutarate; $\mathrm{P}$, mitochondrial proline transporter; $\mathrm{Pi}$, inorganic phosphate; ProT, proline transporter. After Szabados and Savoure (2010).

Shamsul Hayat, (2012) reported that under stressful conditions, plants may accumulate an array of metabolites, particularly amino acids, which traditionally been considered as precursors to and constituents of proteins, and play an important role in plant metabolism and development particularly under stress condition either salinity or drought. There is a positive correlation between proline accumulation and plant stress. Proline, an amino acid, plays a highly beneficial role in plants exposed to various stress conditions. Besides acting as an excellent osmolyte, proline plays three major roles during stress, i.e., as a metal chelators, an antioxidative defense molecule and a signaling molecule. Stressful of environment resulting an overproduction of proline in plants which in turn imparts stress tolerance by maintaining cell turgor or osmotic balance; stabilizing membranes thereby preventing electrolyte leakage; and bringing concentrations of reactive oxygen species (ROS) within normal ranges, thus preventing oxidative burst in plants.

Several researchers Shamsul Hayat, (2012) Vogel and Davis (1952), reported that plants, proline is synthesized by two pathways viz. glutamate pathway and orinithine pathway. Glutamate pathway accounts for major proline accumulation during osmotic stress. The synthesized proline is from glutamatic acid via intermediate $\Delta^{\prime}$-pyrroline-5-carboxylate (P5C). The reaction is catalyzed by $\Delta^{\prime}-$ pyrroline-5-carboxylate synthetase (P5CS) and $\Delta^{\prime}$-pyrroline-5-carboxylate reductase (P5CR) as presented in Fig. (1). Aarzoo Qamar et al., (2015), reported that P5C, an N-substituted imino acid containing imino and carboxyl functional groups (IUPAC, 1997), is an intermediate not only in proline biosynthesis but also in its catabolism Fig. (20) P5C is synthesized from glutamate by pyrroline-5carboxylate synthase P5CS; Hu et al., (1992) and then converted to proline by pyrroline-5-carboxylate reductase P5CR; Szoke et al., (1992); Hare and Cress, (1997) in cytosol and plastids. Proline is transported into mitochondria by membrane located transporters for its catabolism. Proline dehydrogenase (ProDH) catalyzes conversion of proline to $\mathrm{P} 5 \mathrm{C}$, which is then converted to glutamate by pyrroline-5-carboxylate dehydrogenase (P5CDH) in mitochondria Elthon and Stewart, (1981); Hare and Cress, (1997). In addition to proline catabolism by ProDH Boggess et al., (1978); Kiyosue et al., (1996), catabolism of arginine to ornithine by arginase ARG; Goldraij and Polacco, 2000). Later transamination of ornithine by delta-ornithine amino transferase ( $\delta \mathrm{OAT})$ also synthesizes P5C, Delauney et al., (1993); Roosens et al., (1998); Sekhar et al., (2007); Funck et al., (2008); Stránská et 
al., (2008). P5C remains in rapid equilibrium with glutamate semi-aldehyde GSA; Vogel and Davis, (1952). This equilibrium is $\mathrm{pH}$ dependent and P5C form is favored over GSA at physiological $\mathrm{pH}$ of around 7.0 (Lewis et al., 1993; Bearne and Wolfenden, 1995).

Two genes encode Sekhar et al., (2007) P5CS whereas P5CR is encoded by only one in most plant species. Strizhov et al., (1997) Armengaud et al., (2004) Verbruggen et al., (1993) Proline catabolism occurs in mitochondria by means of the chronological action of proline dehydrogenase or proline oxidase (PDH or POX) producing $\mathrm{P} 5 \mathrm{C}$ from proline and $\mathrm{P} 5 \mathrm{C}$ dehydrogenase (P5CDH) which converts $\mathrm{P} 5 \mathrm{C}$ to glutamate. Two genes encode $\mathrm{PDH}$, whereas a single $\mathrm{P} 5 \mathrm{CDH}$ gene has been identified in Arabidopsis and tobacco (Nicotiana tabacum) (Deuschle et al., 2001; Ribarits et al., 2007). PDH transcription is activated by rehydration but repressed by dehydration, thus preventing proline degradation during abiotic stress. Kiyosue et al., (1996), Verbruggen et al., (1996), an alternative pathway, proline can be synthesized from ornithine, which is transaminated to P5C by orinithine- $\delta$ aminotransferase (Verbruggen et al., 1996).

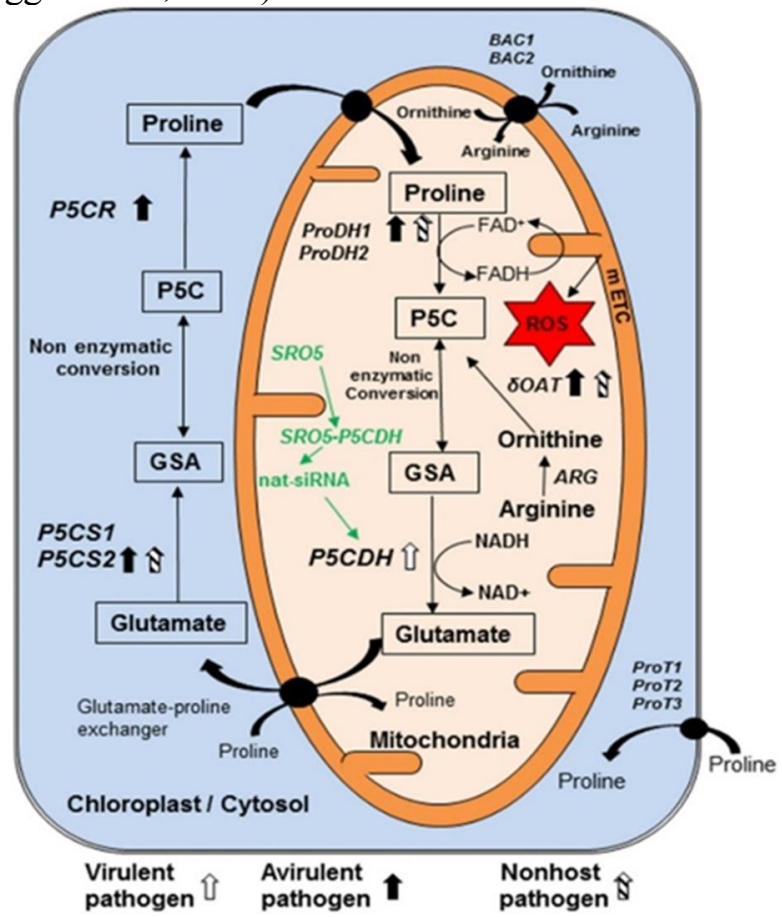

Fig. 20: Model showing genes and pathways possibly involved in synthesis and catabolism of P5C in plant cell and their regulation in response to pathogen infection. Pyrroline 5-carboxylate (P5C) is the intermediate product of both biosynthesis and catabolism of proline. It is synthesized in mitochondria during catabolism of proline by enzyme proline dehydrogenase (ProDH1/2). We speculate that like their counterparts from bacteria and yeast, this enzyme reduces FAD+ to FADH and increases electron flow in mitochondrial electron transport chain (mETC). Arginine is converted into ornithine by arginase (ARG) enzyme. Another enzyme delta-ornithine amino transferase $(\delta \mathrm{OAT})$ convert ornithine to $\mathrm{P} 5 \mathrm{C}$ in mitochondria. $\mathrm{P} 5 \mathrm{C}$ is catabolized by pyrroline 5-carboxylate dehydrogenase (P5CDH) in mitochondria into glutamate. In addition, P5C is synthesized in cytosol and chloroplast, from glutamate by pyrroline 5-carboxylate synthase 1 and 2 (P5CS1, P5CS2) and converted to proline by pyrroline 5-carboxylate reductase (P5CR). P5C and glutamate semi aldehyde (GSA) are non-enzymatically inter-convertible forms. Virulent pathogen infection in plants increases transcript accumulation of ProDH1. Avirulent pathogen infection increases transcript accumulation of P5CS2 and ProDH1. Non-hos pathogen infection increases transcript accumulation of $\delta \mathrm{OAT}$ as well as ProDH1 and P5CS2. Three transporters located on plasma membrane are ProT1, ProT2 and ProT3. Arginine is imported into mitochondria directly and/or in exchange of ornithine by basic amino acid career (BAC1) and BAC2. P5CDH gene is down regulated post transcriptionally by natural siRNAs from similar to RCD one-5 (SRO5) genes. No direct evidence available for this pathway shown in green color during plant-pathogen interaction and this information is speculated based on evidence available under salt stress. Compounds shown in rectangle are important component of metabolism of P5C and line arrows indicates the direction of synthesis. Curved arrows show the transport of compounds. Transporters shown in circle are present on membrane. Block thick arrows show upregulation of genes, in which white arrow indicates virulent pathogen, dark arrows represent avirulent pathogen and striped arrows indicate non-host pathogen. ROS, reactive oxygen species. This model is predominantly based on information from Arabidopsis thaliana literature. After Aarzoo et al., (2015) 
It has been suggested that the ornithine pathway is important during seedling development and in some plants for stress-induced proline accumulation. Armengaud et al., (2004) Roosens et al., (1998), Xue et al., (2009) Accumulation of proline has been suggested to contribute to stress tolerance in many ways. As proline acts as the molecular chaperon, it is able to maintain the protein integrity and enhance the activities of different enzymes. (Rajendrakumar et al., 1997). Numerous studies have reported that proline as an antioxidant suggesting its role as ROS scavenger and singlet oxygen quencher (Matysik et al., 2002; Smirnoff et al., 1989). Exogenous proline application reduces ROS levels in fungi and yeast, thus preventing programmed cell death, Xue et al., (2009) and prevents lipid peroxidation in alga cells exposed to heavy metals. Mehta et al., (1999) Pretreatment of proline also mitigated $\mathrm{Hg}^{2+}$ toxicity in rice (Oryza sativa) through ROS scavenging, such as $\mathrm{H}_{2} \mathrm{O}_{2}$ (Wang et al., 2009). Damaging effects of ROS on Photosystem II (PSII) can be reduced by proline in isolated thylakoid membranes (PSII). Alia PPS, Mohanty (1997). Internal proline content can be determined by biosynthesis, catabolism and transport between cells and different cellular compartments. The biosynthetic enzymes (P5CS1, P5CS2 and $\mathrm{P} 5 \mathrm{CR}$ ) are predicted to be localized in the cytosol whereas a mitochondrial localization is predicted for the enzymes involved in proline catabolism (such as PDH1/ERD5, PDH2, P5CDH and OAT). Shamsul Hayat, (2012) Intercellular transport of proline occurs between cytosol, chloroplasts and mitochondria as implied by compartmentalization of proline metabolism (Fig. 1). It has been reported that uptake of proline in mitochondria is an active process suggesting the existence of specific amino acid transporters, (Yu et al., 1983). These transporters have been identified in Arabidopsis thaliana Rentsch et al., (1996), in addition, in tomato pollen. Chen et al., (2001). At least three transporters (Pro T1, Pro T2 and AAP6) of proline were identified in Arabidopsis thaliana based on C-DNA technology, Rentsch et al., (1996).

These transporters belong to the amino acid permease (AAP) family and are expressed during stressful conditions. Pro T1 expresses ubiquitously but in Arabidopsis thaliana plants exposed to salinity stress, higher levels of Pro T1 were recorded in roots, stems and flowers. Young flowers showed highest expression, particularly in floral stalk phloem. Under water or salinity stress, strong expression of Pro T2 was recorded whereas, AAP6 transcripts were detected mainly in sink tissues (roots, cauline leaves) (Rentsch et al., 1996). In the halophyte species Limonium latifolium, proline was sequestered to vacuoles in non-stressed plants, whereas, high proline content was detected in the cytosol of saltstressed plants, suggesting the importance of de novo proline biosynthesis as well as transport for proline accumulation (Gagneul et al., 2007). Proline metabolism has been studied for more than $40 \mathrm{y}$ in plants, but little is known about the signaling pathways involved in its regulation. The proline biosynthetic pathway is activated and its catabolism repressed during dehydration, whereas rehydration regulates in the opposite direction. Strizhov et al., (1997), Deuschle et al., (2001) Verbruggen et al., (1993) Xue et al., (2009) Yoshiba et al., (1995) Chen et al., (2001) indicated that proline accumulation in detached rice leaves upon exposure to excess $\mathrm{Cu}$ was due to proteolysis and increased activities of $\Delta$ 1-pyrroline- 5-carboxylate reductase or ornithine- $\delta$-aminotransferase, which are enzymes of proline metabolism. It has also been revealed that $\mathrm{Cu}$-induced proline synthesis and accumulation in detached rice leaves was mediated by ABA Chen et al., (2001) Zhang et al., (2008), reported that Cu-induced proline synthesis is associated with NO generation. In this study, the authors reported that exposure of Chlamydomonas reinhardtii to increasing concentration of $\mathrm{Cu}$ resulted in an increased synthesis of proline and a concomitant increase of intracellular NO levels. The authors argued that this intracellular $\mathrm{NO}$ generation was involved in $\mathrm{Cu}$-induced proline accumulation and signaling and this theory was largely based on the fact that the application of sodium nitroprusside (a potent NO donor) increased the activity and transcript amount of P5CS (a key enzyme of proline biosynthesis) in Cu-treated algae which was blocked if a NO scavenger instead of NO donor was used (Zhang et al., 2008). Furthermore, it was reported in scenedesmus that the exogenous proline acts by detoxifying the ROS generated in response to the heavy metal $(\mathrm{Cu}$ or $\mathrm{Zn})$ treatment rather than by improving the antioxidative defense system. (Tripathi and Gaur, 2004).Similarly, Wang et-al. also demonstrated that the protective effect of proline against $\mathrm{Hg}$ toxicity in rice was through detoxifying ROS generated in response to metal treatment.

\section{Chlorides improve nitrates uptake and (NUE) in plant}

Nitrogen $(\mathrm{N})$ is the main limiting nutrient for plants and classified as an essential macronutrient. Nitrate $\left(\mathrm{NO}_{3}{ }^{-}\right)$represents the major $\mathrm{N}$ source and a signal molecule involved in the control of many 
physiological and developmental processes, strongly improving crop yield (Frink et al., 1999; Wang et al.,2012; Krapp et al., 2014; Guan, 2017). The decisive role of $\mathrm{N}$ in crop yield has led to excessive use of $\mathrm{NO}_{3}{ }^{-}$in agriculture over decades generating serious environmental problems like water pollution, which is harmful to people and nature (Nitrates Directive, 1991; Kant et al., 2011). In addition, when the application rate of $\mathrm{NO}_{3}{ }^{-}$exceeds the plant growth needs, over accumulation of $\mathrm{NO}_{3}{ }^{-}$in leaves reduces the nutritional quality of crops (Prasad and Chetty, 2008; Xing et al., 2019). Many large-leaved plants such as beets, cabbage, celery, lettuce, or spinach tend to store huge amounts of $\mathrm{NO}_{3}{ }^{-} \mathrm{MAFF},(1998)$, posing a serious risk to human health. When ingested, $\mathrm{NO}_{3}{ }^{-}$is rapidly converted to nitrite and $\mathrm{N}$-nitrous compounds as nitrosamines or nitric oxide causing methemoglobinemia or "blue baby syndrome" in infants and gastric cancer among other pathological disorders (Comly, 1945; Santamaria et al., 1999; Mensinga et al., 2003). Considering that the growing world population is predicted to reach 9.8 billion in 2050, global efforts are being made to increase food resources by improving crop or agronomic practices (Tilman et al., 2002; Godfray et al., 2010). Since plants use only 30-40\% of the N applied to soil, a greater $\mathrm{N}$ use efficiency ( $N U E$ ) could improve the yield and quality of crops, reducing economic costs as well as decreasing environmental degradation (Baligar et al., 2001). NUE can be defined as the vegetative or reproductive biomass yield per unit of $\mathrm{N}$ available in the soil (Moll et al., 1982; Woodend and Glass, 1993; Ríos et al., 2010). This concept has many variants that can be split into two main elements: (a) $\mathrm{N}$ uptake efficiency (NUPE), defined as the capacity of plant roots to take $\mathrm{N}$ from soil, and (b) $\mathrm{N}$ utilization efficiency (NUTE), defined as the fraction of plant acquired $\mathrm{N}$ to be converted to total biomass or grain yield (Xu et al., 2012). Both are considered important traits in agriculture to reduce the abusive use of $\mathrm{N}$ fertilizers or when low $\mathrm{N}$ availability constrains plant growth, with substantial benefits for farmers and to the environment (Baligar et al., 2001; Han et al., 2016). Crops with higher NUE promote greater yields under limited $\mathrm{N}$ in soil, or require lower $\mathrm{N}$ to produce the same yield as those with lower NUE capacity (Ruiz et al., 2006; Kant et al., 2011; Rubio-Wilhelmi et al., 2012). Therefore, when NUE is increased, both crop-production costs and the harmful input of $\mathrm{NO}_{3}{ }^{-}$ into ecosystems are reduced.

Chloride $\left(\mathrm{Cl}^{-}\right)$considered an essential micronutrient for plants (White and Broadley, 2001; Broadley et al., 2012). It has been uncovered as beneficial when accumulated to macronutrient levels in plant tissues Franco-Navarro et al., (2016); Raven, (2017); Wege et al., (2017); Colmenero-Flores et al., (2019), with new biological functions that improve tissue water balance, whole-plant water relations, photosynthesis performance, and water-use efficiency (Franco- Navarro et al., 2016,2019; Nieves-Cordones et al., 2019). Chloride represents the dominant inorganic anion in the vacuole, promoting cell osmoregulation, turgor-driven processes, leaf cell elongation, and a reduction in stomatal conductance (Franco-Navarro et al., 2016). In addition, $\mathrm{Cl}^{-}$specifically increases mesophyll diffusion conductance to $\mathrm{CO}_{2}(\mathrm{gm})$ as a consequence of the greater surface area of chloroplasts exposed to the intercellular airspace of mesophyll cells, which in turn points towards $\mathrm{Cl}^{-}$playing a role in chloroplast performance (Franco-Navarro et al., 2019). Thus, $\mathrm{Cl}^{-}$specifically reduces gas and water loss through transpiration without affecting the photosynthetic capacity due $\mathrm{CO}_{2}(\mathrm{gm})$ stimulation, resulting in overall higher water-use efficiency (Franco-Navarro et al., 2016, 2019; Maron, 2019). Nitrate and $\mathrm{Cl}^{-}$ are the most abundant inorganic anions, having similar physical and osmoregulatory properties and sharing transport mechanisms (Colmenero-Flores et al., 2019). This is probably the reason why $\mathrm{NO}_{3}{ }^{-}$ and $\mathrm{Cl}^{-}$show strong dynamic interactions in plants Wege et al., (2017), a phenomenon that has been described as a competitive interaction between these two monovalent anions. Different studies have reported a negative effect of $\mathrm{Cl}^{-}$on root $\mathrm{NO}_{3}{ }^{-}$uptake and accumulation (Siddiqi et al., 1990; Cerezo et al., 1997; Xu et al., 2000). For this reason and because of the toxicity generated by excessive $\mathrm{Cl}^{-}$ accumulation in sensitive crops under salt-stress conditions Li et al., (2017); Geilfus, (2018), $\mathrm{Cl}^{-}$has been considered detrimental to agriculture. Overall, $\mathrm{Cl}^{-}$is believed to reduce NUE by limiting $\mathrm{NO}_{3}{ }^{-}$ uptake and accumulation in plant tissues, reducing in turn its availability for plant metabolism (Xu et al., 2000; Anjana and Iqbal, 2007; Wege et al., 2017). However, $\mathrm{Cl}^{-}$is a non-metabolized anion readily accumulated in plant tissues, whose vacuolar sequestration requires a lower energy cost than the accumulation of $\mathrm{NO}_{3}^{-}$(Wege et al., 2017). Thus, considering the close interactions between these two anions, it has been hypothesized that preferential $\mathrm{Cl}^{-}$compartmentalization may reduce vacuolar $\mathrm{NO}_{3}{ }^{-}$ storage in leaves Flowers, (1988), allowing higher $\mathrm{NO}_{3}{ }^{-}$availability for plant metabolism and, consequently, promoting more efficient use of this N source, and higher NUE (Colmenero-Flores et al., 2019). 


\subsection{Sequestration and partitioning of chloride under salinity condition}

Under high chloride content, shoot chloride must be away from dividing cells and sites of primary photosynthesis, because cells cannot tolerate high concentrations of $\mathrm{Cl}$ (Tavakkoli et al., 2010; Teakle and Tyerman 2010). This can be achieved by inter- and intracellular compartmentation (Fricke et al., 1996; Teakle and Tyerman 2010). The intracellular sequestration of $\mathrm{Cl}$ into the vacuoles of roots Storey et al., (2003) or leaves is a strategy for controlling cytosolic $\mathrm{Cl}$ concentrations under conditions of $\mathrm{Cl}$ salinity (Britto et al., 2004; Li et al., 2017). Glycophytes can easily accumulate up to $40 \mathrm{mM} \mathrm{Cl}$ in the vacuole (Barbier-Brygoo et al., 2000; Wege et al., 2017). In this regard, a $\mathrm{Cl} / \mathrm{H}^{+}$antiport has been demonstrated at the tonoplast (Nakamura et al., 2006; Isayenkov et al., 2010; Nguyen et al., 2016). The soybean CLC family member GmCLC1 encodes an anion transporter that has putative $\mathrm{Cl} / \mathrm{H}^{+}$antiporter activity. This anion transporter has been localized to the tonoplast where it may sequester $\mathrm{Cl}$ into the vacuoles ( $\mathrm{Li}$ et al., 2006). The activity of the GmCLC1 protein delays the accumulation of $\mathrm{Cl}$ in the cytosol under conditions of $\mathrm{Cl}$ toxicity (Wong et al., 2013). The overexpression of GmCLC1 in the hairy roots of soybean enhances salt tolerance because less $\mathrm{Cl}$ accumulates in the shoot because of its sequestration into the root vacuoles (Wei et al., 2016). AtCLCa is a further vacuolar anion/ $\mathrm{H}+$ antiporter protein that has been localized to the mesophyll tonoplast. AtCLCa is able to transport nitrate and $\mathrm{Cl}$ from the cytosol to the vacuolar lumen with high selectivity for nitrate over $\mathrm{Cl}$ (De AngeLi et al., 2006; Wege et al., 2010). Despite the preference for nitrate, the AtCLCa protein activity may be relevant for vacuolar $\mathrm{Cl}$ compartmentalization under conditions when cytosolic $\mathrm{Cl}$ concentrations increase during $\mathrm{Cl}$ salinity. This might be the case because nitrate is not so abundant in the cytosol, immediately reduced to nitrite for metabolic assimilation, whereas $\mathrm{Cl}$ abundance is increasing in the cytosol during salinity (Lorenzen et al., 2004). Another member of the $\mathrm{Cl}$ channel family, AtCLCg, is located at the vacuolar membrane of mesophyll cells and contributes to an accumulation of $\mathrm{Cl}$ in vacuoles of $\mathrm{NaCl}$-stressed leaves (Nguyen et al., 2016). AtCLCc is the third member of the CLC protein family in Arabidopsis but this protein has been localized to the tonoplast of guard cells. Unlike other guard cell anion channels such as SLAC1 and SLAH3 that exhibit a high permeability for nitrate over Cl Geiger et al., (2011), AtCLCc has a high selectivity for $\mathrm{Cl}$ over nitrate. During stomatal opening, AtCLCc is involved in vacuolar chloride accumulation in guard cell vacuoles in which $\mathrm{Cl}$ acts as an osmotically active anion facilitating guard cell swelling. Since it has not been localized in the mesophyll Kusumi et al., (2017), its role in the tissue sequestration of $\mathrm{Cl}$ is questionable. Nevertheless, the protein AtCLCc has been shown to be essential for stomatal movement and salt tolerance by regulating $\mathrm{Cl}$ homeostasis (Jossier et al., 2010).

The protein ALMT9, a member of the aluminum-activated malate transporter protein family, is located at the tonoplast of the leaf mesophyll, the leaf vasculature Barbier-Brygoo et al., (2011), the endodermis, the pericycle, the guard cells and the root vasculature Eisenach and De Angeli (2017), and it mediates $\mathrm{Cl}$ flux to the vacuolar lumen during salt stress. By these means, it helps in the maintenance of cytosolic ion homeostasis (Baetz et al., 2016).Therefore leaf partitioning is a strategy for keeping $\mathrm{Cl}$ below toxic levels at sites that expand or at the primary sites of photosynthesis (Boursier and La"uchli, 1989). James et al., (2006) have found that $\mathrm{Cl}$ can accumulate in the cells of the epidermis, thereby avoiding high $\mathrm{Cl}$ concentrations in the mesophyll. In sorghum (Sorghum bicolor), $\mathrm{Cl}$ can be partitioned via the phloem in the leaf sheath in order to keep these toxic ions away from the photosynthetically active leaf blades (Boursier and La"uchli, 1989). However, tissue sequestration or vacuolar ion inclusion are associated with the problem that, under conditions of incessant $\mathrm{Cl}$ uptake, internal storages sites may become filled. With regard to sodium toxicity, some evidence exists for a mechanism to recirculate sodium from the shoot back to the root via the phloem. This process includes phloem loading and unloading as mediated by the Arabidopsis high-affinity potassium transporter (HKT) protein 1;1 (AtHKT1;1) (Berthomieu et al., 2003; Tester and Davenport, 2003). The export of sodium from leaves via the phloem correlates with tolerance to salinity. However, in comparison with the transpirationdriven uptake of sodium, its re-translocation is relatively small (Munns, 2002). In contrast to sodium, no indication has been found that such a mechanism exists for $\mathrm{Cl}$, although this cannot be excluded because thorough tests have not been carried out. A study on barley has indicated that phloem sap contains only $1 / 10$ th of the $\mathrm{Cl}$ that was delivered through the xylem, implying that phloem-based basipetal re-translocation is not effective in keeping shoot $\mathrm{Cl}$ concentrations low (Munns and Fisher, 1986). Furthermore, studies involving the use of $36 \mathrm{Cl}$ as a tracer have failed to demonstrate that $\mathrm{Cl}$ from the shoots of barley can be released into the external solution of their roots (Greenway et al., 
1965). $36 \mathrm{Cl}$ efflux from the roots into the external solution is known to be very low (Lessani and Marschner, 1978). Plant endeavors to maintain the shoot $\mathrm{Cl}$ concentration below toxic levels. The vacuole acts as a storage compartment to keep the cytosolic $\mathrm{Cl}$ concentration low. For some plants, the accumulation of $\mathrm{Cl}$ in the cells of the epidermis or leaf sheaths is a mechanism for avoiding high $\mathrm{Cl}$ concentrations in the mesophyll of photo synthetically active cells.

\subsection{Anion competition with chloride under salinity stress and their physiological effects}

The way in which high concentrations of $\mathrm{Cl}$ impede growth and cause toxicity has only been sparsely studied. Antagonistic $\mathrm{Cl}$ anion-anion competition with regard to the cellular uptake of nitrate and phosphate is considered to hamper growth and yield Fig. (21).
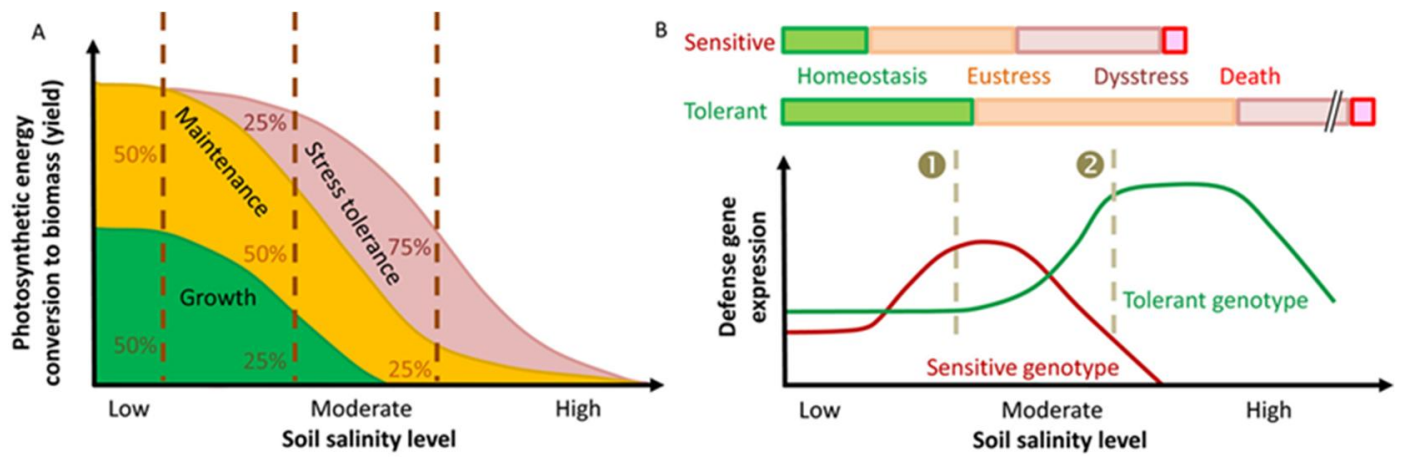

Fig. 21: Schematic of energy gain and energy use by a crop plant and performance of crops under salinity stress. (A) The proportion of energy used for maintenance, growth and stress defense is illustrated The relative proportions will change depending on the developmental stage of the plant and exposure to salt stress maintenance costs will be greater when plants are larger. Total energy gain will decrease with greater salinity by decreasing photosynthetic rate following induced closure of stomata and damage to cellular and photosynthetic machinery. Stress tolerance mechanisms represent additional costs to the plant required to deal with the salt load in the soil (for example, but not limited to, greater costs in ion exclusion or compartmentation, maintaining ion homeostasis and reactive oxygen species (ROS) detoxification). At high salinity, there will be zero growth, as the total costs to the plant equal energy gain; when costs exceed energy gained, then tissue will senesce. (B) Response of a sensitive and a tolerant crop to soil salinity. Both crop types display response to salinity that can be grouped in phases: homeostasis maintains high growth rate, eustress elicits defense gene expression and dysstress causes stagnation and death. The salinity range is narrow in sensitive crops and broad in tolerant ones. The induction of defense in sensitive crops occurs early, with less magnitude. After Zörb et al., (2019).

Zörb et al., (2019) reported that thirty crop species provide $90 \%$ of our food, most of which display severe yield losses under moderate salinity. Securing and augmenting agricultural yield in times of global warming and population increase is urgent and should, a side from ameliorating saline soils include attempts to increase crop plant salt tolerance. It provides an overview of the processes that limit growth and yield in saline conditions. Yield is reduced if soil salinity surpasses crop specific thresholds, with cotton, barley and sugar beet being highly tolerant, while sweet potato, wheat and maize display high sensitivity. Apart from $\mathrm{Na}^{+}$, also $\mathrm{Cl}^{-}, \mathrm{Mg}^{2+}, \mathrm{SO}_{4}{ }^{2-}$ or $\mathrm{HCO}_{3}{ }^{-}$contribute to salt toxicity. The inhibition of biochemical or physiological processes cause imbalance in metabolism and cell signalling and enhance the production of (ROS) reactive oxygen species interfering with cell redox and energy state. Plant development and root patterning is disturbed, and this response depends on redox and reactive oxygen species signalling, calcium and plant hormones.

Under conditions of $\mathrm{Cl}$ salinity, proteins for cellular nitrate or phosphate uptake are thought to leak $\mathrm{Cl}$ because they cannot discriminate between $\mathrm{Cl}$ and nitrate (or phosphate). This missing selectivity for nitrate or phosphate over $\mathrm{Cl}$ may lead to a reduced uptake of nitrogen or phosphorus when external $\mathrm{Cl}$ concentrations increase excessively. Finally hampering growth and yield, as shown for tomato (Solanum lycopersicum; Papadopoulos and Rendig 1983) or wheat (Hu and Schmidhalter 1997); with the exception of maize (Zea mays L.) (Hu"tsch et al., 2016).

Chloride is the most recent addition to the list of essential elements. Many people make the common mistake of confusing the plant nutrient chloride $\left(\mathrm{Cl}^{-}\right)$, with the toxic form chlorine $(\mathrm{Cl})$. Chlorine is not the form that plants use. Chlorine exists either as a gas, or dissolved in water, such as bleach, and is not found in fertilizer. The gas form of chlorine is commonly used in municipal water treatment systems. 
As chlorine gas reacts with water, hypochlorous acid $(\mathrm{HOCl})$, hydrogen $\left(\mathrm{H}^{+}\right)$, and chloride $(\mathrm{Cl})$ are formed. This reaction lowers the $\mathrm{pH}$ of the water. The change in $\mathrm{pH}$ depends on how much chlorine gas is injected and on the buffering capacity of the water. Chlorine gas is $100 \%$ available active chlorine. Only 1 pound (lb) of chlorine gas $\left(\mathrm{Cl}_{2}\right)$ is required to provide a 1-ppm concentration of $\mathrm{Cl}_{2}$ to $1,000,000$ $\mathrm{lb}(120,000$ gallons $)$ of water. Similarly, an injection of $1 \mathrm{lb}$ of chlorine gas per hour will provide a 1ppm concentration of $\mathrm{Cl}_{2}$ to a water supply with a flow rate of about 2,000 gallons per minute (gpm). Although Chloride is classified as a micronutrient, plants may take-up as much Chloride as secondary elements such as Sulfur.

\section{Function}

Chloride is essential for many plant functions. Some of them are

- It is essential (working in tandem with $\mathrm{K}^{+}$) to the proper function of the plants stomatal openings, thus controlling internal water balance.

- It also functions in photosynthesis, specifically the water splitting system.

- It functions in cation balance and transport within the plant.

- Research has demonstrated that $\mathrm{Cl}$ diminishes the effects of fungal infections in an, yet undefined, way.

- It is speculated that $\mathrm{Cl}$ competes with nitrate uptake tending to promote the use of ammonium $\mathrm{N}$. This may be a factor in its role in disease suppression, since high plant nitrates have been associated with disease severity.

\subsection{Factors affecting availability}

Most soil chloride is highly soluble and is found predominantly dissolved in the soil water. Chloride is found in the soil as the Chloride anion. Being an anion it is fully mobile except where held by soil anion exchange sites (Kaolinite clays, Iron and Aluminum Oxides). In areas where rainfall is relatively high and internal soil drainage is good, it may be leached from the soil profile. In addition, where muriate of potash fertilizer is not regularly applied Chloride deficiencies can occur. Atmospheric Chloride deposition tends to be rather high along coastal regions and decreases as you progress inland. Chloride, nitrate, sulfate, boron, and molybdenum are all anions in their available forms, and in that form, they are antagonistic to each other. Therefore, an excess of one can decrease the availability of another. Little information is available on other specific interactions that may occur..

\section{Deficiency and toxicity symptoms}

Alfalfa, broccoli, brussel sprouts, cabbage, cauliflower, lettuce, oil palm, potato, small grains, sugar/table beets, and tomatoes. Wilting restricted and highly branched root system, is often with stubby tips. Leaf mottling and leaflet blade tip wilting with chlorosis has also been observed. Chloride insufficiency in cabbage is marked by an absence of the cabbage odor from the plant Fig. (22) illustrates deficiency symptoms in some plants.

Toxic symptoms are similar as is found with typical salt damage. Leaf margins are scorched and abscission is excessive. Leaf/leaflet size is reduced and may appear to be thickened. Overall plant growth is reduced. Chloride accumulation is higher in older tissue than in newly matured leaves Fig. (23). In conifers, the early symptoms are a yellow mottling of the needles, followed by the death of the affected needles Fig (24).

\section{Chloroplastidial Cl homeostasis}

Chloride toxicity-induced chlorosis and necrosis can be derived from results obtained with the common bean (Phaseolus vulgaris); Seemann and Critchley 1985) and field bean Vicia faba; Slabu et al., (2009), which accumulate $\mathrm{Cl}$ in the chloroplast Fig. (24). 
Middle East J. Appl. Sci., 11(1): 76-125, 2021
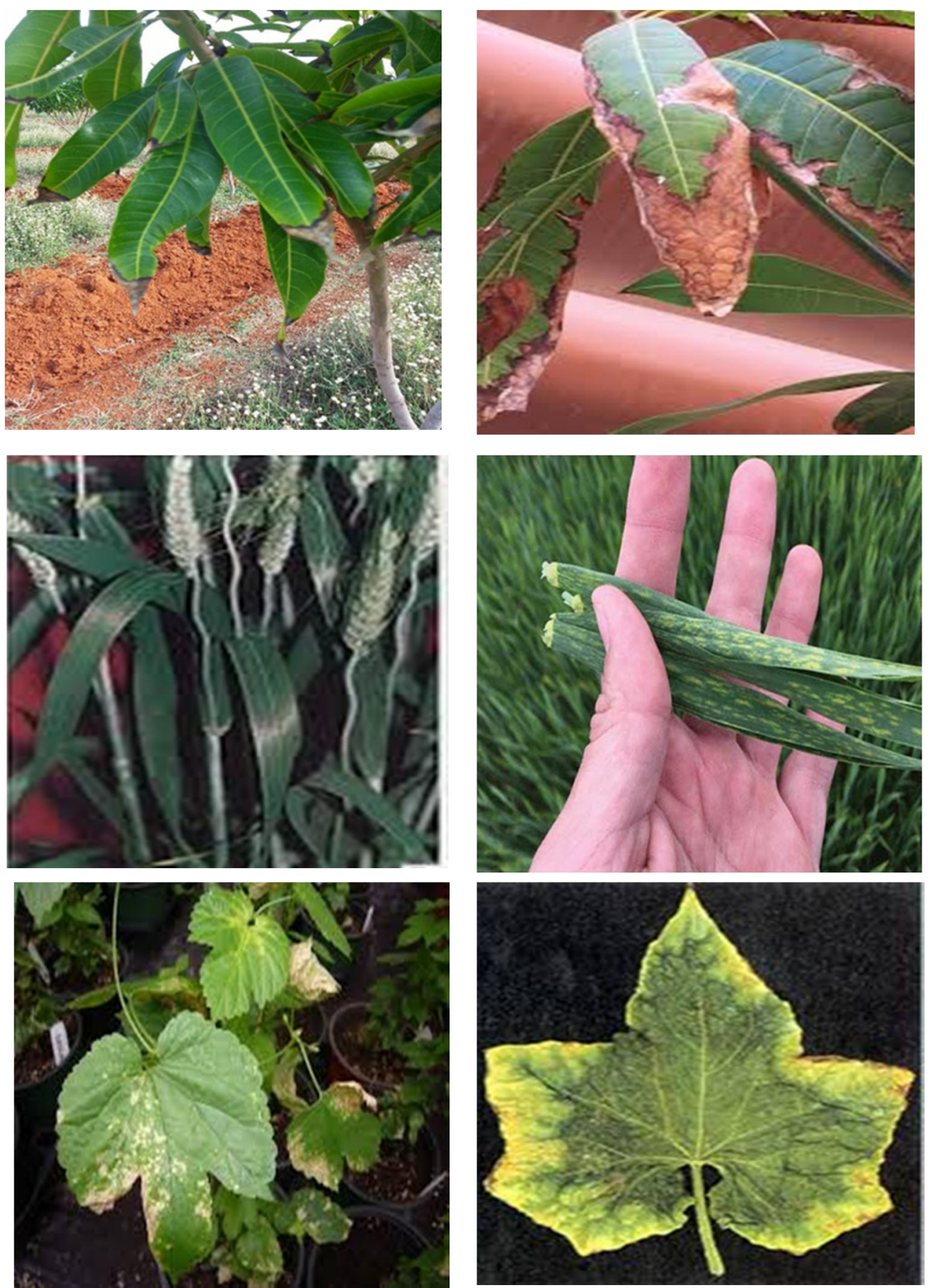

Fig. 22: Illustrates some deficiency symptoms in some plants 
Middle East J. Appl. Sci., 11(1): 76-125, 2021
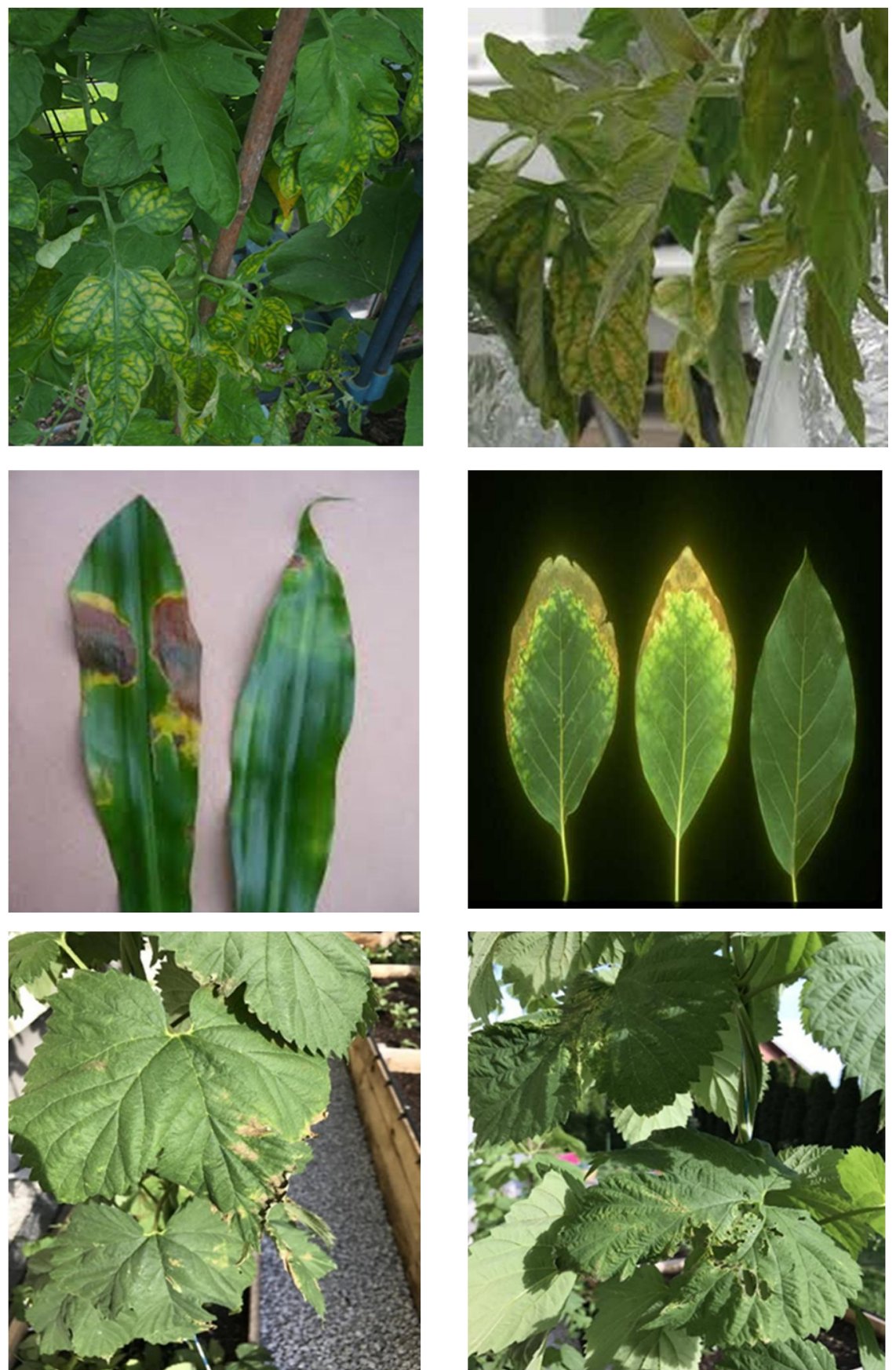

Fig. 23: Illustrates some toxicity symptoms in some plants 

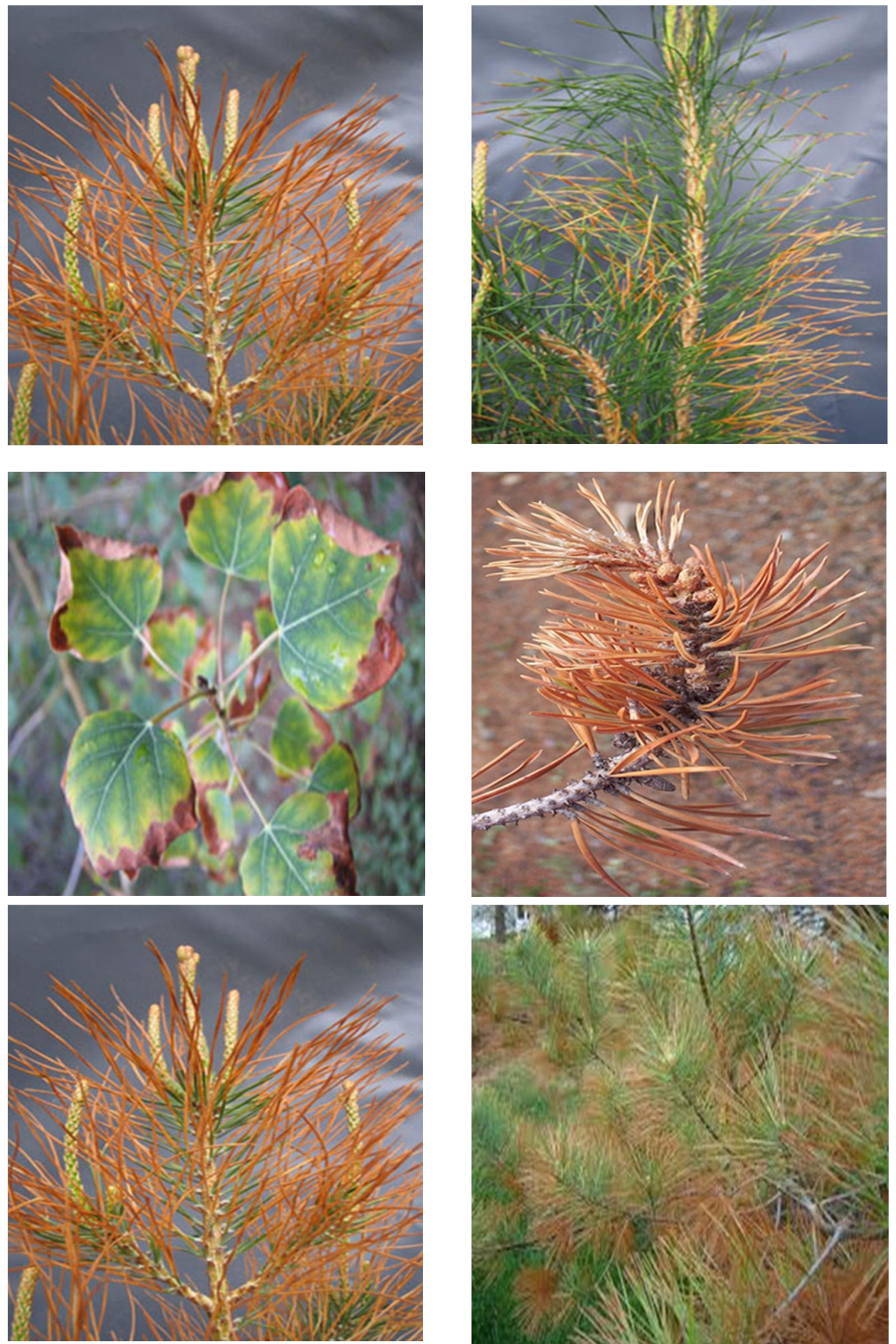

Fig. 23: Illustrates some toxicity, and deficiency in conifers, trees the early symptoms are a yellow mottling of the needles, followed by death 

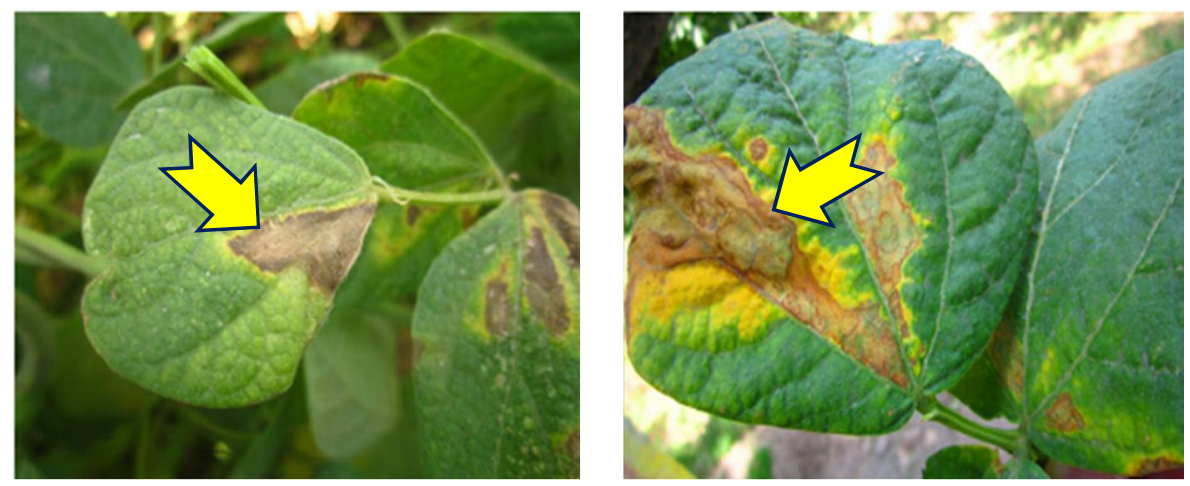

Fig. 24: Illustrates interveinal necrosis with chlorotic

This accumulation is correlated with a reduction in Chl. content, possibly based on Chl. degradation, which is presumably responsible for the reduced photosynthetic quantum yield Slabu et al., (2009), Tavakkoli et al., (2010). The degradation of Chl may explain the formation of chlorosis or necrosis. Studies on spinach (Spinacia oleracea) suggest that plants seek to control Chloroplastidial $\mathrm{Cl}$ homeostasis by excluding $\mathrm{Cl}$, the major anion in the chloroplast of spinach, from being excessively taken up into the chloroplast when Cl Robinson and Downton 1984, Schro"ppe 1Meier and Kaiser 1988) stresses the plant. Efforts by the plant to control $\mathrm{Cl}$ homeostasis in the chloroplast of spinach have also been observed under $\mathrm{Cl}$ deficiency. In spinach (Teardo et al., 2005) and Arabidopsis (Marmagne et al., 2007), the $\mathrm{Cl}$ channel AtCLCe is known to be anchored in the thylakoid membrane. It has been suggested to function in the homeostatic control of $\mathrm{Cl}$ (Herdean et al., 2016a). The loss of the homeostatic control, i.e. the excess accumulation of $\mathrm{Cl}$ in the chloroplast, is anticipated to cause multiple.

\subsection{Suitability of chloride for plant production.}

The idea that only small amounts of $\mathrm{Cl}^{-}$are required for optimal plant growth and that naturally occurring Cl-levels amply meet crops requirements still underlies the agronomic and even the scientific fields (Geifus, 2018). However, according to the findings described above, crops could benefit from $\mathrm{Cl}^{-}$ fertilization more broadly than is generally believed. The amount of $\mathrm{Cl}^{-}$fertilization required to ensure beneficial macronutrient requirements would depend on the levels naturally present in the soil and on the specific necessity of the cultivated crop. In inland regions, far from the ocean, the low deposition of $\mathrm{Cl}^{-}$, a highly mobile molecule subject to leaching in the soil, can limit the yield of crops (Fixen, 1987). Substantial responses to $\mathrm{Cl}^{-}$-containing fertilizers have been reported for different crops in many parts of the world (Xu et al., 2000; Chen et al., 2010). However, most of these studies did not clarify to what extent plant yield enhancement was due to the accompanying cations, or whether other anions could replace $\mathrm{Cl}^{-}$in such a growth-promoting effect. It has been recently proven that a number of physiological disorders impairing the growth and yield of durum wheat under field conditions are specifically due to soil $\mathrm{Cl}^{-}$deficiency (Schwenke et al., 2015). For reasons still unknown, some plant species such as kiwi fruit Smith et al., (1987) and palm trees Braconnier (1990) have higher $\mathrm{Cl}^{-}$requirements, which cannot be alleviated through $\mathrm{NO}_{3}{ }^{-}$addition. These plants can be valuable models for better understanding of the regulation of $\mathrm{Cl}^{-}$homeostasis in higher plants (Wege et al., 2017). For example, coconut plants appear to have greater dependence on $\mathrm{Cl}^{-}$for proper regulation of stomatal function, since stomatal opening is delayed by about $3 \mathrm{~h}$ in $\mathrm{Cl}^{-}$-deficient plants (Xu et al., 2000).

Interestingly, guard cells of another palm tree, Phoenix dactilifera, release $\mathrm{Cl}^{-}$rather than $\mathrm{NO}_{3}{ }^{-}$ during stomatal closure, while $\mathrm{NO}_{3}{ }^{-}$is required as a signal molecule to trigger the abscisic acid (ABA)dependent response (Mueller et al., 2017). This clearly demonstrates that full understanding of Clhomeostasis in higher plants requires going beyond of model plant species. Watanabe et al., (2007) reported leaf $\mathrm{Cl}^{-}$concentrations for 670 species from 138 families of terrestrial seed plants collected from their natural habitats. The most frequent plant $\mathrm{Cl}^{-}$content reported was around $5 \mathrm{mg} \mathrm{g}^{-1} \mathrm{DW}$, which is below the beneficial range of $\mathrm{Cl}^{-}$nutrition. This suggests that plants might frequently benefit from $\mathrm{Cl}^{-}$fertilization in many environments. In the agronomic context, $\mathrm{Cl}^{-}$-deficient soils can be identified in terms of plant growth for important crops like coconut, oil palm, wheat, durum wheat, and maize, $(\mathrm{Xu}$ et al., 2000 and Raven 2017). Therefore, these and most probably other species are favored by Cl- 
fertilization, which is expected to improve plant performance and crop yield. In addition, given the close correlation between $\mathrm{Cl}$ - homeostasis and NUE adequate management of optimal $\mathrm{NO}_{3}{ }^{-} / \mathrm{Cl}^{-}$ratios in different agriculture systems could reduce $\mathrm{NO}_{3}{ }^{-}$input rates without compromising plant performance (Inal et al., 1998). Chloride-dependent reduction of plant $\mathrm{NO}_{3}{ }^{-}$accumulation in vegetables could also be used as a strategy to decrease excessive $\mathrm{NO}_{3}{ }^{-}$content. Vegetables are classified as $\mathrm{NO}^{-}$accumulators Maynard et al., (1976) and the $\mathrm{NO}_{3}{ }^{-}$metabolic derivatives nitrite and nitrosamines are well-known risk factor for human health (European Food Safety Authority, 2008).

\subsection{Ion transport, stomatal response, and water use efficiency (WUE).}

There is evident that stomatal movements of seed plants, including crop plants, arise from the transport, accumulation, and release of osmotically active solutes. A very large body of experimental evidence supports the collective role of ion transport across the plasma membrane and tonoplast in both stomatal opening and closing Willmer and Fricker, (1996); Blatt, (2000); Chen et al., (2012c); Hills et al., (2012) Fig (25).
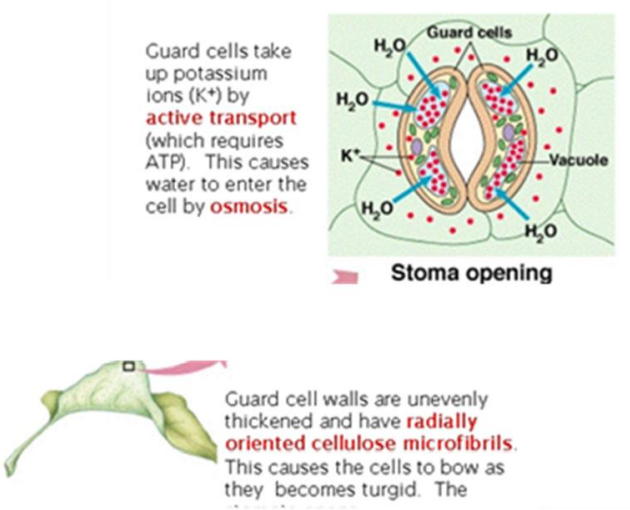

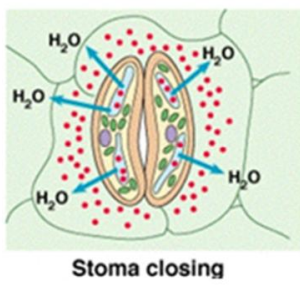

Stoma closing

\section{Control of Stomatal Opening and Closing}

Fig. 25: Stomata movement controlled by potassium

The primary inorganic species transported are $\mathrm{K}^{+}$and $\mathrm{Cl}_{2}$, which, with the organic anion malate22 (Mal) and Suc, comprise the bulk of solute that drives water flux and guard cell turgor (Willmer and Fricker, 1996; Roelfsema and Hedrich, 2005; McAinsh and Pittman, 2009). Because mature guard cells lack functional plasmodesmata Wille and Lucas, (1984), these solutes must be transported across the plasma membrane. Much of this solute uptake must also be transported across the tonoplast. The guard cell vacuole, like that of most mature plant cells, makes up the bulk of the cell volume and, hence, plays a very important role as a "repository" for osmotically active solutes (Gao et al., 2005; MacRobbie, 2006; Chen et al., 2012c). Mal metabolism (notably its synthesis within the guard cell cytosol) makes a substantial contribution to the osmotic content of the guard cell, while Mal loss during stomatal closure occurs largely via efflux across the plasma membrane (Willmer and Fricker, 1996; Wang and Blatt, 2011). Stomata determining plant productivity and water use efficiency.

Stomatal regulation consists of much more than guard cell signaling, however. It also involves tissue- and leaf-scale biophysical factors that translate guard cell function into changes in stomatal conductance Fig. (26). For example, the water potential of guard cells may be affected by vapor exchange with relatively dry air within the stomatal pore channel (Peak and Mott, 2011), or with relativelymoist air in the airspaces between sun-warmedmesophyll cells (Pieruschka et al., 2010). Water status may be actively sensed in guard cells Bauer et al., (2013), or in other tissues such as mesophyll (McAdam and Brodribb, 2018) or phloem companion cells Endo et al., (2008), which experience different degrees of water stress. Understanding of stomatal function in intact leaves thus rests not only on guard cell biology, but also on features of leaf and plant biophysics such as finescale gradients in temperature and water potential. (Buckley, 2019). Stomatal responses to humidity, soil moisture and other factors that influence plant water status are critical drivers of photosynthesis, productivity, water yield, Ecohydrology and climate forcing, yet we still lack a thorough mechanistic understanding of these responses. Here I review historical and recent advances in stomatal water relations. Clear evidence 
now implicates a metabolically mediated response to leaf water status ('hydro active feedback') in stomatal responses to evaporative demand and soil drought, possibly involving abscisic acid production in leaves. Other hypothetical mechanisms involving vapor and heat transport within leaves may contribute to humidity, light and temperature responses, but require further theoretical clarification and experimental validation. Variation and dynamics in hydraulic conductance, particularly within leaves, may contribute to water status responses. Continuing research to fully resolve mechanisms of stomatal responses to water status should focus on several areas: validating and quantifying the mechanism of leaf-based hydro active feedback, identifying where in leaves water status is actively sensed, clarifying the role of leaf vapor and energy transport in humidity and temperature responses, and verifying foundational but minimally replicated results of stomatal hydromechanics across species. Clarity on these matters promises to deliver modelers with a tractable and reliable mechanistic model of stomatal responses to water status.

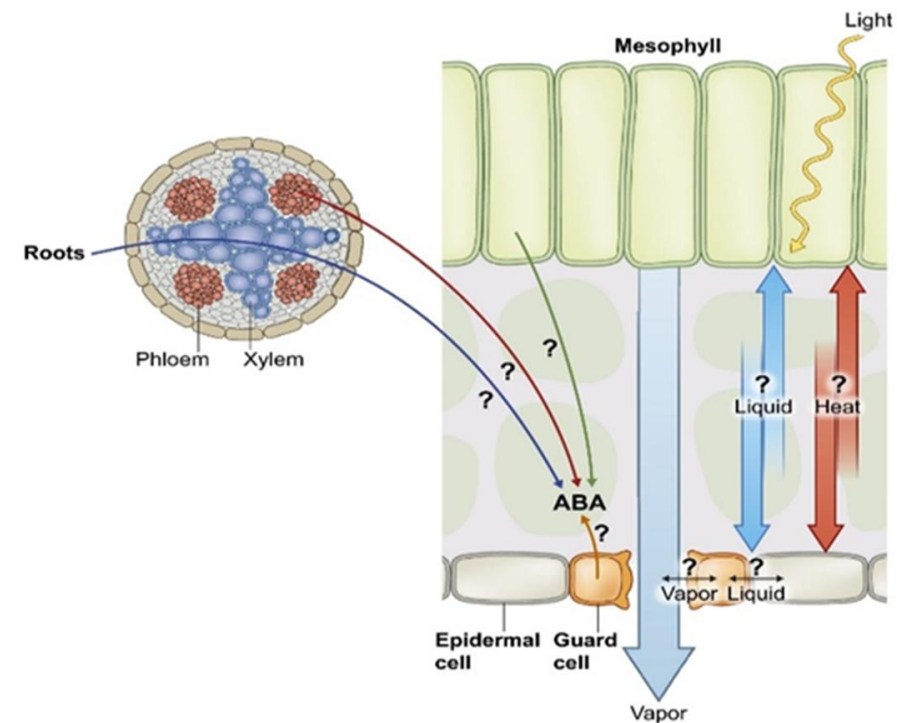

Fig. 26: Stomatal conductance is regulated not only by guard cell biology, which governs guard cell osmotic content, but also by numerous biophysical factors that influence guard and epidermal cell water potentials and link these cells to other tissues across the leaf and plant. Abscisic acid and other signaling compounds may be synthesized in guard cells or synthesized elsewhere and transported to guard cells (Sections III.1, III.2), but may have little impact on stomata in some species (Section III.3). The potential ABA source tissues are located at different positions along the soil-plant-atmosphere continuum, and are thus differentially sensitive to soil drought and evaporative demand (Section III.5). Guard cells may or may not exchange vapor with air in the stomatal pore channel and liquid water with epidermal cells (Section III.4), and heat and liquid water may move in either direction between the mesophyll and epidermis (Sections III.4, III.5).After Buckley, (2019).

The balance between these two processes depends on stomatal responses to environmental and internal cues and the synchrony of stomatal behavior relative to mesophyll demands for $\mathrm{CO}_{2}$. Here we examine the rapidity of stomatal responses with attention to their relationship to photosynthetic $\mathrm{CO}_{2}$ uptake and the consequences for water use. We discuss the influence of anatomical characteristics on the velocity of changes in stomatal conductance and explore the potential for manipulating the physical as well as physiological characteristics of stomatal guard cells in order to accelerate stomatal movements in synchrony with mesophyll $\mathrm{CO}_{2}$ demand and to improve water use efficiency without substantial cost to photosynthetic carbon fixation. 


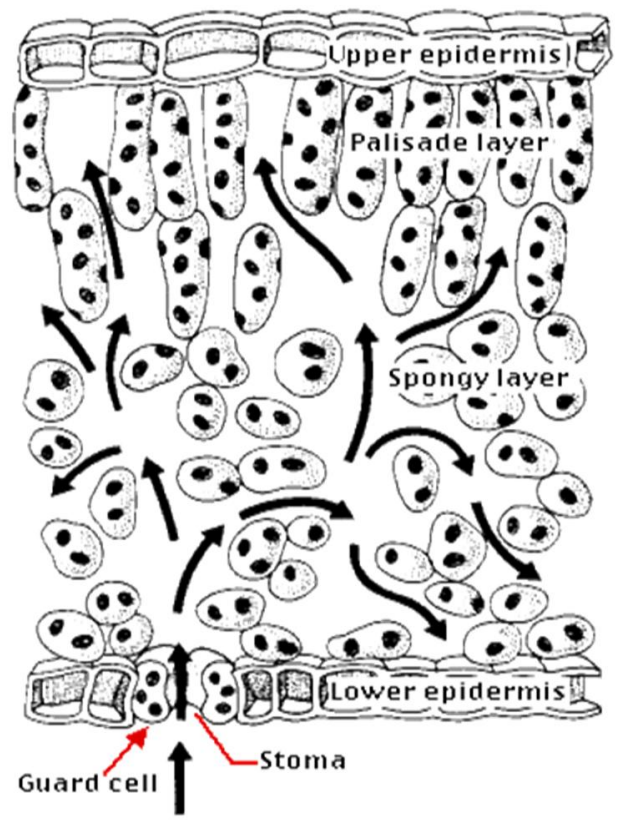

Fig. 27: Illustrates $\mathrm{CO}_{2}$ changes through stomatal structure without substantial cost to photosynthetic carbon fixation

We conclude that manipulating guard cell transport and metabolism is just as, if not more likely to yield useful benefits as manipulations of their physical and anatomical characteristics. Achieving these benefits should be greatly facilitated by quantitative systems analysis that connects directly the molecular properties of the guard cells to their function in the field. In order for plants to function efficiently, they must balance gaseous exchange between inside and outside the leaf to maximize $\mathrm{CO}_{2}$ uptake for photosynthetic carbon assimilation (A) and to minimize water loss through transpiration. Stomata are the "gatekeepers" responsible for all gaseous diffusion, and they adjust to both internal and external environmental stimuli governing $\mathrm{CO}_{2}$ uptake and water loss Fig. (27). The pathway for $\mathrm{CO}_{2}$ uptake from the bulk atmosphere to the site of fixation is determined by a series of diffusional resistances, which start with the layer of air immediately surrounding the leaf (the boundary layer). Stomatal pores provide a major resistance to flux from the atmosphere to the substomatal cavity within the leaf. Further resistance is encountered by $\mathrm{CO}_{2}$ across the aqueous and lipid boundaries into the mesophyll cell and chloroplasts (mesophyll resistance). Water leaving the leaf largely follows the same pathway in reverse, but without the mesophyll resistance component. Guard cells surround the stomatal pore. They increase or decrease in volume in response to external and internal stimuli, and the resulting changes in guard cell shape adjust stomatal aperture and thereby affect the flux of gases between the leaf internal environment and the bulk atmosphere. Stomatal behavior, therefore, controls the volume of $\mathrm{CO}_{2}$ entering the intercellular air spaces of the leaf for photosynthesis. It also plays a key role in minimizing the amount of water lost. Transpiration, by virtue of the concentration differences, is an order of magnitude greater than $\mathrm{CO}_{2}$ uptake, which is an inevitable consequence of free diffusion across this pathway. Although the cumulative area of stomatal pores only represents a small fraction of the leaf surface, typically less than $3 \%$, some $98 \%$ of all $\mathrm{CO} 2$ taken up and water lost passes through these pores. When fully open, they can mediate a rate of evaporation equivalent to one-half that of a wet surface of the same area (Willmer and Fricker, 1996). Early experiments illustrated that photosynthetic rates were correlated with stomatal conductance (gs) when other factors were not limiting (Wong et al., 1979). Low gs limits assimilation rate by restricting CO2 diffusion into the leaf, which, when integrated over the growing season, will influence the carbohydrate status of the leaf with consequences for crop yield. Stomata of well watered plants are thought to reduce photosynthetic rates by about $20 \%$ in most C3 species and by less in C4 plants in the field (Farquhar and Sharkey, 1982; Jones, 1987). However, even this restriction has been shown to impact substantially on yield. For example, Fischer et al., (1998) demonstrated a close correlation between gs and yield in eight different wheat (Triticum aestivum) cultivars. Those studies highlighted the effects gs can have on crop yield, not only through reduced $\mathrm{CO}_{2}$ diffusion but also through the impact on water loss and evaporative cooling of the leaf. Indeed, 
enhancing photosynthesis yields by only $2 \%$ to $3 \%$ is sufficient to substantially increase plant growth and biomass over the course of a growing season (Lefebvre et al., 2005; Zhu et al., 2007).

There are several approaches for improving carbon gain and plant water use efficiency (WUE) that focus on stomata. It is possible to increase or decrease the gaseous conductance of the ensemble of stomata per unit of leaf area (gs) through the manipulation of stomatal densities (Büssis et al., 2006). In addition, there is potential to alter the stomatal response or sensitivity to environmental signals through the manipulation of guard cell characteristics that affect stomatal mechanics (e.g. OPEN STOMATA [ost] mutants; (Merlot et al., 2002). Such approaches have produced an array of mutant plants with altered characteristics and varying impacts on $\mathrm{CO}_{2}$ uptake and transpiration. An intuitive measure of the efficacy of such manipulations is the WUE, commonly defined as the amount of carbon fixed in photosynthesis per unit of water transpired. In general, higher WUE values have been observed in plants with lower gs, but these gains are usually achieved together with a reduction in A and slower plant growth. Plants with higher gs have greater assimilation rates and grow faster under optimal conditions, but they generally exhibit lower WUE. An approach that has not been fully explored or considered in any depth is to select plants for differences in the kinetics of stomatal response or to manipulate stomatal kinetics in ways that improve the synchrony with mesophyll $\mathrm{CO}_{2}$ demand (Lawson et al., (2010, 2012). To date, the majority of studies assessing the impact of stomatal behavior on photosynthetic carbon gain have focused on steady-state measurements of gs in relation to photosynthesis. These studies do not take account of the dynamic situation in the field. As we discuss below, a cursory analysis of stomatal synchrony with mesophyll $\mathrm{CO}_{2}$ demand suggests that gains of $20 \%$ to $30 \%$ are theoretically possible.

Turgor plays an essential role in regulating plant morphology, architecture, and movement, generating tension within the rigid cell wall by appressing the plasma membrane and maintaining stable internal pressure at the cellular level. Changes in the turgor of guard cells are responsible for stomatal movements (Heath, 1947; Daloso et al., 2016 a,b, De Angeli et al., 2013). Turgor changes involve the loss or accumulation of $\mathrm{K}+$, accompanied by a parallel exchange of anions (e.g., $\mathrm{Cl}_{-}$and malate) and organic solutes (e.g., sucrose) (Willmer and Fricker, 1996; Lee et al., 2008; De Angeli et al., 2013). Metabolism of carbohydrates in plants and fungal cells plays an important role in maintaining turgor pressure through the production of osmoactive molecules (Talbott and Zeiger, 1993; Kelly et al., 2013; Daloso et al., $2016 \mathrm{a}, \mathrm{b})$.

Metabolomic analyses indicate that the treatment of Arabidopsis guard cells with abscisic acid (ABA) results in a significant decrease in the concentration of signaling-related metabolites, such as sucrose and malate Kelly et al., (2013); Three distinct osmoregulatory pathways are thought to be involved in the opening of stomata: uptake of $\mathrm{K}^{+}$and $\mathrm{Cl}^{-}$coupled with the biosynthesis of malate, accumulation of sucrose from the breakdown of starch and accumulation of the products of photosynthetic carbon fixation within the guard cells (Amodeo et al., 1996; Talbott and Zeiger, 1996; Lawson et al., 2014). Malate plays an important role in stomatal opening, and ABA mediated stomatal closure is often accompanied by a decrease in malate concentration within the guard cells (Dittrich and Raschke, 1977). In daylight, most malate in guard or mesophyll cells is produced via carboxylation of phosphoenolpyruvate (PEP). Specifically, light-stimulated PEP carboxylase catalyzes the carboxylation of PEP to produce oxaloacetate (OAA) in the cytosol, which is then further converted to malate via the action of NADP-dependent malate dehydrogenase (NADP-MDH or NAD-MDH) (Tcherkez et al., 2005). AtALMT9 (aluminum-activated malate transporter 9) is a malate-activated vacuolar chloride channel required for stomatal opening in Arabidopsis (De Angeli et al., 2013). Another ion channel, AtALMT4, mediates malate2_release from the vacuole, and is required for stomatal closure in response to ABA Eisenach et al., (2017). Sucrose and malate are important substrates for energy production through glycolysis and the tricarboxylic acid (TCA) cycle. Malate also functions as an essential carbon storage molecule (Martinoia and Rentsch, 1994; Fernie and Martinoia, 2009). No other metabolic pathways are known to supply osmolytes for cellular osmoregulation Fig. (28).

Danilo et al., (2017) reported that Stomata are leaf epidermal structures consisting of two guard cells surrounding a pore. Changes in the aperture of this pore regulate plant water-use efficiency, defined as gain of $\mathrm{C}$ by photosynthesis per leaf water transpired. Stomatal aperture is actively regulated by reversible changes in guard cell osmolyte content. Despite the fact that guard cells can photosynthesize on their own, the accumulation of mesophyll-derived metabolites can seemingly act as signals that contribute to the regulation of stomatal movement. 


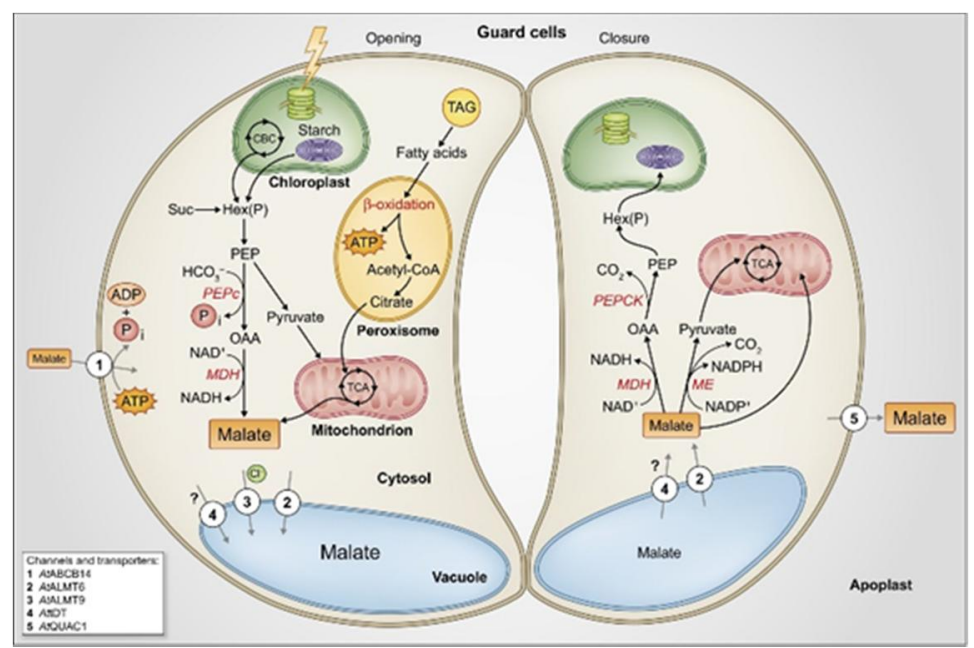

Fig. 28: Proposed pathways involved in the metabolism and transport of malate during stomatal movements. During stomatal opening, the accumulation of malate inside the guard cell occurs mainly due to the influx from the apoplast through the AtABCB14 (1), guard cell photosynthesis, mitochondrial activity and possibly from bluelight-induced starch and lipid breakdown. Cytosolic light-induced PEPc can catalyze the carboxylation of PEP yielding OAA, which is further reduced to malate via NAD+-malate dehydrogenase (NADP-MDH). Malate is additionally transported into vacuoles through the channels AtALMT6 (2), AtALMT9 (3) and possibly through the transporter AttDT (4). In the guard cells, malate acts as an osmoregulator and counter ion for $\mathrm{K}+$ allowing the water inlet, and finally the stomatal aperture. Furthermore, cytosolic malate can increase the Cl- currents through AtALMT9 (3), which is permeable to both $\mathrm{Cl}$ - and malate. By contrast, during stomatal closing, the malate previously accumulated is released to the apoplastic space through AtQUAC1 (5), or it can be metabolized via the decarboxylation byNADP+-malic enzyme (NADP+-ME) or viaNAD+-MDHyielding pyruvate, which can be further metabolized through theTCA cycle and oxalacetate that can be partially converted into starch (not presenting osmotic activity) via the gluconeogenesis pathway. ALMT, Aluminium-activated malate transporters; $\mathrm{CBC}$, Calvin-Benson cycle; Hex-P, hexose phosphate; Mal, malate; MDH, malate dehydrogenase; ME, malic enzyme; OAA, oxalacetate; PEP, phosphoenolpyruvate; PEPc, phosphoenolpyruvate carboxylase; PEPCK, phosphoenolpyruvate carboxykinase; QUAC1, quick activating anion channel; Suc, sucrose; TAG, triacylglycerols; tDT, tonoplast dicarboxylate transporter. After Danilo et al., (2017).

It has been shown that malate can act as a signalling molecule and a counter-ion of potassium, a well-established osmolyte that accumulates in the vacuole of guard cells during stomatal opening. By contrast, their efflux from guard cells is an important mechanism during stomatal closure. It has been hypothesized that the breakdown of starch, sucrose and lipids is an important mechanism during stomatal opening, which may be related to ATP production through glycolysis and mitochondrial metabolism, and/or accumulation of osmolytes such as sugars and malate. However, experimental evidence supporting this theory is lacking. Here we highlight the particularities of guard cell metabolism and discuss this in the context of the guard cells themselves and their interaction with the mesophyll cells.

\section{Concluding}

The levels at which $\mathrm{Cl}^{-}$accumulates in plants, typical of a macronutrient, and the consequent improvement of plant performance have led to its designation as beneficial macronutrient. Tobacco plants with macronutrient $\mathrm{Cl}^{-}$levels display more effective use of water, nitrogen, and carbon/energy. Significant WUE improvement results from concurrent stimulation of growth and reduction of water use. Despite the $\mathrm{Cl}^{-}$-dependent improvement of water balance and water relations, a specific consequence of $\mathrm{Cl}^{-}$on root hydraulic conductivity is an issue yet unresolved. WUE enhancement by macronutrient $\mathrm{Cl}^{-}$nutrition probably increases the ability of plants to withstand water deficit, a hypothesis that must be explored. Although increased dry biomass of $\mathrm{Cl}^{-}$-treated plants clearly points to a more efficient use of $\mathrm{N}$, direct evidence is still required to confirm whether Cl- improves NUE. $\mathrm{Cl}^{-}$ must also clarify it if NUE is favored by an efficient compartmentalization of NO3 - or because of NO3replacement in the vacuole. The positive effect of $\mathrm{Cl}^{-}$on chloroplast performance may be due to various factors like the regulation of thylakoid swelling, improved photosynthetic electron transport, and photo 
protective mechanisms. More research is required to clarify these issues, as well as whether $\mathrm{Cl}^{-}$ stimulates chloroplast biogenesis. Chloride promotes cell elongation because of better and "cheaper" osmoregulatory and turgor-generating ability. That is apparently the reason why auxin stimulates the influx of $\mathrm{Cl}^{-}$into plant cells and why ABA may have the opposite effect. It is therefore important to confirm these points and to accurately determine the signaling pathways that regulate these processes, as well as the inhibition by ABA of ion xylem translocation. We expect that many crops could benefit from $\mathrm{Cl}^{-}$fertilization to a higher extent than previously believed, resulting in the improvement of crop performance, stress resilience, and yield. Further research is also required to clarify the role of Cl- in vesicular trafficking and to confirm whether $\mathrm{Cl}^{-}$homeostasis regulates the plant immunity response. The recent identification of transporters involved in cell $\mathrm{Cl}^{-}$influx will give a decisive boost to a better understanding of $\mathrm{Cl}^{-}$nutrition. For this reason, it will be very important to identify which residues determine $\mathrm{Cl}^{-}$selectivity in the substrate-binding pocket of NPF proteins.

Natural variability of the $\mathrm{Cl}^{-}$inclusion/exclusion rates exhibited by different plant species and varieties suggests the occurrence of an array of genes and alleles responsible for different $\mathrm{NO}^{-}$versus $\mathrm{Cl}^{-}$selectivities (as observed for different members of the NPF and CLC families). Differential NO3 $/ \mathrm{Cl}^{-}$selectivities are expected to occur at different levels: The root soil, the symplast-xylem, and the cytosol vacuole interfaces. Characterization of $\mathrm{Cl}^{-}$channels implicated in releasing $\mathrm{Cl}$ - to the rhizosphere, which fine-tunes net $\mathrm{Cl}^{-}$uptake in the root, is another issue that requires attention. Genes encoding these channels, as well as R-type channels involved in root-to-shoot $\mathrm{Cl}^{-}$translocation and PM transport proteins involved in $\mathrm{Cl}^{-}$allocation through the phloem, remain unexplored so far. The function of NPF transporters from the NAXT subfamily involved in $\mathrm{Cl}^{-}$excretion from plant cells could be relevant under specific physiological conditions, possibly complementing those of $\mathrm{S}^{-}$and R-type channels. However, this hypothesis requires further research. New experiments are also required to better understand the localization and biological function of CCC transporters in order to clearly establish their biological functions. This and other endomembrane Cl- transporters like AtALMT9, GmCLC1, GsCLC2, and possibly GmSALT3/CHX1 involved in intracellular $\mathrm{Cl}^{-}$homeostasis have been proposed to regulate shoot $\mathrm{Cl}^{-}$accumulation and salinity tolerance. In particular, intracellular $\mathrm{Cl}^{-}$ compartmentalization in vascular cells apparently plays a crucial, but still obscure, role in controlling whole-plant ion (e.g., $\mathrm{Cl}^{-}$and $\mathrm{Na}^{+}$) distribution. Finally, more research on hormonal regulation and signal transduction processes that control $\mathrm{Cl}^{-}$nutrition at the whole-plant level is urgently required.

\section{References}

Aarzoo Q., K.S.M. Kiran and S.-K. Muthappa, 2015. Role of proline and pyrroline-s carboxylate metabolism in plant defense against invading pathogens, plant science, 6(503):1-9.

Abdelkader, A.F., H. Aronsson, K. Solymosi, B. Bo“ddi, and C. Sundqvist, 2007. High salt stress induces swollen prothylakoids in dark-grown wheat and alters both prolamellar body transformation and reformation after irradiation. J. Exp. Bot. 58: 2553-2564.

Alia, P.P.S., and P. Mohanty, 1997. Involvement of proline in protecting thylakoid membranes against free radical- induced photodamage. J Photochem Photobiol., 38:253-7.

Allakhverdiev, S.I., 2011. Recent progress in the studies of structure and function of Photosystem II, J. Photochem. Photobiol. B 104: 1-8.

Amodeo, G., L.D. Talbott, and E. Zeiger 1996. Use of potassium and sucrose by onion guard cells during a daily cycle of osmoregulation. Plant and Cell Physiology, 37: 575-579.

Anjana, S.U., and M. Iqbal, 2007. Nitrate accumulation in plants, factors affecting the process, and human health implications: a review. Agron. Sustain. Dev. 27: 45-57.

Anraku, Y., 1996. In: W.N. Kornings, H.R. Kaback, J.S. Lolkema (Eds.), Handbook of Biological Physics, Elsevier, Amsterdam, 99-109.

Anschütz, U., D. Becker, and S. Shabala, 2014. Going beyond nutrition: Regulation of potassium homoeostasis as a common denominator of plant adaptive responses to environment. J. Plant Physiol. 171, 670-687. Doi: 10.1016/j.jplph.2014.01.009

Armengaud, P., L. Thiery, N. Buhot, G. Grenier-De March, and A. Savouré, 2004. Transcriptional regulation of proline biosynthesis in Medicago truncatula reveals developmental and environmental specific features. Physiol Plant, 120:442-50. 
Ayliffe, M.A., J.K. Roberts, H.J. Mitchell, R. Zhang, G.J. Lawrence, J.G. Ellis, et al. 2002. A plant geneup -regulate datrust infection sites. Plant Physiol. 129: 169-180

Baetz, U., C. Eisenach, T. Tohge, E. Martinoia, and A. De Angeli, 2016. Vacuolar chloride fluxes impact ion content and distribution during early salinity stress. Plant Physiol., 172: 1167-1181

Baligar, V.C., N.K. Fageria, and Z.L. He, 2001. Nutrient use efficiency in plants. Commun. Soil Sci. Plant Anal. 32:921-950.

Bar, Y., A. Apelbaum, U. Kafkafi, and R. Goren, 1997. Relationship between chloride and nitrate and its e_ect on growth and mineral composition of avocado and citrus plants. J. Plant Nutr., 20: 715731.

Barbier-Brygoo, H., A. De Angeli, S. Filleur, J.M. Frachisse, F. Gambale, S. Thomine, et al. 2011. Anion channels/transporters in plants: from molecular bases to regulatory networks. Annu. Rev. Plant Biol. 62: 25-51.

Barbier-Brygoo, H., M. Vinauger, J. Colcombet, G. Ephritikhine, J.M. Frachisse, and C. Maurel, 2000. Anion channels in higher plants: functional characterization, molecular structure and physiological role. Biochim. Biophys. Acta. 1465: 199-218.

Bauer, H., P. Ache, S. Lautner, J. Fromm, W. Hartung, K.A. Al-Rasheid, S. Sonne wald, U. Sonne wald, S. Kneitz, and N. Lachmann, 2013. The stomatal response to reduced relative humidity requires guard cell-autonomous ABA synthesis. Current Biology, 23: 53-57.

Bazihizina, N., T.D. Colmer, T.A. Cuin, S. Mancuso, and S. Shabala, 2019. Friend or Foe? Chloride Patterning in Halophytes. Trends Plant Sci. 24, 142- 151. Doi: 10.1016/j.tplants.2018.11.003

Bearne, S.L., and R. Wolfenden, 1995. Glutamate gamma-semialdehydeasa natural transition state analogue inhibitor of Escherichiacoli glucosamine- 6-phosphatesynthase. Biochemistry 34: $11515-11520$.

Bernal-Uruchurtu, M. I. and I. Ortega-Blake, 1995. J. Chem. Phys. 130: 1588.

Berthomieu, P., G. Cone'je'ro, A. Nublat, W.J. Brackenbury, C. Lambert, C. Savio, et al., 2003. Functional analysis of AtHKT1 in Arabidopsis shows that Na and recirculation by the phloem is crucial for salt tolerance. EMBO J. 22: 2004-2014.

Blatt, M.R., 2000. Cellular signaling and volume control in stomatal movements in plants. Annu. Rev. Cell Dev. Biol. 16: 221-241

Bockris, J.O.M., 1977. Energy the Solar Hydrogen Alternative, Wiley and Sons, New York.

Boggess, S.F., D.E. Koeppe, and C.R. Stewart, 1978. Oxidation of proline plant mitochondria. Plant Physiol. 62, 22-25

Borsani, O., J. Zhu, P.E. Verslues, R. Sunkar, and J.-K. Zhu, 2005. Endogenous iRNAs derived from a pair of natural is-antisense transcripts regulate salt tolerance in Arabidopsis. Cell, 123: 1279-1291.

Bose, J., R. Munns, S. Shabala, M. Gilliham, B. Pogson, and S.D. Tyerman, 2017. Chloroplast function and ion regulation in plants growing on saline soils: lessons from halophytes. J. Exp. Bot. 68: 31293143.

Boursier, P. and A. La"uchli, 1989. Mechanisms of chloride partitioning in the leaves of salt-stressed Sorghum bicolor L. Physiol. Plant. 77: 537-544.

Boyer, J.S., W.K. Silk, and M. Watt 2010. Path of water for root growth. Functional Plant Biology 37: $1105-1116$.

Braconnier, S., and J. Dauzac, 1990. Chloride and stomatal conductance in coconut. Plant Physiol. Biochem., 28: 105-111.

Britto, D.T., T.J. Ruth, S. Lapi, and H.J. Kronzucker, 2004. Cellular and whole-plant chloride dynamics in barley: insights into chloride-nitrogen interactions and salinity responses. Planta, 218: 615-622.

Britto, D.T., and H.J. Kronzucker, 2006. Futile cycling at the plasma membrane: A hallmark of lowa nity nutrient transport. Trends Plant Sci., 11: 529-534.

Broadley, M., P. Brown, I. Cakmak, Z. Rengel, and F. Zhao, 2012. Chapter 7 - function of nutrients: micronutrients, in Marschner's Mineral Nutrition of Higher Plants (Third Edition), ed. P. Marschner (San Diego: Academic Press), 191-248

Broadley, M., P. Brown, I. Cakmak, J.F. Ma, Z. Rengel, F. Zhao, 2012. Chapter 8-Beneficial Elements. In Marschner's Mineral Nutrition of Higher Plants, 3rd ed.; Marschner, P., Ed.; Academic Press: San Diego, CA, USA, 249-269.

Broyer, T.C., A.B. Carlton, C.M. Johnson, and P.R. Stout, 1954. Chlorine-A micronutrient element for higher plants. Plant Physiol., 29: 526-532. 
Brucher, D., 2007. Verhalten von Chlorid in der ungesa"ttigten Zone und dessen Eignung als hydrologischer Tracer. Diploma Thesis, Institut fu"r Hydrologie der Albert-Ludwigs-Universita" $t$ zu Freiburg. http://www.hydrology.uni-freiburg.de/abschlus s/ Brucher_D 2007 DA.pdf.

Brumo's, J., J.M. Colmenero-Flores, A. Conesa, P. Izquierdo, G. Sa'nchez, D.J. Iglesias, et al. 2009. Membrane transporters and carbon metabolism implicated in chloride homeostasis differentiate salt stress responses in tolerant and sensitive Citrus rootstocks. Funct. Integr. Genomics, 9: 293309.

Brumo's, J., M. Talon, R.Y.M. Bouhlal, and J.M. Colmenero-Flores, 2010. Cl- homeostasis in includer and excluder citrus rootstocks: transport mechanisms and identification of candidate genes. Plant Cell Environ. 33: 2012-2027.

Büssis, D., U. VonGroll, J. Fisahn, and T.A. Altmann, 2006. Stomatal aperture can compensate altered stomatal density in Arabidopsis thaliana at growth light conditions. Funct Plant Biol. 33: 10371043

Byrt, C.S., R. Munns, R.A. Burton, M. Gilliham, and S. Wege, 2018. Root cell wall solutions for crop plants in saline soils. Plant Sci. 269: 47-55.

Carrillo-Trippa, M., S.-M. Humberto and O.-B. Iva'n, 2017. A comparative study of the hydration of $\mathrm{Na}_{i}$ and $\mathrm{K}_{i}$ with refined polarizable model potentials, Journal Of Chemical Physics, 118: 15.

Castro-Rodriguez, V., I. Assaf-Casals, J. Perez-Tienda, X.R. Fan, C. Avila, A. Miller, and F.M. Canovas, 2016. Deciphering the molecular basis of ammonium uptake and transport in maritime pine. Plant, Cell and Environment, 39: 1669-1682.

Cecchini, N.M., M.I. Monteoliva, and M.E. Alvarez, 2011. Proline dihydrogen as econtributes to pathogen defense in Arabidopsis. Plant Physiol. 155: 1947-1959

Cerezo, M., P. Tillard, S. Filleur, S. Munos, F. Daniel-Vedele, and A. Gojon, 2001. Major alterations of the regulation of rootNO3 uptake are associated with the mutation of NRT2.1 and NRT2.2 genes in Arabidopsis. Plant Physiology, 127: 262-271.

Cerezo, M., P. Garcia-Agustin, M.D. Serna, and E. Primo-Millo, 1997. Kinetics of nitrate uptake by citrus seedlings and inhibitory effects of salinity. Plant Sci. 126: 105-112.

Cheeseman, J.M., 2013. The integration of activity in saline environments: problems and perspectives. Funct. Plant Biol. 40: 759-774.

Chen, C.T., L. Chen, C.C. Lin, and C.H. Kao, 2001. Regulation of proline accumulation in detached rice leaves exposed to excess copper. Plant Sci; 160:283-90

Chen, L.S., and D.R. Bush, 1997. LHT1, a lysine- and histidine-specific amino acid transporter in Arabidopsis. Plant Physiology, 115: 1127-1134.

Chen, Z.H., A. Hills, U. Bätz, A. Amtmann, V.L. Lew, and M.R. Blatt, 2012c. Systems dynamic modeling of the stomatal guard cell predicts emergent behaviors in transport, signaling, and volume control. Plant Physiol. 159: 1235-1251

Chen, C.Z., X.F. Lv, J.Y. Li, H.Y. Yi, and J.M. Gong, 2012. Arabidopsis NRT1.5 is another essential component in the regulation of nitrate reallocation and stress tolerance. Plant Physiol. 159: 15821590.

Chen, W., Z.L. He, X.E. Yang, S. Mishra, and P.J. Sto_ella, 2010. Chlorine nutrition of higher plants: Progress and perspectives. J. Plant Nutr., 33, 943-952.

Chen, Z.C., Yamaji, N., Fujii-Kashino, M. and Ma, J.F. 2016. A cation-chloride cotransporter gene is required for cell elongation and osmoregulation in rice. Plant Physiol. 171: 494-507.

Churchill, K.A. and H. Sze, 1984. Anion-sensitive, $h{ }^{\text {and }}$-pumping atpase of oat roots-Direct effects of cl-, no3-, and a disulfonic stilbene. Plant Physiol., 76: 490-497.

Colmenero-Flores, J.M., J.D. Franco Navarro, P. Cubero Font, P. Peinado- Torrubia, and M.A. Rosales, 2019. Chloride as a beneficial macronutrient in higher plants: new roles and regulation. Int. J. Mol. 20: 4686.

Colmenero-Flores, J.M., G. Martı'nez, G. Gamba, N. Va'zquez, D.J. Iglesias, J. Brumo's, et al., 2007. Identification and functional characterization of cation-chloride cotransporters in plants. Plant $\mathrm{J}$. 50: 278-292.

Comly, H. H. 1945. Cyanosis in infants caused by nitrates in well water. JAMA-J. Am. Med. Assoc. 129: 112-116.

Conlan, B., W. Hillier, and T. Wydrzynski, 2007. Engineering model proteins for Photosystem II function, Photosynth. Res. 94: 225-233. 
Cordomi, A., O. Edholm, and J.J. Perez, 2008. Effect of ions on a dipalmitoyl phosphatidylcholine bilayer. A molecular dynamics simulation study. J. Phys. Chem. B. 112: 1397-1408.

Couturier, J., B. Montanini, F. Martin, A. Brun, D. Blaudez, M. Chalot 2007. The expanded family of ammonium transporters in the perennial poplar plant. New Phytologist, 174: 137-150.

Cramer, G.R., A. La uchli, and V.S. Polito, 1985. Displacement of $\mathrm{Ca} 2$ and by $\mathrm{Na}$ and from the plasmalemma of root cells a primary response to salt stress? Plant Physiol. 79: 207-211.

Cubero-Font, P., 2017. Functional Characterization of Anion Channels of the SLAC/SLAH Family in Arabidopsis Thaliana, Escuela Internacional de Doctorado (EIDUS); Universidad de Sevilla: Seville, Spain,

Cubero-Font, P., Maierhofer, T., Jaslan, J., Rosales, M.A., Espartero, J., D1'az- Rueda., et al. 2016. Silent S-type anion channel subunit SLAH1 gates SLAH3 open for chloride root-to shoot translocation. Curr. Biol. 26: 2213-2220.

Daloso, D.M., L. dos Anjos, and A.R. Fernie 2016a. Roles of sucrose in guard cell regulation. New Phytologist., 211: 809-818.

Daloso, D.M., T.C.R. Williams, W.C. Antunes, D.P. Pinheiro, C. M€uller, M.E. Loureiro, and A.R. Fernie 2016b. Guard cell-specific upregulation of sucrose synthase 3 reveals that the role of sucrose in stomatal function is primarily energetic. New Phytologist., 209: 1470-1483.

Daniel, M.D.E.A., 2008. Economical electrolyser solution, Int. J. Hydrogen Energy, 33, 3041-3044.

Danilo M.D., B.M. David, A. Letıcia dos, Y. Takuya, L.A. Wagner and R.F. Alisdair, 2017. Metabolism within the specialized guard cells of plants, New Phytologist., 216: 1018-1033.

De Angeli, A., D. Monachello, G. Ephritikhine, J.M. Frachisse, S. Thomine, F. Gambale, and H. Barbier-Brygoo 2006. The nitrate/proton antiporter AtCLCa mediates nitrate accumulation in plant vacuoles. Nature, 442: 939-942.

De Angeli, A., J. Zhang, S. Meyer, and E. Martinoia, 2013. AtALMT9is a malate-activated vacuolar chloride channel required for stomatal opening in Arabidopsis. Nature Communications 4: 1804.

Deinlein, U., A.B. Stephan, T. Horie, W. Luo, G. Xu, and J.I. Schroeder, 2014. Plant salt-tolerance mechanisms. Trends Plant Sci. 19, 371-379. Doi: 10.1016/j. tplants.2014.02.001

Delauney, A., C. Hu, P.K. Kishor, and D. Verma, 1993. Cloning of ornithined-amino transferase cDNA by trans-complementation in Escherichia coli and regulation of proline biosynthesis. J. Biol.Chem. 268: $18673-18678$.

Deuschle, K., D. Funck, H. Hellmann, K. Daschner, S. Binder, and W.B. Frommer, 2001.A nuclear gene encoding mitochondrial Delta-pyrroline-5-carboxylate dehydrogenase and its potential role in protection from proline toxicity. Plant J., 27:345-56

Dittrich, P., and K. Raschke 1977. Malate metabolism in isolated epidermis of Commelina communis L. in relation to stomatal functioning. Planta, 134: 77-81.

Downton, W.J.S., 1985. Growth and mineral-composition of the sultana grapevine as influenced by salinity and rootstock. Aust. J. Agric. Res., 36: 425-434.

Dreyer, I., and N. Uozumi, 2011. Potassium channels in plant cells. FEBS J. 278, 4293-4303. Doi: 10.1111/j.1742-4658.2011.08371.x

Eisenach, C. and A. De Angeli, 2017. Ion transport at the vacuole during stomatal movements. Plant Physiol. 174: 520-530.

Elthon, T.E., and C.R. Stewart, 1981. Submit chondrite all cation and electron transport characteristics of enzymes involved in proline oxidation. Plant Physiol. 67: 780-784.

Endo, A., Y. Sawada, H. Takahashi, M. Okamoto, K. Ikegami, H. Koiwai, M. Seo, T. Toyomasu, W. Mitsuhashi, and K. Shinozaki, 2008. Drought induction of Arabidopsis 9-cis-epoxycarotenoid dioxygenase occurs in vascular parenchyma cells. Plant Physiology, 147: 1984-1993.

Enz, C., T. Steinkamp, and R. Wagner, 1993. Ion channels in the thylakoid membrane (a patch-clamp study. Biochim. Biophys. Acta., 1143: 67-76.

European Food Safety Authority, 2008. Opinion of the Scientific Panel on Contaminants in the Food chain on a request from the European Commission to perform a scientific risk assessment on nitrate in vegetables. EFSA, J., 689: 1-79.

Faiyue, B., M.J. Al-Azzawi, and T.J. Flowers, 2012. A new screening technique for salinity resistance in rice (Oryza sativa L. seedlings using bypass flow. Plant, Cell and Environment, 35: 1099-1108.

Fan, X., M. Naz, X. Fan, W. Xuan, A.J. Miller, and X. Xu 2017. Plant nitrate transporters: From gene function to application. Journal of Experimental Botany, 68: 2463-2475. 
Farquhar, D.G., and T.D. Sharkey, 1982. Stomatal conductance and photosynthesis. Annu Rev Plant Physiol., 33: 317-345

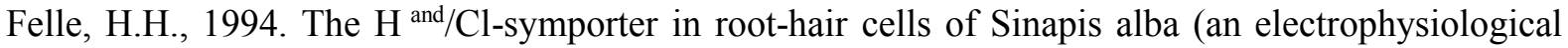
study using ion-selective microelectrodes. Plant Physiol. 106: 1131-1136.

Ferjani, A., S. Segami, G. Horiguchi, A. Sakata, M. Maeshima, and H. Tsukaya, 2012. Regulation of pyrophosphate levels byH ${ }^{\text {and }}$-PPase is central for proper resumption of early plant development. Plant Signaling and Behavior, 7: 38-42.

Ferreira L.M., V.M. de Souza, O.C.H. Tavares, E. Zonta, C. Santa-Catarina, S.R. de Souza, MS Fernandes, and LA. Santos, 2015. OsAMT1.3 expression alters rice ammonium uptake kinetics and root morphology. Plant Biotechnology Reports, 9: 221-229.

Filleur, S., M.F. Dorbe, M. Cerezo, M. Orsel, F. Granier, A. Gojon, and F. Daniel-Vedele, 2001. An Arabidopsis T-DNA mutant affected in NRT2 genes is impaired in nitrate uptake. FEBS Letters, 489: 220-224.

Fischer, K.A., D. Ress, K.D. Sayre, Z.M. Lu, A.G. Condon, and A.L. Saavedra 1998. Wheat yield progress associated with higher stomatal conductance and photosynthetic rate and cooler canopies. Crop Sci. 38: 1466-1475.

Fixen, P.E., 1987. Chloride fertilization. Crop. Soils Manag., 39: 14-16.

Flowers, T.J., 1988. Chloride as a nutrient and as an osmoticum, in Advances. in Plant. Nutrition, Vol. 3, eds P. B. Tinker and A. Laüchli (New York, NY: Praeger), 55-78.

Flowers, T.J., M.A. Hajibagherp, and A.R. Yeo, 1991. Ion accumulation in the cell walls of rice plants growing under saline conditions: evidence for the Oertli hypothesis. Plant. Cell Environ. 14: 319325.

Flowers, T.J., R. Munns, and T.D. Colmer, 2015. Sodium chloride toxicity and the cellular basis of salt tolerance in halophytes. Ann. Bot. 115: 419-431.

Foster, K.J., and S.J. Miklavcic 2017. A comprehensive biophysical model of ion and water transport in plant roots. I. Clarifying the roles of endodermal barriers in the salt stress response. Frontiers in Plant Science, 8: 1326.

Foyer, C.H., M. Lelandais, and K.J. Kunert, 1994. Photooxidative stress in plants. Physiol. Plant. 92: 696-717.

Franco-Navarro J.D., J. Brumós, M.A. Rosales, A. Vázquez-Rodríguez, B.J. Sañudo, P. Díaz-Rueda, C. Rivero, M. Talón, and J.M. Colmenero-Flores, 2016. Chloride Nutrition Regulates Water Balance in Plants, XII Portuguese-Spanish Symposium on Plant Water Relations.

Franco-Navarro, J.D., J. Brumós, M.A. Rosales, P. Cubero-Font, M. Talón, and J.M. Colmenero-Flores, 2016. Chloride regulates leaf cell size and water relations in tobacco plants. J. Exp. Bot. 67: 873891. Doi: $10.1093 /$ jxb/erv502

Franco-Navarro, J.D., M.A. Rosales, P. Cubero-Font, P. Calvo, R. Álvarez, A. Díaz- Espejo, et al. 2019. Chloride as macronutrient increases water use efficiency by anatomically driven reduced stomatal conductance and increased mesophyll diffusion to CO2. Plant J. 99: 815-831.

Franco-Navarro, J.D., M.A. Rosales, P. Cubero-Font, P. Calvo, R. Álvarez, A. Diaz-Espejo, et al. 2019. Chloride as macronutrient increases water use efficiency by anatomically driven reduced stomatal conductance and increased mesophyll diffusion to $\mathrm{CO} 2$ Running Title: $\mathrm{Cl}$ - simultaneously reduces g s and increases g m. Plant J. 99, 1-17. Doi: 10.1111/tpj.14423

Fricke, W., R.A. Leigh, and A.D. Tomos, 1996. The intercellular distribution of vacuolar solutes in the epidermis and mesophyll of barley leaves changes in response to NaCl. J. Exp. Bot. 47: 1413-1426.

Frink, C.R., P.E. Waggoner, and J.H. Ausubel, 1999. Nitrogen fertilizer: retrospect and prospect. Proc. Natl. Acad. Sci. U.S.A. 96, 1175-1180.

Fromme, P., and I. Grotjohann, 2011. Structure of cyanobacterial photosystems I and II, in G.A. Peschek, C. Obinger, G. Renger (Eds.), Springer, Dordecht, 285-335, chap. 12.

Fu, Y.L., H.Y. Yi, J. Bao, and J.M. Gong, 2015. LeNRT2.3 functions in nitrate acquisition and longdistance transport in tomato. FEBS Letters, 589: 1072-1079

Funck, D., B. Stadelhofer, and W. Koch, 2008. Ornithine- $\delta$-amino transfer as is essential for arginine catabolism but not for proline biosynthesis. BMC Plant Biol. 8:40.

Futai, M., T. Noumi, and M. Maeda, 1989. Annu. Rev. Biochem. $58,111$. 
Gagneul, D., A. Aïnouche, C. Duhazé, R. Lugan, F.R. Larher, and A. Bouchereau, 2007. A reassessment of the function of the so-called compatible solutes in the halophytic plumbaginaceae Limonium latifolium. Plant Physiol., 144:1598-611

Ganeteg, U., I. Ahmad, S. Jamtgard, C. Aguetoni-Cambui, E. Inselsbacher, H. Svennerstam, S. Schmidt, and T. N€asholm 2017. Amino acid transporter mutants of Arabidopsis provides evidence that a non-mycorrhizal plant acquires organic nitrogen from agricultural soil. Plant, Cell and Environment, 40: 413-423.

Gao, X.Q., C.G. Li, P.C. Wei, X.Y. Zhang, J. Chen, and X.C. Wang, 2005. The dynamic changes of tonoplasts in guard cells are important for stomatal movement in Vicia faba. Plant Physiol., 139: $1207-1216$

Garnett, T., V. Conn, D. Plett, S. Conn, J. Zanghellini, N. Mackenzie, A. Enju, K. Francis, L. Holtham, U. Roessner et al., 2013. The response of the maize nitrate transport system to nitrogen demand and supply across the lifecycle. New Phytologist, 198: 82-94.

Gaxiola, R.A., K. Regmi, J. Paez-Valencia, G. Pizzio, and S. Zhang, 2016. PlantH ${ }^{\text {and-PPases: reversible }}$ enzymes with contrasting functions dependent on membrane environment. Molecular Plant, 9: 317-319.

Gazzarrini, S., L. Lejay, A. Gojon, O. Ninnemann, W.B. Frommer, and N. von Wiren 1999. Three functional transporters for constitutive, diurnally regulated, and starvation-induced uptake of ammonium into arabidopsis roots. Plant Cell, 11: 937-947.

Ge-Hong S.-W., W. Yoh, F. Masamitsu, 2004. Diverse and essential roles of mammalian vacuolar-type proton pump ATPase: toward the physiological understanding of inside acidic compartments, Biochimica et Biophysica Acta. 1658: 106- 114

Geiger, D., T. Maierhofer, K.A. Al-Rasheid, S. Scherzer, P. Mumm, A. Liese, et al., 2011. Stomatal closure by fast abscisic acid signaling is mediated by the guard cell anion channel SLAH3 and the receptor RCAR1. Sci. Signal 4: ra32.

Geilfus, C.M., 2018. Chloride: from nutrient to toxicant. Plant Cell Physiol. 59, 877-886

Geilfus, C.M., 2018a. Chloride: From Nutrient to Toxicant. Plant Cell Physiol. 59, 877-886. Doi: $10.1093 /$ pcp/pcy071

Geilfus, C.M., 2018b. Review on the significance of chlorine for crop yield and quality. Plant Sci. 270, 114-122. Doi: 10.1016/j.plantsci.2018.02.014

Geilfus, C.M., 2017. The $\mathrm{pH}$ of the apoplast: dynamic factor with functional impact under stress. Mol. Plant, 10: 1371-1386.

Geilfus, C.M. and K.H. Mu"hling, 2013. Ratiometric monitoring of transient apoplastic alkalinizations in the leaf apoplast of living Vicia faba plants: chloride primes and PM-H-ATPase shapes NaClinduced systemic alkalinizations. New Phytol., 197: 1117-1129.

Geilfus, C.M. and K.H. Mu"hling, 2014. Microscopic and macroscopic monitoring of adaxial-abaxial $\mathrm{pH}$ gradients in the leaf apoplast of Vicia faba L. as primed by $\mathrm{NaCl}$ stress at the roots. Plant Sci., 223: 109-115.

Geilfus, C.M., 2018. Review on the significance of chlorine for crop yield and quality. Plant Sci., 270: $114-122$.

Geilfus, C.M., J. Ludwig-Mu"ller, G. Ba'rdos, and C. Zo“rb, 2018. Early response to salt ions in maize (Zea mays L. J. Plant Physiol. 220: 173-180.

Geilfus, C.M., A. Mitho“fer, J. Ludwig-Mu"ller, C. Zo“rb, and K.H. Muehling, 2015a. Chlorideinducible transient apoplastic alkalinizations induce stomata closure by controlling abscisic acid distribution between leaf apoplast and guard cells in salt-stressed Vicia faba. New Phytol. 208:

Geilfus, C.M., K. Niehaus, V. Go“dde, M. Hasler, C. Zo“rb, K. Gorzolka, et al. 2015b. Fast responses of metabolites in Vicia faba L. to moderate $\mathrm{NaCl}$ stress. Plant Physiol. Biochem., 92: 19-29.

Geilfus, C.M., R. Tenhaken, and S.C. Carpentier, 2017. Transient alkalinization of the leaf apoplast stiffens the cell wall during onset of chloridesalinity in corn leaves. J. Biol. Chem., 292: 1880018813.

Genc, Y., J. Taylor, J. Rongala, and K. Oldach, 2014. A major locus for chloride accumulation on chromosome 5A in bread wheat. PLoS One, 9: e98845.

Genet, S., R. Costalat, and J. Burger, 2001. The influence of plasma membrane electrostatic properties on the stability of cell ionic composition. Biophys. J. 81: 2442-2457. 
Gibson, T.S., J. Speirs, and C.J. Brady, 1984. Salt-tolerance in plants. II. In vitro translation of m-RNAs from salt-tolerant and salt-sensitive plants on wheat germ ribosomes. Responses to ions and compatible organic solutes. Plant. Cell Environ., 7: 579-587.

Gilliham, M. and M. Tester, 2005. The regulation of anion loading to the maize root xylem. Plant Physiol., 137: 819-828.

Godfray, H.C.J., J.R. Beddington, I.R. Crute, L. Haddad, D. Lawrence, J.F. Muir, et al. 2010. Food security: the challenge of feeding 9 billion people. Science 327, 812-818

Goldraij, A., and Polacco,J.C. 2000. Arginine degradation by arginine in mitochondria of soybean seedling cotyledons. Planta, 4: 652-658.

Gong, H., D. Blackmore, P. Clingeleffer, S. Sykes, D. Jha, M. Tester, et al., 2011. Contrast in chloride exclusion between two grapevine genotypes and itsvariation in their hybrid progeny. J. Exp. Bot., 62: 989-999.

Govindjee, J.F.K., J. Messinger, and J. Whitmarsh, 2010. PhotosystemII, Encyclopedia of Life Sciences (ELS), John Wiley and Sons, Ltd., Chichester, ), doi:10.1002/978047 0015902. a0000669.pub2, (Se http://www.life.illinois.edu/govindjee/recent papers. Html.

Grallath, S., T. Weimar, A. Meyer, C. Gumy, M. Suter-Grotemeyer, J.M. Neuhaus, and D. Rentsch 2005. The AtProT family. Compatible solute transporters with similar substrate specificity but differential expression patterns. Plant Physiology, 137: 117-126.

Greenway, H., A. Gunn, M.G. Pitman, and D.A. Thomas, 1965. Plant response to saline substrates V. Chloride regulation in the individual organs of Hordeum vulgare during treatment with sodium chloride. Aust. J. Biol. Sci. 18: 525-540.

Guan, P., 2017. Dancing with Hormones: A current Perspective of Nitrate Signaling and Regulation in Arabidopsis, Front Plant Sci. 8:1697

Han, Y.L., H.X. Song, Q. Liao, Y. Yu, S.F. Jian, J.E. Lepo, et al. 2016. Nitrogen use efficiency is mediated by vacuolar nitrate sequestration capacity in roots of Brassica napus. Plant Physiol., 170: $1684-1698$.

Hanin, M., C. Ebel, M. Ngom, L. Laplaze, and K. Masmoudi, 2016. New insights on plant salt tolerance mechanisms and their potential use for breeding. Front. Plant Sci. 7: 1-17. Doi: $10.3389 /$ fpls.2016.01787

Hanson, B., S.R. Grattan, and A. Fulton, 1999. Agricultural Salinity and Drainage. University of California Irrigation Program, University of California, Davis. http:// hos.ufl.edu /sites /default /files/faculty/gdliu/ HansonGrattan2006_0.pdf.

Hare, P.D., and W.A. Cress, 1997. Metabolic implications of stress- induced proline accumulation in plants. Plant Growth Regul. 21, 79-102

Hason-Porath, E. and A. Poljakoff-Mayber, 1970. Effect of chloride and sulphate types of salinity on the nicotinamide-adenine-dinucleotides in pea root tips. J. Exp. Bot. 21: 300-303.

Heath, O., 1947. Role of starch in light-induced stomatal movement. Nature 159: 647-648.

Heber, U. and H.W. Heldt, 1981. The chloroplast envelope: structure, function and role in leaf metabolism. Annu. Rev. Plant Physiol. 32: 139-168.

Hedrich, R., 1994. Voltage-dependent chloride channels in plant cells: identification, characterization, and regulation of guard cell anion channel. Curr. Topics Membr. 42: 1-33.

Henderson, S.W., U. Baumann, D.H. Blackmore, A.R. Walker, R.R. Walker, and M. Gilliham, 2014. Shoot chloride exclusion and salt tolerance in grapevine is associated with differential ion transporter expression in roots. BMC Plant Biol. 14: 273.

Henderson, S.W., S. Wege, J. Qiu, D.H. Blackmore, A.R. Walker, S.D. Tyerman, et al. 2015. Grapevine and Arabidopsis cation-chloride cotransporters localize to the Golgi and trans-Golgi network and indirectly influence long-distance ion transport and plant salt tolerance. Plant Physiol., 169: 22152229.

Herdean, A., H. Nziengui, O. Zsiros, K. Solymosi, G. Garab, B. Lundin, et al. 2016a. The Arabidopsis thylakoid chloride channel AtCLCe functions in chloride homeostasis and regulation of photosynthetic electron transport. Front. Plant Sci. 7: 115.

Herdean, A., E. Teardo, A.K. Nilsson, B.E. Pfeil, O.N. Johansson, R. U“ nnep, et al., 2016b. A voltagedependent chloride channel fine-tunes photosynthesis in plants. Nat. Commun. 24: 11654. 
Hill, J.F., 2012. Early pioneers of photosynthesis research, in: J.J. Eaton-Rye, B.C. Tripathy, T.D. Sharkey (Eds.), Photosynthesis: Plastid Biology, Energy Conversion and Carbon Assimilation, Advances in Photosynthesis and Respiration, vol. 34, Springer, Dordrecht, 769-798.

Hills, A., Z.H. Chen, A. Amtmann, M.R. Blatt, and V.L. Lew, 2012. On guard, a computational platform for quantitative kinetic modeling of guard cell physiology. Plant Physiol., 159: 1026-1042

Hind, G., H.Y. Nakatani, and S. Izawa, 1974. Light-dependent redistribution of ions in suspensions of chloroplast thylakoid membranes. Proc. Natl. Acad. Sci. USA 71: 1484-1488.

Hirner, A., F. Ladwig, H. Stransky, S. Okumoto, M. Keinath, A. Harms, W.B. Frommer, and W. Koch, 2006. Arabidopsis LHT1 is a high-affinity transporter for cellular amino acid uptake in both root epidermis and leaf mesophyll. Plant Cell, 18:1931-1946.

Homann, P.H., 1986. The relation between the chloride status of the photosynthetic water splitting complex and the inhibitory effectiveness of amines. Photosynth. Res. 10: 497-505.

Horie, T., I. Karahara, and M. Katsuhara, 2012. Salinity tolerance mechanisms in glycophytes: An overview with the central focus on rice plants. Rice 5: 1-18. Doi: 10.1186/1939-8433-5-11

Hu, C.A., A.J. Delauney, and D.P. Verma, 1992. A bifunctional enzyme (_1-pyrroline-5-carboxylate synthetase. catalyzes the first two steps in proline biosynthesis in plants. Proc.Natl.Acad.Sci.U.S.A. 89, 9354-9358.

Hu, Y. and U. Schmidhalter, 1997. Interactive effects of salinity and macronutrient level on wheat. II. Composition. J. Plant Nutr. 20: 1169-1182.

Hütsch, B.W., W. He, and S. Schubert, 2016. Nitrogen nutritional status of young maize plants (Zea mays. is not limited by $\mathrm{NaCl}$ stress. J. Plant Nutr. Soil Sci. 179: 775-783.

Huang, N.C., C.S. Chiang, N.M. Crawford, and Y.F. Tsay, 1996. CHL1 encodes a component of the low-affinity nitrate uptake system in Arabidopsis and shows cell type-specific expression in roots. Plant Cell, 8: 2183-2191.

Huang, N.C., K.H. Liu, H.J. Lo, and Y.F. Tsay, 1999. Cloning and functional characterization of an Arabidopsis nitrate transporter gene that encodes a constitutive component of low-affinity uptake. Plant Cell, 11: 1381-1392.

Inal, A., A. Gunes, M. Alpaslan, and K. Demir, 1998. Nitrate versus chloride nutrition e_ects in a soilplant system on the growth, nitrate accumulation and nitrogen, potassium, sodium, calcium and chloride content of carrot. J. Plant Nutr., 21: 2001-2011.

Isayenkov, S., J.C. Isner, and F.J. Maathuis, 2010. Vacuolar ion channels: roles in plant nutrition and signalling. FEBS Lett., 584: 1982-1988.

Jacoby, B. and B. Rudich, 1980. Proton-chloride symport in barley roots. Ann. Bot. 46: 493-498.

Jacoby, R.P., M.H. Che-Othman, A.H. Millar, and N.L. Taylor, 2016. Analysis of the sodium chloridedependent respiratory kinetics of wheat mitochondria reveals differential effects on phosphorylating and non-phosphorylating electron transport pathways. Plant Cell Environ., 39: 823-833.

James, R.A., R.J. Davenport, and R. Munns, 2006. Physiological characterization of two genes for Na and exclusion in durum wheat, Nax1 and Nax2. Plant Physiol., 142: 1537-1547.

Johnson, C.M., P.R. Stout, T.C. Broyer, A.B. Carlton, 1957. Comparative chlorine requirements of di erent plant species. Plant Soil, 8: 337-353.

Jones, H.G., 1987. Breeding for stomatal characters. In E Zeiger, GD Farquhar, IR Cowan, eds, Stomatal Function. Stanford University Press,Stanford, CA, 431-443.

Jossier, M., L. Kroniewicz, F. Dalmas, D. Le Thiec, G. Ephritikhine, S. Thomine, et al. 2010. The Arabidopsis vacuolar anion transporter, AtCLCc, is involved in the regulation of stomatal movements and contributes to salt tolerance. Plant J. 64: 563-576.

Kaiser, W.M., G. Schro"ppel-Meier, and E. Wirth, 1986. Enzyme activities in an artificial stroma medium. Planta, 167: 292-299.

Kalir, A. and T.J. Flowers, 1982. The effect of salts on malate dehydrogenase from leaves of Zea mays. Phytochemistry, 21: 2189-2193.

Kant, S., Y.M. Bi, and S.J. Rothstein, 2011. Understanding plant response to nitrogen limitation for the improvement of crop nitrogen use efficiency. J. Exp. Bot. 62: 1499-1509

Kawakami, K., Y. Umena, N. Kamiya, and J.R. Shen, 2009. Location of chloride and its possible functions in oxygen-evolving photosystem II revealed by X-ray crystallography. Proc. Natl. Acad. Sci. USA, 106: 8567-8572. 
Kelly, G., M. Moshelion, R. David-Schwartz, O. Halperin, R. Wallach, Z. Attia, E. Belausov, and D. Granot, 2013. Hexokinase mediates stomatal closure. Plant Journal, 75: 977-988.

Khadilkar, A.S., U.P. Yadav, C. Salazar, V. Shulaev, J. Paez-Valencia, G.A. Pizzio, R.A. Gaxiola, and B.G. Ayre, 2016. Constitutive and companion cell-specific overexpression of AVP1, encoding a proton-pumping pyrophosphatase, enhances biomass accumulation, phloem loading, and longdistance transport. Plant Physiology, 170: 401-414.

Kiba, T., A.B. Feria-Bourrellier, F. Lafouge, L. Lezhneva, S. Boutet-Mercey, M. Orsel, V. Brehaut, A. Miller, F. Daniel-Vedele, H. Sakakibara et al. 2012. The Arabidopsis nitrate transporter NRT2.4 plays a double role in roots and shoots of nitrogen starved plants. Plant Cell, 24: 245-258.

Kim, J., S. Lee, S.J. Cho, B.J. Mhin, and K.S. Kim, 1995. J. Chem. Phys.102, 839

Kirchhoff, H. 2014. Structural changes of the thylakoid membrane network induced by high light stress in plant chloroplasts. Philos. Trans. R. Soc. B: Biol. Sci. 369: 20130225.

Kirchhoff, H., C. Hall, M. Wood, M. Herbstova', O. Tsabari, R. Nevo, et al. 2011. Dynamic control of protein diffusion within the granal thylakoid lumen. Proc. Natl. Acad. Sci. USA, 108: 2024820253.

Kiyosue, T., Y. Yoshiba, K. Yamaguchi-Shinozaki, and K. Shinozaki, 1996. A nuclear gene encoding mitochondrial proline dehydrogenase , an enzyme involved in proline metabolism, is upregulated by proline but down regulated by dehydration in Arabidopsis. Plant Cell, 8: 1323-1335-35

Klasczyk, B., V. Knecht, R. Lipowsky, and R. Dimova, 2010. Interactions of alkali metal chlorides with phosphatidylcholine vesicles. Langmuir, 26: 18951-18958.

Ko "hler, B. and K. Raschke, 2000. The delivery of salts to the xylem. Three types of anion conductance in the plasmalemma of the xylem parenchyma of roots of barley. Plant Physiol., 122: 243-254.

Kobayashi, M., H. Katoh, and M. Ikeuchi, 2006. Mutations in a putative chloride efflux transporter gene suppress the chloride requirement of photosystem II in the cytochrome c550-deficient mutant. Plant Cell Physiol., 47: 799-804.

Komarova, N.Y., K. Thor, A. Gubler, S. Meier, D. Dietrich, A. Weichert, M.S. Grotemeyer, M. Tegeder, and D. Rentsch 2008. AtPTR1 and AtPTR5 transport dipeptides in planta. Plant Physiology, 148: 856-869

Krapp, A., L.C. David, C. Chardin, T. Girin, A. Marmagne, A.S. Leprince, et al. 2014. Nitrate transport and signalling in Arabidopsis. J. Exp. Bot. 65: 789-798.

Kriegel, A., Z. Andr_es, A. Medzihradszky, F. Kr€uger, S. Scholl, S. Delang, M.G. Patir- Nebioglu, G. Gute, H. Yang, A.S. Murphy et al., 2015. Job sharing in the endomembrane system: vacuolar acidification requires the combined activity of V-ATPase and V-PPase. Plant Cell, 27: 3383-3396.

Kusumi, K., A. Hashimura, Y. Yamamoto, J. Negi, and K. Iba, 2017. Contribution of the S-type anion channel SLAC1 to stomatal control and its dependence on developmental stage in rice. Plant Cell Physiol., 58: 2085-2094.

Lawson, T., and M.R. Blatt 2014. Stomatal size, speed, and responsiveness impact on photosynthesis and water use efficiency. Plant Physiology, 164: 1556-1570.

Lawson, T., D.M. Kramer, and C.A. Raines, 2012. Improving yield by exploiting mechanisms underlying natural variation of photosynthesis. Curr Opin Biotechnol., 23: 215-220S

Lawson, T., S. von Caemmerer, and I. Baroli, 2010. Photosynthesis and stomatal behavior. Prog Bot. 72: $265-304$

Lee, M., Y. Choi, B. Burla, Y.-Y. Kim, B. Jeon, M. Maeshima, J.-Y. Yoo, E. Martinoia, and Y. Lee, 2008. The $\mathrm{ABC}$ transporter AtABCB14 is a malate importer and modulates stomatal response to CO2. Nature Cell Biology, 10: 1217-1223.

Lee, Y.H., J. Foster, J. Chen, L.M. Voll, APM Weber, and M. Tegeder, 2007. AAP1 transports uncharged amino acids into roots of Arabidopsis. Plant Journal, 50: 305-319

Lefebvre, S., T. Lawson, O.V. Zakhleniuk, J.C. Lloyd, C.A. Raines, and M. Fryer, 2005. Increased sedoheptulose-1,7-bisphosphatase activity in transgenic tobacco plants stimulates photosynthesis and growth from an early stage in development. Plant Physiol 138: 451-460.

Lehmann, S., C. Gumy, E. Blatter, S. Boeffel, W. Fricke, and D. Rentsch, 2011. In planta function of compatible solute transporters of the AtProT family. Journal of Experimental Botany, 62: 787796. 
Leran, S., K. Varala, J.C. Boyer, M. Chiurazzi, N. Crawford, F. Daniel-Vedele, L. David, R. Dickstein, E. Fernandez, B. Forde, et al., 2014. A unified nomenclature of nitrate transporter 1/peptide transporter family members in plants. Trends in Plant Science 19: 5-9.

Lessani, H. and H. Marschner, 1978. Relation between salt tolerance and long-distance transport of sodium and chloride in various crop species. Aust. J. Plant Physiol. 5: 27-37.

Lewis, M.L., C.J. Rowe, N. Sewald, J.D. Sutherland, E.J. Wilson, and M.C. Wright, 1993. The effect of $\mathrm{pH}$ on the solution structure of delta-1-pyrroline-2- carboxy licacid as revealed by NMR and electro spray mass spectroscopy. Bioorg. Med. Chem.Lett. 3: 1193-1196.

Lewis, N.S., 2007. Toward cost-effective solar energy use, Science, 315: 798-801.

Lezhneva, L., T. Kiba, A.B. Feria-Bourrellier, F. Lafouge, S. Boutet-Mercey, P. Zoufan, H. Sakakibara, F. Daniel-Vedele, and A. Krapp 2014. The Arabidopsis nitrate transporter NRT2.5 plays a role in nitrate acquisition and remobilization in nitrogen-starved plants. Plant Journal, 80: 230-241.

Li, C., Z. Tang, J. Wei, H.Y. Qu, Y.J. Xie, and G.H. Xu ,2016. The OsAMT1.1 gene functions in ammonium uptake and ammonium-potassium homeostasis over low and high ammonium concentration ranges. Journal of Genetics and Genomics, 43: 639-649.

Li, W.B., Y. Wang, M. Okamoto, N.M. Crawford, M.Y. Siddiqi, and ADM. Glass, 2007. Dissection of the AtNRT2.1: AtNRT2.2 inducible high-affinity nitrate transporter gene cluster. Plant Physiology, 143: 425-433.

Li, W.Y.F., F.L. Wong, S.N. Tsai, T.H. Phang, G.H. Shao, and H.M. Lam, 2006. Tonoplast located GmCLC1 and GmNHX1 from soybean enhance $\mathrm{NaCl}$ tolerance in transgenic bright yellow (BY)2 cells. Plant, Cell and Environment, 29: 1122-1137.

Li, B., C. Byrt, J. Qiu, U. Baumann, M. Hrmova, A. Evrard, et al. 2016a. Identification of a stelarlocalised transport protein that facilitates root to-shoot transfer of chloride in Arabidopsis. Plant Physiol., 170: 1014- 1029.

Li, B., J. Qiu, M. Jayakannan, B. Xu, Y. Li, G.M. Mayo, et al., 2016b. AtNPF2. 5 modulates chloride (Cl_. efflux from roots of Arabidopsis thaliana. Front. Plant Sci. 7: 2013.

Li, B., M. Tester, and M. Gilliham, 2017. Chloride on the Move. Trends Plant Sci., 22: 236-248.

Li, B., M. Tester, and M. Gilliham, 2017b. Chloride on the Move. Trends Plant Sci. 22, 236-248. doi: 10.1016/j.tplants.2016.12.004

Li, W.Y.F., F.L. Wong, S.N. Tsai, T.H. Phang, G.H. Shao, and H.M. Lam, 2006. Tonoplast-located GmCLC1 and $\mathrm{GmNHX} 1$ from soybean enhance $\mathrm{NaCl}$ tolerance in transgenic bright yellow (BY)2 cells. Plant. Cell Environ. 29: 1122-1137.

Lin, S.H., H.F. Kuo, G. Canivenc, C.S. Lin, M. Lepetit, P.K. Hsu, P. Tillard, H.L. Lin, Y.Y. Wang, C.B. Tsai et al., 2008. Mutation of the Arabidopsis NRT1.5 nitrate transporter causes defective root-to-shoot nitrate transport. Plant Cell, 20: 2514-2528.

Little, D.Y., H.Y. Rao, S. Oliva, F. Daniel-Vedele, A. Krapp, and J.E. Malamy, 2005. The putative high-affinity nitrate transporter NRT2.1 represses lateral root initiation in response to nutritional cues. Proceedings of the National Academy of Sciences, USA 102: 13693-13698.

Liu, K.H., C.Y. Huang, and Y.F. Tsay, 1999. CHL1 is a dual-affinity nitrate transporter of Arabidopsis involved in multiple phases of nitrate uptake. Plant Cell, 11: 865-874.

Loque, D., L. Yuan, S. Kojima, A. Gojon, J. Wirth, S. Gazzarrini, K. Ishiyama, H. Takahashi, and N. von Wiren, 2006. Additive contribution of AMT1;1 and AMT1;3 to high-affinity ammonium uptake across the plasma membrane of nitrogen-deficient Arabidopsis roots. Plant Journal, 48: $522-534$.

Lorenzen, I., T. Aberle, and C. Plieth, 2004. Salt stress-induced chloride flux: a study using transgenic Arabidopsis expressing a fluorescent anion probe. Plant, J. 38: 539-544.

Maathuis, F. J. M. 2014. Sodium in plants: Perception, signalling, and regulation of sodium fluxes. J. Exp. Bot. 65, 849-858. doi: 10.1093/jxb/ert326

MacRobbie, E.A.C., 2006. Osmotic effects on vacuolar ion release in guard cells. Proc Natl Acad Sci USA 103: 1135-1140.

MAFF, 1998. 1997/8 UK monitoring programme of nitrate in lettuce and spinach, food surveillance information sheet $\mathrm{n} 8$ 154. London: MAFF.

Marmagne, A., M. Vinauger-Douard, D. Monachello, A.F. De Longevialle, C. Charon, M. Allot, et al., 2007. Two members of the Arabidopsis CLC (chloride channel. family, AtCLCe and AtCLCf, are associated with thylakoid and Golgi membranes, respectively. J. Exp. Bot. 58: 3385-3393. 
Maron, L.G., 2019. From foe to friend: the role of chloride as a beneficial macronutrient. Plant J. 99: 813-814.

Marschner, H.M., 2012. Mineral Nutrition of Higher Plants, 3rd ed.; Academic Press: London, UK,.

Matysik J.A., B. Bhalu, and P. Mohanty, 2002 Molecular mechanisms of quenching of reactive oxygen species by proline under stress in plants. Curr. Sci; 82:525- 32.

Maynard, D.N., A.V.Barker, P.L. Minotti, and N.H. Peck, 1976, Nitrate accumulation in vegetables. Adv. Agron. 28: 71-118.

McAdam, S., and T. Brodribb, 2018. Mesophyll cells are the main site of abscisic acid biosynthesis in water-stressed leaves. Plant Physiology, 177: 911-917.

McAinsh, M.R., and J.K. Pittman, 2009. Shaping the calcium signature. New Phytol. 181: 275-294.

Mehta, S.K., and J.P. Gaur, 1999 Heavy-metal-induced proline accumulation and its role in ameliorating metal toxicity in Chlorella vulgaris. New Phytol., 143:253-9.

Mensinga, T.T., J.G.A. Speijers, and J. Meulenbelt, 2003. Health implications of exposure to environmental nitrogenous compounds. Toxicol. Rev. 14:576584.

Merlot, S., A.C. Mustilli, B. Genty, H. North, V. Lefebvre, B. Sotta, A. Vavasseur, and J. Giraudat, 2002. Use of infrared thermal imaging to isolate Arabidopsis mutants defective in stomatal regulation. Plant J., 30: 601-609

Metroplis, N., A.W. Rosenbluth, M.N. Rosenbluth, A.H. Teller, and E. Teller, 1953. J. Chem. Phys. 21, 1087

Metzler, D.E., 1979. Biochemistry: The Chemical Reactions of Living Cells; Academic Press: New York, NY, USA.

Miller, G., A. Honig, H. Stein, N. Suzuki, R. Mitler, and A. Zilberstein, 2009. Unravelingdelta1pyrroline-5-carboxylate-prolinecycleinplantsbyuncoupled expression of proline oxidation enzymes. J. Biol.Chem. 289: 26482-26492.

Moll, R.H., E.J. Kamprath, and W.A. Jackson, 1982. Analysis and interpretation of factors which contribute to efficiency of nitrogen utilization 1. Agron. J. 74, 562-564.

Moya, J.L., A. Go'mez-Cadenas, E. Primo-Millo, and M. Talon, 2003. Chloride absorption in saltsensitive Carrizo citrange and salt-tolerant Cleopatra mandarin citrus rootstocks is linked to water use. J. Exp. Bot. 54: 825-833.

Mueller, H.M., N. Schaefer,; H. Bauer,; D. Geiger,; S. Lautner,; J. Fromm,; M. Riederer,; A. Bueno,; T. Nussbaumer,; K. Mayer,; et al., 2017. The desert plant Phoenix dactylifera closes stomata via nitrate-regulated SLAC1 anion channel. New Phytol., 216: 150-162.

Munns, R., 2002. Comparative physiology of salt and water stress. Plant. Cell Environ. 25: 239-250.

Munns, R., and M. Tester, 2008. Mechanisms of salinity tolerance. Annu. Rev. Plant Biol. 59: 651681. doi: 10.1146/annurev.arplant.59.032607.092911

Munns, R., D.B. Fisher, and M.L. Tonnet, 1986. Na and and Cl--transport in the phloem from leaves of NaCl-treated barley. Aust. J. Plant Physiol. 13: 757-766.

Munns, R., A.D. David, F. Wieland, W. Michelle, A. Borjana, J.B. Bronwyn, B. Jayakumar, S.B. Caitlin, Ch. Zhong-Hua, J.F. Kylie, G. Matthew, W.H. Sam, L.D.J.Colin, J.K. Herbert, J.M. Stanley, P. Darren, J.R. Stuart, S. Sergey, C.S. Megan, L.S. Kathleen, L.T. Nicolas, T. Mark, W. Stefanie, H.W. Lars and D.T. Stephen, 2020. Energy costs of salt tolerance in crop plants, New Phytologist 225: 1072-1090

Nakamura, A., A. Fukuda, S. Sakai, and Y. Tanaka, 2006. Molecular cloning, functional expression and subcellular localization of two putative vacuolar voltage-gated chloride channels in rice (Oryza sativa L. Plant Cell Physiol., 47: 32-42.

Nguyen, C.T., A. Agorio, M. Jossier, S. Depre, S. Thomine, and S. Filleur, 2016. Characterization of the chloride channel-like, AtCLCg, involved in chloride tolerance in Arabidopsis thaliana. Plant and Cell Physiology, 57: 764-775.

Nguyen, V.L., S.A. Ribot, O. Dolstra, R.E. Niks, R.G. Visser, and C.G. van der Linden, 2013. Identification of quantitative trait loci for ion homeostasis and salt tolerance in barley (Hordeum vulgare L. Mol. Breed., 31: 137-152.

Nieves-Cordones, M., F. García-Sánchez, J.G. Pérez-Pérez, J.M. Colmenero-Flores, F. Rubio, and M.A. Rosales, 2019. Coping with water shortage: an update on the role of $\mathrm{K}$ and, $\mathrm{Cl}$, and water transport mechanisms on drought resistance. Front. Plant Sci. 10:1619. 
Nitrates, D., 1991. Council Directive 91/676/EEC concerning the protection of waters against pollution. Available online at: https: //ec.europa.eu/environment/water/water-nitrates/index_en.html (accessed September 15, 2019).

Oertli, T.J., 1968. Extracellular salt accumulation, a possible mechanism of salt injury in plants. Agrochimica, 12: 461-469.

Orsel, M., F. Chopin, O. Leleu, S.J. Smith, A. Krapp, F. Daniel-Vedele, and A.J. Miller, 2006. Characterization of a two-component high-affinity nitrate uptake system in Arabidopsis. Physiology and protein-protein interaction. Plant Physiology, 142: 1304-1317

Pace, R., 2005. An integrated artificial photosynthesis model, in: A.F. Collings, C. Critchley (Eds.), Artificial Photosynthesis: From Basic Biology to Industrial Application, First ed., Wiley-VCH, Weinheim, 13-34.

Pandit, A., V. Rai, S. Bal, S. Sinha, V. Kumar, M. Chauhan, et al., 2010. Combining QTL mapping and transcriptome profiling of bulked RILs for identification of functional polymorphism for salt tolerance genes in rice (Oryza sativa L.. Mol. Genet. Genomics, 284: 121-136.

Pantazis, D.A., 2018. Missing pieces in the puzzle of biological water oxidation. ACS Catal 8:94779507

Papadopoulos, I., and V.V. Rendig, 1983. Interactive effects of salinity and nitrogen on growth and yield of tomato plants. Plant Soil, 73: 47-57.

Parker, M.B., G.J. Gascho, and T.P. Gaines, 1983. Chloride toxicity of soybeans grown on Atlantic coast flatwoods soils. Agron. J., 75: 439-443.

Paungfoo-Lonhienne, C., T.G.A. Lonhienne, D. Rentsch, N. Robinson, M. Christie, R.I. Webb, H.K. Gamage, B.J. Carroll, P.M. Schenk, and S. Schmidt, 2008. Plants can use protein as a nitrogen source without assistance from other organisms. Proceedings of the National Academy of Sciences, USA, 105: 4524-4529.

Peak, D., and K.A. Mott, 2011. A new, vapour-phase mechanism for stomatal responses to humidity and temperature. Plant, Cell and Environment, 34: 162-178.

Perchlik, M., J. Foster, M. Tegeder, 2014. Different and overlapping functions of Arabidopsis LHT6 and AAP1 transporters in root amino acid uptake. Journal of Experimental Botany, 65: 5193-5204.

Pieruschka, R., G. Huber, and JA. Berry, 2010. Control of transpiration by radiation. Proceedings of the National Academy of Sciences, USA 107: 13372- 13377.

Pizzio, G.A., J. Paez-Valencia, A.S. Khadilkar, K. Regmi, A. Patron-Soberano, S. Zhang, J. SanchezLares, T. Furstenau, J. Li, C. Sanchez-Gomez, et al., 2015. Arabidopsis type I proton-pumping pyrophosphatase expresses strongly in phloem, where it is required for pyrophosphate metabolism and photosynthate partitioning. Plant Physiology, 167: 1541-1553.

Prasad, S., and A.A. Chetty, 2008. Nitrate-N determination in leafy vegetables: study of the effects of cooking and freezing. Food Chem., 106, 772-780.

Pratelli, R., and G. Pilot 2014. Regulation of amino acid metabolic enzymes and transporters in plants. Journal of Experimental Botany, 65: 5535-5556.

Qiu, J., S.W. Henderson, M. Tester, S.J. Roy, and M. Gilliham, 2016. SLAH1, a homologue of the slow type anion channel SLAC1, modulates shoot $\mathrm{Cl}_{-}$accumulation and salt tolerance in Arabidopsis thaliana. J. Exp. Bot., 67: 4495-4505.

Rabinowitch, E., 1945. Photosynthesis and Related Processes, vol. I, Interscience Publishers, Inc., New York, NY, 599 .

Rahnama, A., R. Munns, K. Poustini, and M. Watt, 2011. A screening method to identify genetic variation in root growth response to a salinity gradient. Journal of Experimental Botany, 62: 6977.

Rajendrakumar, C.S.V., T. Suryanarayana, and A.R. Reddy, 1997. DNA helix destabilization by proline and betaine: possible role in the salinity tolerance process. FEBS Lett., 410:201-5.

Raven, J.A., 2017. Chloride: Essential micronutrient and multifunctional beneficial ion. J. Exp. Bot. 68 : 359-367. doi: 10.1093/jxb/erw421

Reinhardt, D.H., and T.L. Rost 1995. On the correlation of primary root growth and tracheary element size and distance from the tip in cotton seedlings grown under salinity. Environmental and Experimental Botany, 35: 575-588. 
Remans, T., P. Nacry, M. Pervent, T. Girin, P. Tillard, M. Lepetit, and A. Gojon 2006. A central role for the nitrate transporter NRT2.1 in the integrated morphological and physiological responses of the root system to nitrogen limitation in Arabidopsis. Plant Physiology 140: 909-921.

Rentsch D, B Hirner, E Schmelzer, and WB. Frommer, 1996. Salt stress-induced proline transporters and salt stress-repressed broad specificity amino acid permeases identified by suppression of a yeast amino acid permease-targeting mutant. Plant Cell 8: 1437-1446.

Rentsch, D., S. Schmidt, and M. Tegeder, 2007. Transporters for uptake and allocation of organic nitrogen compounds in plants. FEBS Letters, 581: 2281-2289.

Ribarits, A., A. Abdullaev, A. Tashpulatov, A. Richter, E. Heberle-Bors, and A. Touraev, 2007. Two tobacco proline dehydrogenases are differentially regulated and play a role in early plant development. Planta, 225:1313-24

Rich, S.M., and M. Watt, 2013. Soil conditions and cereal root system architecture: review and considerations for linking Darwin and Weaver. Journal of Experimental Botany, 64: 1193-1208.

Ríos, J.J., B. Blasco, L.M. Cervilla, M.M. Rubio-Wilhelmi, M.A. Rosales, E. Sanchez-Rodriguez, et al., 2010. Nitrogen-use efficiency in relation to different forms and application rates of Se in lettuce plants. J. Plant Growth Regul. 29: 164-170.

Robinson, S.P. and W.J.S. Downton, 1984. Potassium, sodium, and chloride content of isolated intact chloroplasts in relation to ionic compartmentation in leaves. Arch. Biochem. Biophys. 228: 197206.

Roelfsema, M.R.G., R. Hedrich, 2005. In the light of stomatal opening: new insights into 'the Watergate.' New Phytol. 167: 665-691

Rognes, S.E., 1980. Anion regulation of lupin asparagine synthetase-Chloride activation of the glutamine-utilizing reactions. Phytochemistry, 19: 2287-2293.

Roosens, N.H., T.T. Thu, H.M. Iskandar , and M. Jacobs, 1998. Isolation of the ornithine- $\delta$-amino transfer as ec DNA and effect of salts tress on its expression in Arabidopsis thaliana. Plant Physiol., 117: 263-271.

Rubio-Wilhelmi, M.M., E. Sanchez-Rodriguez, M.A. Rosales, B. Blasco, J.J. Rios, L. Romero, et al., 2012. Ammonium formation and assimilation in PSARKVV IPT tobacco transgenic plants under low N. J. Plant Physiol. 169: 157-162

Ruiz, J.M., R.M. Rivero, L.M. Cervilla, R. Castellano, and L. Romero, 2006. Grafting to improve nitrogen-use efficiency traits in tobacco plants. J. Sci. Food Agr. 86: 1014-1021.

Saleh, L., and C. Plieth, 2013. A9C sensitive Cl_accumulation in A. thaliana root cells during salt stress is controlled by internal and external calcium. Plant Signal Behav. 8: e24259.

Sanchez, D.H., F.L. Pieckenstain, F. Escaray, A. Erban, U.T.E. Kraemer, M.K. Udvardi, et al., 2011. Comparative ionomics and metabolomics in extremophile and glycophytic Lotus species under salt stress challenge the metabolic pre-adaptation hypothesis. Plant Cell Environ., 34: 605-617.

Sanders, D., and U.P. Hansen, 1981. Mechanism of Cl_transport at the plasma membrane of Chara corallina: II. Transinhibition and the determination of $\mathrm{H}^{\text {and }} / \mathrm{Cl}_{-}$binding order from a reaction kinetic model. J. Membr. Biol. 58: 139-153.

Santamaria, P., A. Elia, F. Serio, and E. Todaro, 1999. A survey of nitrate and oxalate content in fresh vegetables. J. Sci. Food Agr., 79:1882-1888.

Schilling, R.K., M. Tester, P. Marschner, D.C. Plett, and S.J. Roy, 2017. AVP1: one protein, many roles. Trends in Plant Science, 22: 154-162.

Schro"ppel-Meier, G. and W.M. Kaiser, 1988. Ion homeostasis in chloroplasts under salinity and mineral deficiency. Plant Physiol., 87: 828-832. Homann, P.H. 1986. The relation between the chloride status of the photosynthetic water splitting complex and the inhibitory effectiveness of amines. Photosynth. Res. 10: 497-505.

Schwenke, G.D., S.R. Simpfendorfer, and B.C.Y. Collard, 2015 Confirmation of chloride deficiency as the cause of leaf spotting in durum wheat grown in the Australian northern grains region. Crop Pasture Sci., 66: 122-134.

Seemann, J.R., and C. Critchley, 1985. Effects of salt stress on the growth, ion content, stomatal behaviour and photosynthetic capacity of a salt-sensitive species, Phaseolus vulgaris L. Planta. 164: 151-162. doi: 10.1007/BF00396077 
Segonzac, C., J.C. Boyer, E. Ipotesi, W. Szponarski, P. Tillard, B. Touraine, N. Sommerer, M. Rossignol, and R. Gibrat, 2007. Nitrate efflux at the root plasma membrane: Identification of an Arabidopsis excretion transporter. Plant Cell, 19: 3760-3777.

Sekhar, P.N., R.N. Amrutha, S. Sangam, D.P.S. Verma, and P.K. Kishor, 2007. Biochemical characterization, homology modeling and docking studies of ornithine $\delta$-amino transferase - an important enzyme in proline biosynthesis of plants. J. Mol.Graph.Model. 26: 709-719.

Senthil-Kumar, M., and K.S. Mysore, 2012. Ornithine-delta-amino transferase and proline dihydrogen as e genes playaroleinn on -host disease resistancebyregulatingpyrroline-5-carboxylate metabolism-induced hypersensitive response. Plant Cell Environ. 35: 1329-1343.

Shabala, S., L. Shabala, J. Barcelo, and C. Poschenrieder, 2014. Membrane transporters mediating root signalling and adaptive responses to oxygen deprivation and soil flooding. Plant, Cell and Environment, 37: 2216-2233.

Shabala, S., and I. Pottosin, 2014. Regulation of potassium transport in plants under hostile conditions: Implications for abiotic and biotic stress tolerance. Physiol. Plant, 151: 257-279. doi: $10.1111 / \mathrm{ppl} .12165$

Shabir, H.W., K. Vinay, K. Tushar, G. Rajasheker, P. Maheshwari, S. Katalin, S. Penna, and K. Kavi, 2020. Engineering salinity tolerance in plants: progress and prospects, Planta, 251:76

Shamsul, H., H. Qaiser, N.A. Mohammed, S.W. Arif, P. John and A. Aqil, 2012. Role of proline under changing environments A review, Plant Signaling and Behavior, 7:11, 1456-1466;

Shelden, M.C., U. Roessner, R.E. Sharp, M. Tester, and A. Bacic, 2013. Genetic variation in the root growth response of barley genotypes to salinity stress. Functional Plant Biology, 40: 516-530.

Shin, K., S. Lee, W.Y. Song, R.A. Lee, I. Lee, K. Ha, J.C. Koo, S.K. Park, H.G. Nam, Y. Lee, et al. 2015. Genetic identification of ACC-RESISTANT2 reveals involvement of lysine histidine transporter1 in the uptake of 1- aminocyclopropane-1-carboxylic acid in Arabidopsis thaliana. Plant Cell Physiology, 56: 572-582.

Siddiqi, M.Y., A.D. Glass, T.J. Ruth, and T.W. Rufty, 1990. Studies of the uptake of nitrate in barley: I. Kinetics of 13NO3- influx. Plant Physiol. 93: 1426-1432.

Smirnoff, N., and QJ. Cumbes, 1989. Hydroxyl radical scavenging activity of compatible solutes. Phytochem, 28:1057-60

Smith, G.S., C.J. Clark, and P.T. Holland, 1987. Chlorine Requirement of Kiwifruit (Actinidia deliciosa. New Phytol. 106: 71-80.

Snapp, S.S., and C. Shennan, 1992. Effects of salinity on root growth and death dynamics of tomato, Lycopersicon esculentum Mill. New Phytologist, 121: 71-79.

Sonoda, Y., A. Ikeda, S. Saiki, N. von Wiren, T. Yamaya, and J. Yamaguchi, 2003. Distinct expression and function of three ammonium transporter genes (OsAMT1;1-1;3. in rice. Plant and Cell Physiology, 44: 726-734

Sotta, N., and T. Fujiwara, 2017. Preparing thin cross sections of Arabidopsis roots without embedding. BioTechniques 63: 281-283.

Stránská, J., D. Kope`cný, M. Tylichová, J. Snégaroff, and M. Šebela, 2008. Ornithine $\delta$-amino transferase: an enzyme implicates din salt tolerance in higher plants. Plant Signal. Behav. 3: 929935.

Strizhov, N., E. Abrahgm, L. Okrész, S. Blickling, A. Zilberstein, J. Schell, et al., 1997. Differential expression of two P5CS genes controlling proline accumulation during salt-stress requires ABA and is regulated by ABA1, ABI1 and AXR2 in Arabidopsis. Plant J; 12:557-69

Svennerstam, H., S. Jamtgard, I. Ahmad, K. Huss-Danell, T. N€asholm, and U. Ganeteg 2011. Transporters in Arabidopsis roots mediating uptake of amino acids at naturally occurring concentrations. New Phytologist, 191: 459-467.

Svennerstam, H., U. Ganeteg, and T. N€asholm, 2008. Root uptake of cationic amino acids by Arabidopsis depends on functional expression of amino acid permease. New Phytologist, 180: $620-630$

Szabados, L., and A. Savouré, 2010. Proline: a multifunctional amino acid. Trends Plant Sci; 15:89-97.

Szoke, A., G.H. Miao, Z. Hong, and D.P. Verma, 1992. Subcellular Location of delta1-pyrroline-5carboxylatereductaseinroot/noduleandleafofsoybean. Plant Physiol. 99: 1642-1649.

Talbott, L.D., and E. Zeiger 1993. Sugar and organic acid accumulation in guard cells of vicia faba in response to red and blue light. Plant Physiology, 102: 1163-1169. 
Talbott, L.D., and E. Zeiger 1996. Central roles for potassium and sucrose in guard-cell osmoregulation. Plant Physiology, 111: 1051-1057.

Tavakkoli, E., F. Fatehi, S. Coventry, P. Rengasamy, and G.K. McDonald, 2011. Additive effects of $\mathrm{Na}$ and and $\mathrm{Cl}$ - ions on barley growth under salinity stress. J. Exp. Bot. 62: 2189-2203. doi: $10.1093 / \mathrm{jxb} / \mathrm{erq} 422$

Tavakkoli, E., P. Rengasamy, and G.K. McDonald, 2010. High concentrations of Na and and Cl- ions in soil solution have simultaneous detrimental effects on growth of faba bean under salinity stress. J. Exp. Bot. 61: 4449-4459. doi: 10.1093/jxb/ erq251

Tcherkez, G., G. Cornic, R. Bligny, E. Gout, and J. Ghashghaie, 2005. In vivo respiratory metabolism of illuminated leaves. Plant Physiology, 138: 1596-1606.

Thomas, N.B., 2019. How do stomata respond to water status? New Phytologist, 224: 1-36.

Tilman, D., K.G. Cassman, P.A. Matson, R. Naylor, and S. Polasky, 2002. Agricultural sustainability and intensive production practices. Nature, 418: 671-677.

Timothy, T.D., K.S. Gregory, L.F. John, H.M.B. Thomas, G.M.D.B. Mirza, W. Jan, M.D.B. Jurg Hutter,e, X.S. Zhao and J.M. Christopher, 2020. Quantifying the hydration structure of sodium and potassium ions: taking additional steps on Jacob's Ladder, Phys. Chem. Chem. Phys., 22: 1064110652.

Tripathi, B.N., and J.P. Gaur, 2004 Relationship between copper and zinc-induced oxidative stress and proline accumulation in Scenedesmus sp. Planta; 219:397-404.

Tsay, Y.F., J.I. Schroeder, K.A. Feldmann, and NM. Crawford, 1993. The herbicide sensitivity gene CHL1 of Arabidopsis encodes a nitrate-inducible nitrate transporter. Cell 72: 705-713.

Varney, G.T., M.J. Canny, X.L. Wang, and M.E. McCully, 1991. The branch roots of Zea. I. First order branches, their number, sizes and division into classes. Annals of Botany, 67: 357-364.

Verbruggen, N., X.J. Hua, M. May, and M. Van Montagu, 1996. Environmental and developmental signals modulate proline homeostasis: evidence for a negative transcriptional regulator. Proc Natl. Acad. Sci. U S A; 93:8787-91

Verbruggen, N., R. Villarroel, and M. Van Montagu, 1993. Osmoregulation of a pyrroline-5carboxylate reductase gene in Arabidopsis thaliana. Plant Physiol., 103:771-81.

Verslues, P.E., and S. Sharma, 2010. Proline metabolism and its implications for plant-environment interaction. Arabidopsis Book 8: e0140.doi:10.1199/ tab.0140

Vogel, H.J., and B.D. Davis, 1952. Glutamic $\gamma$-semialdehyde and _1-pyrroline- 5-carboxylic acid, inter mediates in the biosynthesis of proline. J. Am. Chem. Soc. 74: 109-112.

Wang, F., B. Zeng, Z. Sun, and C. Zhu, 2009. Relationship between proline and Hg2 and-induced oxidative stress in a tolerant rice mutant. Arch Environ Contam Toxicol; 56:723-31.

Wang, R.C., D. Liu, and N.M. Crawford 1998. The Arabidopsis CHL1 protein plays a major role in high-affinity nitrate uptake. Proceedings of the National Academy of Sciences, USA, 95: 1513415139

Wang, Y., and M.R. Blatt, 2011. Anion channel sensitivity to cytosolic organic acids implicates a central role for oxaloacetate in integrating ion flux with metabolism in stomatal guard cells. Biochem. J., 439: 161-170

Wang, M., Q. Zheng, Q. Shen, and S. Guo, 2013. The critical role of potassium in plant stress response. Int. J. Mol. Sci. 14: 7370-7390. doi: 10.3390/ijms14047370

Wang, Y.Y., P.K. Hsu, and Y.F. Tsay, 2012. Uptake, allocation and signaling of nitrate. Trends Plant Sci. 17: 458-467.

Watanabe, T., M.R. Broadley, S. Jansen, P.J. White, J. Takada, K. Satake, T. Takamatsu,; S.J.Tuah, and M. Osaki, 2007 Evolutionary control of leaf element composition in plants. New Phytol., 174: 516-523.

Watt, M., K. Schneebeli, P. Dong, and I.W. Wilson, 2009. The shoot and root growth of Brachypodium and its potential as a model for wheat and other cereal crops. Functional Plant Biology, 36: 960969.

Watt, M., L.J. Magee, and M.E. McCully, 2008. Types, structure and potential for axial water flow in the deepest roots of field-grown cereals. New Phytologist, 178: 135-146.

Wege, S., M. Gilliham, and S.W. Henderson, 2017. Chloride: Not simply a "cheap osmoticum", but a beneficial plant macronutrient. J. Exp. Bot. 68: 3057-3069. doi: 10.1093/jxb/erx050 
White, P.J., and M.R. Broadley, 2001. Chloride in soils and its uptake and movement within the plant: a review. Ann. Bot. 88: 967-988.

Willmer, C., and M.D. Fricker, 1996. Stomata. Chapman and Hall, London

Wong, S.C., I.R. Cowan, and G.D. Farquhar, 1979. Stomatal conductance correlates with photosynthetic capacity. Nature, 282: 424-426

Woodend, J.J., and A.D.M. Glass, 1993. Genotype-environment interaction and correlation between vegetative and grain production measures of potassium use-efficiency in wheat (T. aestivum L.. grown under potassium stress. Plant Soil, 151: 39-44.

$\mathrm{Wu}, \mathrm{H} ., 2018$. Plant salt tolerance and $\mathrm{Na}$ and sensing and transport. Crop J. 6: 215- 225. doi: 10.1016/j.cj.2018.01.003

Wu, H., L. Shabala, E. Azzarello, Y. Huang, C. Pandolfi, N. Su, et al., 2018a. Na and extrusion from the cytosol and tissue-specific $\mathrm{Na}$ and sequestration in roots confer differential salt stress tolerance between durum and bread wheat. J. Exp. Bot. 69: 3987-4001. Doi: 10.1093/jxb/ery194

Wu, H., L. Shabala, X. Liu, E. Azzarello, M. Zhou, C. Pandolfi, et al. 2015. Linking salinity stress tolerance with tissue-specific $\mathrm{Na}$ and sequestration in wheat roots. Front. Plant Sci. 6, 71. doi: $10.3389 /$ fpls.2015.00071

Wu, H., L. Shabala, S. Shabala, and J.P. Giraldo, 2018b. Hydroxyl radical scavenging by cerium oxide nanoparticles improves Arabidopsis salinity tolerance by enhancing leaf mesophyll potassium retention. Environ. Sci. Nano, 5: 1567-1583. Doi: 10.1039/c8en00323h

Wu, H., X. Zhang, J.P. Giraldo, and S. Shabala, 2018c. It is not all about sodium: revealing tissue specificity and signalling roles of potassium in plant responses to salt stress. Plant Soil 431: 1-17. Doi: 10.1007/s11104-018-3770-y

Xia, X.D., X.R. Fan, J. Wei, H.M. Feng, H.Y. Qu, D. Xie, A.J. Miller, and G.H. Xu, 2015. Rice nitrate transporter OsNPF2.4 functions in low-affinity acquisition and longdistance transport. Journal of Experimental Botany, 66: 317-331.

Xing, Y., W. Jiang, X. He, S. Fiaz, S. Ahmad, X. Lei, et al. 2019. A review of nitrogen translocation and nitrogen-use efficiency. J. Plant Nutr. 42: 2624-2641.

Xu, G., Fan, X., and Miller, A. J. 2012. Plant nitrogen assimilation and use efficiency. Annu. Rev. Plant Biol. 63: 153-182

Xu, G.H., H. Magen, J. Tarchitzky, and U. Kafkafi, 2000. Advances in chloride nutrition of plants. In Advances in Agronomy; Sparks, D.L., Ed.; Academic Press: San Diego, CA, USA, Volume 68: $97-150$.

Xue, X., A. Liu, and X. Hua, 2009. Proline accumulation and transcriptional regulation of proline biosynthesis and degradation in Brassica napus. BMB Rep; 42:28- 34

Yoshiba, Y., T. Kiyosue, T. Katagiri, H. Ueda, T. Mizoguchi, K. Yamaguchi-Shinozaki, et al., 1995. Correlation between the induction of a gene for delta 1-pyrroline-5-carboxylate synthetase and the accumulation of proline in Arabidopsis thaliana under osmotic stress. Plant J; 7:751-60

Yu, C., D.L. Claybrook, and AH. Huang, 1983. Transport of glycine, serine, and proline into spinach leaf mitochondria. Arch Biochem Biophys., 227:180-7.

Yuan, L.X., D. Loque, S. Kojima, S. Rauch, K. Ishiyama, E. Inoue, H. Takahashi, and N. von Wiren, 2007a. The organization of high-affinity ammonium uptake in Arabidopsis roots depends on the spatial arrangement and biochemical properties of AMT1-type transporters. Plant Cell, 19: 26362652.

Zhang, L.P., S.K. Mehta, Z.P. Liu, and Z.M. Yang, 2008 Copper induced proline synthesis is associated with nitric oxide generation in Chlamydomonas reinhardtii. Plant Cell Physiol., 49:411-9

Zhu, X.G., E. de Sturler, and S.P. Long, 2007. Optimizing the distribution of resources between enzymes of carbon metabolism can dramatically increase photosynthetic rate: a numerical simulation using an evolutionary algorithm. Plant Physiol., 145: 513-526

Zolla, G., Y.M. Heimer, and S. Barak, 2010. Mild salinity stimulates a stress-induced morphogenic response in Arabidopsis thaliana roots. Journal of Experimental Botany, 61: 211-224.

Zörb, C., C.-M. Geilfus and K.-J. Dietz, 2019. Salinity and crop yield, Plant Biology 21 (Suppl. 1. 31$38)$. 